\title{
HIGH- AND LOW-VOLTAGE MITIGATION IN DISTRIBUTION SYSTEMS USING RESIDENTIAL STATIC VOLT-AMPERE REACTIVE COMPENSATORS
}

by

Andrés Valdepeña Delgado

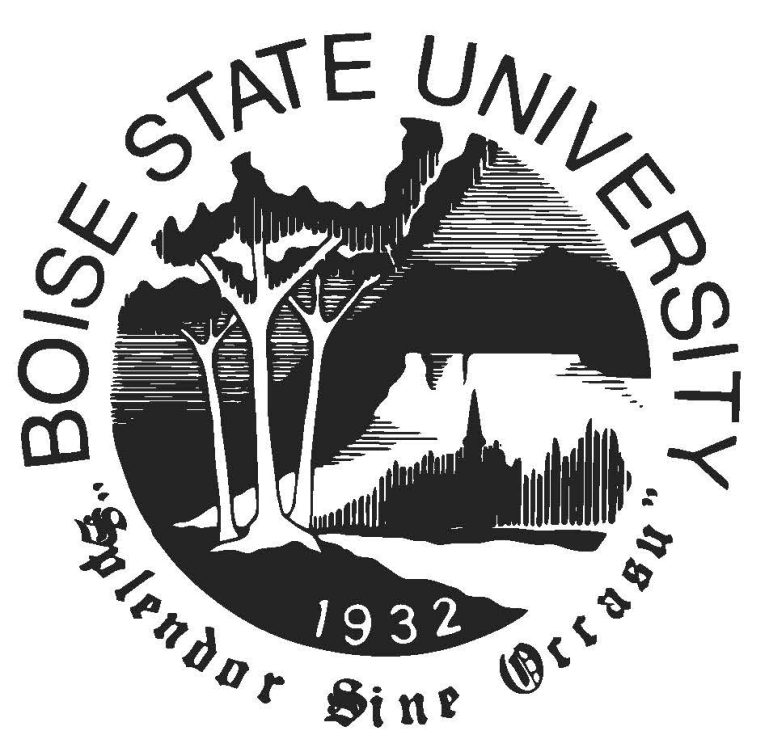

A dissertation

submitted in partial fulfillment

of the requirements for the degree of

Doctor of Philosophy in Electrical and Computer Engineering

Boise State University

May 2020 
(C) 2020

Andrés Valdepeña Delgado

ALL RIGHTS RESERVED 
BOISE STATE UNIVERSITY GRADUATE COLLEGE

\title{
DEFENSE COMMITTEE AND FINAL READING APPROVALS
}

\author{
of the Dissertation submitted by
}

Andrés Valdepeña Delgado

Dissertation Title: High- and Low-Voltage Mitigation in Distribution Systems using Residential Static Volt-Ampere Reactive Compensators

Date of Oral Examination: December 2019

The following individuals read and discussed the dissertation submitted by student Andrés Valdepeña Delgado, and they evaluated the presentation and response to questions during the final oral examination. They found that the student passed the final oral examination.

Said Ahmed-Zaid, Ph.D. Chair, Supervisory Committee

Thaddeus Welch, Ph.D. Member, Supervisory Committee

Nader Rafla, Ph.D. Member, Supervisory Committee

Brian K. Johnson, Ph.D External Examiner

The final reading approval of the Dissertation was granted by Said Ahmed-Zaid, Ph.D., Chair of the Supervisory Committee. The dissertation was approved by the Graduate College. 
To my wife Kasandra and my parents Jorge and Olivia 


\section{ACKNOWLEDGMENTS}

First of all, I would like to express my most sincere gratitude to my advisor, Dr. Said Ahmed-Zaid, for his supervision, guidance and advice during my time at Boise State University. Dr. Ahmed-Zaid's encouragement was key for the completion of this work. Dr. Ahmed-Zaid was always willing to help, it didn't matter if it was late at night or over the weekends, he always provided guidance and support.

I would also like to express my gratitude to Dr. Thaddeus Welch. Dr. Welch provided invaluable support in my time at BSU. Dr. Welch was always willing to help and provide words of wisdom, for academic related purposes or for personal reasons. I am truly in debt to him.

I am also thankful to Mrs. Donna Welch, her patience with my writing is highly appreciated. Mrs. Welch's willingness to help even when she was recovering from surgery is invaluable and does not go unnoticed. I would also like to thank Dr. Nader Rafla for serving on my dissertation committee despite his busy schedule. I would like to thank the Department of Electrical and Computer Engineering at BSU for providing me with the opportunity to carry out my research.

I would like to thank all the members of the Power Research lab at BSU. I would like to personally acknowledge and thank Dr. Kamran Latif and Dr. Danyal Mohammadi for their friendship and help that was instrumental for this research. I will miss the countless nights we stayed up at the lab discussing homework, research and sports.

I would like to thank my parents for all the sacrifices they made to make sure I received a good education through my entire life. They provided me with their unconditional support. 
Their hard work and the way they approach life was the source of inspiration for me. Thank you to my brothers that provided support and the always needed laugh. Even in the hard times they know how to get a smile out of me.

I would like to thank Idaho Power Company, especially the planning department, for all their support and flexibility to allow me to finish my studies. I would like to personally thank Daniel Arjona, Dave Angell and Phil Anderson from the planning department who have shown me how to be a better engineer and especially a better person. To all my friends for their friendship and support my most sincere gratitude. Samantha and Davita Eichner, Kyle Craft and Justin Muraski, thank you for making feel at home and that I have a family in this country.

Finally, I would like to thank my wife for all her love and support. I simply could not have done it without her. I will be forever indebted to her. 


\begin{abstract}
Power distribution systems are experiencing a fast transformation from simple one-way radial feeders to complex systems with multiple sources and bidirectional power flows. The rapid increase of Distributed Generation (DG) connected to the distribution system over the last decade, especially solar photovoltaic (PV), has been the key element to this transformation.

The variable nature of PV-based DG has increased the complexity of voltage regulation in distribution systems. Electric utilities are facing an increasing number of voltage issues in distribution systems with high penetration of DGs, leading customers to experience voltage levels outside of range A of the ANSI C84.1 standard. Electric utilities have to expend resources, both human and economic, to mitigate the voltage issues caused by the interconnection of DG. The economic impact of voltage issues can be considerable in some cases.

Conventional methods to mitigate voltage issues in distribution systems, such as the addition of voltage regulators and capacitor banks, could be ineffective in mitigating localized voltage issues caused by high levels of DG penetration. Other mitigation options, such as increasing the conductor size and the operating voltage of the feeder, are expensive.

There is a clear need in the industry to locally solve voltage issues economically. In this dissertation, a new device, a Residential Static Volt-Ampere Reactive Compensator (RSVC), is proposed. The RSVC is used to mitigate low and high voltage issues by deploying them in a feeder with a high DG penetration level.

This dissertation will investigate the interaction between solar inverters, voltage regula-
\end{abstract} vii 
tors and capacitor banks with the proposed RSVC. In order to reduce the number of buses to be analysed, the use of loss sensitivity factors will determine the candidate buses to host an RSVC.

The results of this dissertation show that the use of RSVCs is able to mitigate low and high voltage conditions. Simulation results show that the RSVCs are able to control the voltage by absorbing and injecting reactive power according to the voltage seen at their terminals. Similar commercially available devices are not able to handle the injection and absorption of reactive power and are limited to handle either injection of reactive power or absorption of reactive power. The most common devices provide the capability of injecting reactive power. 


\section{TABLE OF CONTENTS}

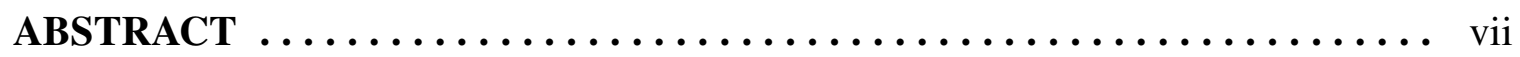

LIST OF TABLES $\ldots \ldots \ldots \ldots \ldots \ldots \ldots \ldots \ldots \ldots \ldots \ldots \ldots \ldots \ldots \ldots \ldots \ldots \ldots$ xiii

LIST OF FIGURES $\ldots \ldots \ldots \ldots \ldots \ldots \ldots \ldots \ldots \ldots \ldots \ldots \ldots \ldots \ldots \ldots \ldots \ldots$ xiv

LIST OF ABBREVIATIONS $\ldots \ldots \ldots \ldots \ldots \ldots \ldots \ldots \ldots \ldots \ldots \ldots$ xvii

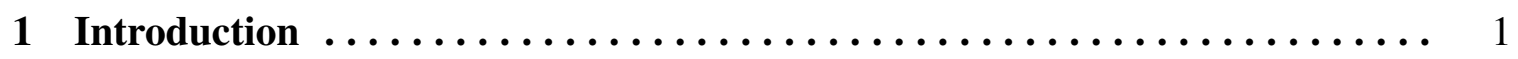

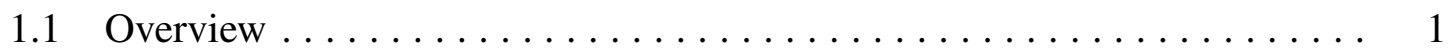

1.2 Research Motivation ...................... 2

1.3 Proposed Method $\ldots \ldots \ldots \ldots \ldots \ldots \ldots \ldots \ldots \ldots \ldots \ldots \ldots \ldots$

1.4 Dissertation Organization $\ldots \ldots \ldots \ldots \ldots \ldots \ldots \ldots \ldots \ldots \ldots \ldots \ldots \ldots \ldots \ldots$

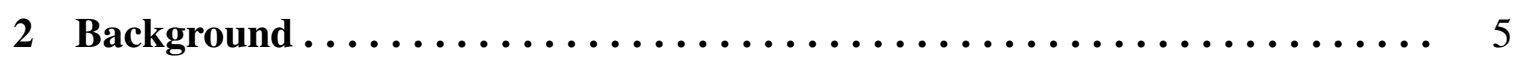

$2.1 \quad$ ANSI C84.1 Voltage Ratings $\ldots \ldots \ldots \ldots \ldots \ldots \ldots \ldots \ldots \ldots \ldots \ldots \ldots$

2.1.1 Range A Service Voltage .................... 9

2.1.2 Range A Utilization Voltage . . . . . . . . . . . . . . . . 9

2.1.3 Range B Service and Utilization Voltage .............. 9

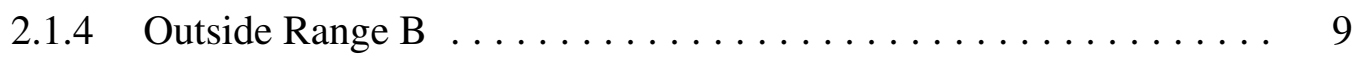

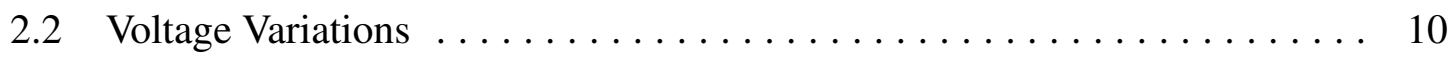

2.2.1 Changes in Voltage Due to Load . . . . . . . . . . . . . . . . 10

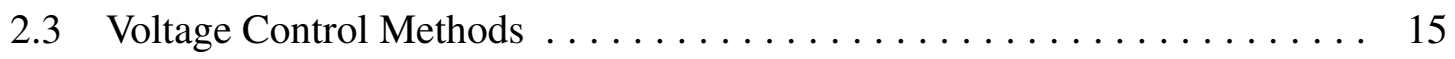


2.3.1 Capacitor Banks ......................... 17

2.3.2 Load Tap Changers $\ldots \ldots \ldots \ldots \ldots \ldots \ldots \ldots \ldots \ldots \ldots$

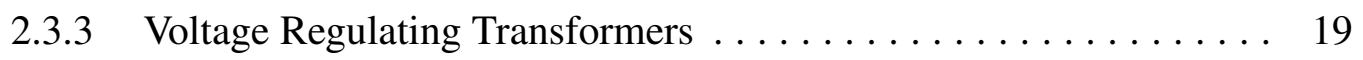

2.3.4 Voltage Impact of Distributed Energy Resources ........... . 20

2.4 Voltage Control in Distribution Systems with Higher Penetration of DG . . 22

2.5 Voltage Control in Feeders with Distributed Generation ............ 24

2.6 Reactive Compensation in Distribution Systems ................ 25

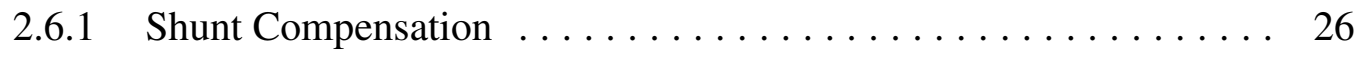

2.6.2 Series Compensation $\ldots \ldots \ldots \ldots \ldots \ldots \ldots \ldots \ldots \ldots \ldots \ldots \ldots$

3 Loss Sensitivity Factors.......................... 29

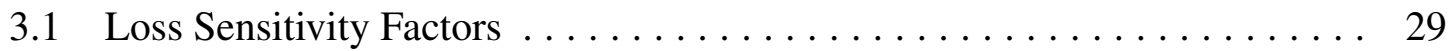

3.2 Derivation of Loss Sensitivity Factors $\ldots \ldots \ldots \ldots \ldots \ldots \ldots \ldots \ldots$

$3.2 .1 \quad$ Sensitivity Factors $\ldots \ldots \ldots \ldots \ldots \ldots \ldots \ldots \ldots \ldots \ldots \ldots \ldots \ldots$

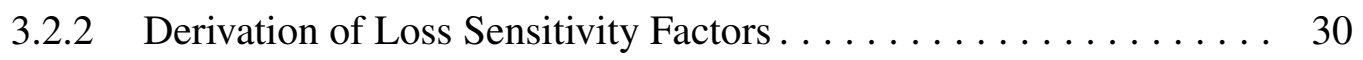

3.2.3 Loss Sensitivity Factors at Peak Load . . . . . . . . . . . 32

3.2.4 Loss Sensitivity Factors in OpenDSS . . . . . . . . . . . . 32

3.2.5 Daily Sensitivity Factors $\ldots \ldots \ldots \ldots \ldots \ldots \ldots \ldots \ldots \ldots$

3.3 Similar Devices ............................... 36

3.3.1 Varentec.............................. 36

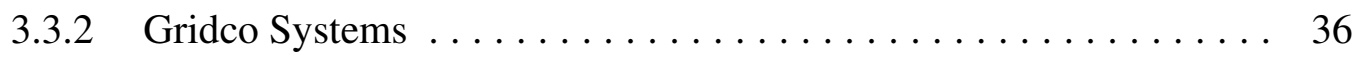

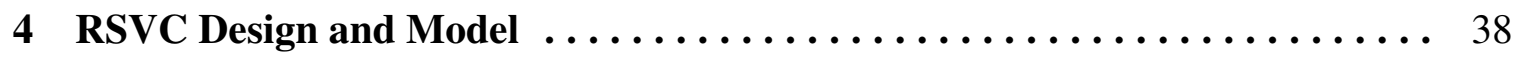

4.1 Residential Static VAR Compensator . . . . . . . . . . . . . . . . . 38

4.1.1 Distribution System Modeling $\ldots \ldots \ldots \ldots \ldots \ldots \ldots \ldots \ldots$

4.1.2 Sizing of RSVC components $\ldots \ldots \ldots \ldots \ldots \ldots \ldots \ldots \ldots, 41$ 


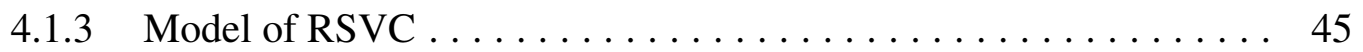

$5 \quad \operatorname{RSVC}$ Deployment $\ldots \ldots \ldots \ldots \ldots \ldots \ldots \ldots \ldots \ldots \ldots \ldots \ldots \ldots \ldots$

5.1 Description of Test Feeder $\ldots \ldots \ldots \ldots \ldots \ldots \ldots \ldots \ldots \ldots \ldots$

5.2 Voltage Rise due to Distributed Generation ................ 54

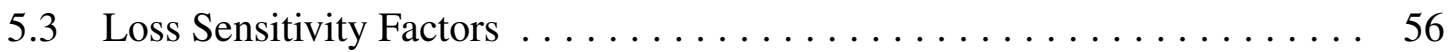

$5.4 \quad$ RSVC Deployment............................... 58

5.4 .1 Low Voltage Mitigation $\ldots \ldots \ldots \ldots \ldots \ldots \ldots \ldots \ldots \ldots$

5.4 .2 High Voltage Mitigation ..................... 62

6 Time Series Analysis $\ldots \ldots \ldots \ldots \ldots \ldots \ldots \ldots \ldots \ldots \ldots \ldots \ldots \ldots$

6.1 Photovoltaic (PV) Data . . . . . . . . . . . . . . . . . . . . . . . . . 69

6.2 Time-Series Analysis . . . . . . . . . . . . . . . . . . . . . . . . . . 70

$6.2 .1 \quad$ Minimum Voltage $\ldots \ldots \ldots \ldots \ldots \ldots \ldots \ldots \ldots \ldots \ldots \ldots$

6.2.2 Maximum Voltage $\ldots \ldots \ldots \ldots \ldots \ldots \ldots \ldots \ldots \ldots \ldots \ldots \ldots \ldots$

6.2 .3 Voltage Variability $\ldots \ldots \ldots \ldots \ldots \ldots \ldots \ldots \ldots \ldots \ldots \ldots$

6.2.4 Number of Operations of Voltage Regulating Devices ........ 74

6.2.5 Loss Sensitivity Factors $\ldots \ldots \ldots \ldots \ldots \ldots \ldots \ldots \ldots \ldots$

6.3 RSVC Deployment.............................. 77

6.3 .1 Minimum Voltage $\ldots \ldots \ldots \ldots \ldots \ldots \ldots \ldots \ldots \ldots \ldots$

6.3.2 Maximum Voltage $\ldots \ldots \ldots \ldots \ldots \ldots \ldots \ldots \ldots \ldots \ldots$

6.3.3 Voltage Variability ........................ 79

6.3.4 Number of Operations of Voltage Regulating Devices ......... . 79

6.3.5 RSVC Output............................. 81

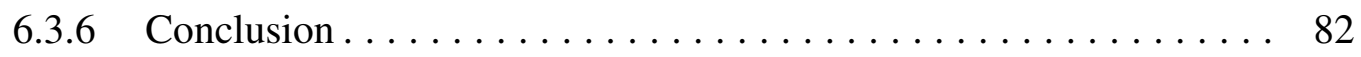


7 Low Voltage Mitigation: Case Study $\ldots \ldots \ldots \ldots \ldots \ldots \ldots \ldots \ldots \ldots$

7.1 Traditional low voltage mitigation $\ldots \ldots \ldots \ldots \ldots \ldots \ldots \ldots \ldots \ldots$

7.2 RSVC Option to Mitigate Low Voltage $\ldots \ldots \ldots \ldots \ldots \ldots \ldots \ldots$

7.2.1 Feeder Modeling in OpenDSS _.................. 85

7.2.2 Mitigation of Voltage Violations using RSVCs _.......... 87

7.3 Voltage Mitigation Using Solar Photovoltaic ................ 91

7.3.1 Modeling and optimizing the size of the solar PV system . . . . . . 91

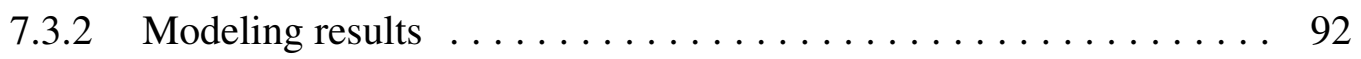

7.3.3 Project Implementation and Results $\ldots \ldots \ldots \ldots \ldots \ldots \ldots . \ldots 3$

8 Conclusions and Future Work $\ldots \ldots \ldots \ldots \ldots \ldots \ldots \ldots \ldots \ldots \ldots$

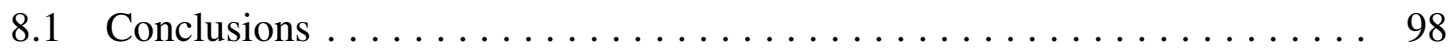

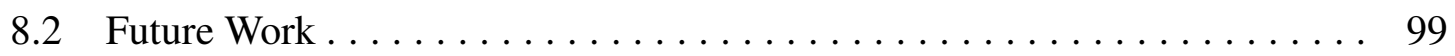

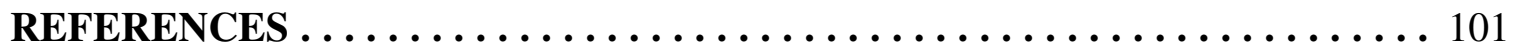




\section{LIST OF TABLES}

3.1 Loss Sensitivity Factors Results Comparison $\ldots \ldots \ldots \ldots \ldots$

6.1 Number of Voltage Regulator Operations $\ldots \ldots \ldots \ldots \ldots \ldots \ldots$

6.2 Number of Voltage Regulator Operations with the RSVCs Deployed . . . 80

7.1 Voltage swing for each customer without $\mathrm{RSVC} \ldots \ldots \ldots \ldots$

7.2 Voltage swing for each customer with $\mathrm{RSVC} \ldots \ldots \ldots \ldots$

7.3 Low Voltage Results . . . . . . . . . . . . . . . . . . . 94

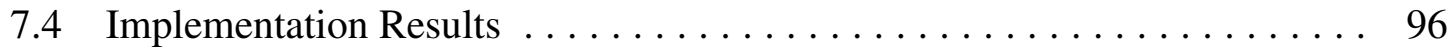




\section{LIST OF FIGURES}

2.1 Representation of a typical distribution circuit $\ldots \ldots \ldots \ldots \ldots$

2.2 Typical Voltage Profile Under Heavy Load . . . . . . . . . . . . . . . 7

2.3 ANSI C84.1 Voltage Range $\ldots \ldots \ldots \ldots \ldots \ldots \ldots \ldots \ldots \ldots \ldots \ldots \ldots$

2.4 Thevenin representation of the power system $\ldots \ldots \ldots \ldots \ldots \ldots \ldots$

2.5 Typical diagram of an LTC . . . . . . . . . . . . . . . 19

2.6 Single Phase Voltage Regulator $\ldots \ldots \ldots \ldots \ldots \ldots \ldots \ldots \ldots \ldots \ldots \ldots \ldots$

2.7 Single line diagram of a secondary feeder with a DER connected at the end

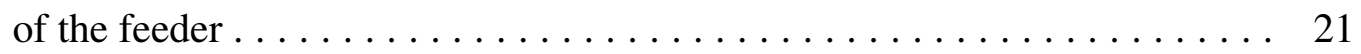

2.8 Reactive Shunt Compensation with phasor diagram $\ldots \ldots \ldots \ldots \ldots$

2.9 Reactive Series Compensation with phasor diagram $\ldots \ldots \ldots \ldots \ldots \ldots$

3.1 Distribution Line section $\ldots \ldots \ldots \ldots \ldots \ldots \ldots \ldots \ldots \ldots \ldots \ldots \ldots \ldots \ldots$

3.2 Loss Sensitivity Factors Using OpenDSS . . . . . . . . . . . . 34

3.3 Hourly Loss Sensitivity Factors $\ldots \ldots \ldots \ldots \ldots \ldots \ldots \ldots \ldots \ldots \ldots \ldots \ldots \ldots \ldots$

4.1 Residential Static VAR Compensator Schematic . . . . . . . . . . . . . . 39

4.2 PowerWorld Model for a Distribution System with uniformly distributed

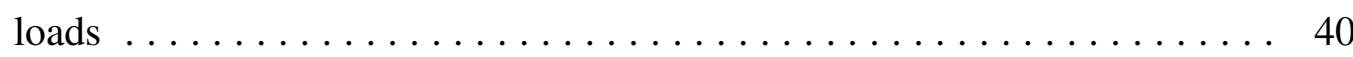

4.3 Impedance Circuit of the distribution system to calculate Thevenin impedance 41

4.4 Circuit to size the capacitive component of the RSVC . . . . . . . . . . 42

4.5 Circuit to size the capacitive component of the RSVC . . . . . . . . 43 
4.6 Source and Load Voltage with RSVC $\ldots \ldots \ldots \ldots \ldots \ldots \ldots \ldots \ldots$

4.7 Circuit to size the inductive component of the RSVC $\ldots \ldots \ldots \ldots \ldots$

4.8 Source and Load Voltage with RSVC $\ldots \ldots \ldots \ldots \ldots \ldots \ldots \ldots \ldots$

4.9 Residential Static VAR Compensator Circuit Implemented in Simulink . . . 46

4.10 Simulink vs OpenDSS (a) input voltage; (b) reactive power . . . . . . . 47

5.1 Topology of the Test Feeder $\ldots \ldots \ldots \ldots \ldots \ldots \ldots \ldots \ldots \ldots \ldots \ldots \ldots \ldots \ldots$

5.2 Voltage Profile with no feeder PV . . . . . . . . . . . . . . . 52

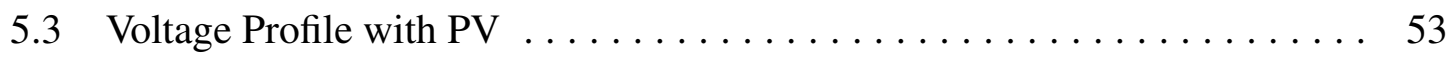

5.4 Voltage Profile During Voltage Change Test $1 \ldots \ldots \ldots \ldots \ldots \ldots . \ldots 4$

5.5 Voltage Profile During Voltage Change Test $2 \ldots \ldots \ldots \ldots \ldots \ldots \ldots$

5.6 Loss Sensitivity Factors with no Solar PV . . . . . . . . . . . . . . . 57

5.7 Loss Sensitivity Factors with Solar PV . . . . . . . . . . . . . 58

5.8 Difference in Loss Sensitivity Factors . . . . . . . . . . . . . . . . . . . 59

5.9 First 100 LSF Sorted from High to Low $\ldots \ldots \ldots \ldots \ldots \ldots \ldots \ldots \ldots$

5.10 Minimum Voltage vs Number of RSVCs Deployed for sudden loss of PV

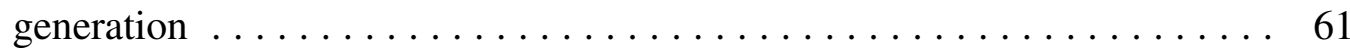

5.11 Voltage Profile with 20 RSVCs Deployed in the Feeder ........... 62

5.12 RSVC Output for Voltage Change Test $1 \ldots \ldots \ldots \ldots \ldots \ldots \ldots \ldots$

5.13 Maximum Voltage vs Number of RSVCs Deployed ............... 64

5.14 Voltage Profile with RSVC Deployed in the Feeder ............. 65

5.15 RSVC Output for Voltage Change Test $2 \ldots \ldots \ldots \ldots \ldots \ldots \ldots$

5.16 RSVC and PV Location ................................. 67

6.1 Normalized PV Output for Site $1 \ldots \ldots \ldots \ldots \ldots \ldots \ldots \ldots \ldots \ldots \ldots \ldots$

6.2 Power Output of PV System Site $1 \ldots \ldots \ldots \ldots \ldots \ldots \ldots \ldots \ldots \ldots \ldots$ 
6.3 Voltage at PV System Site 1 Terminals . . . . . . . . . . . . . 72

6.4 Minimum Voltage at Each Solution Interval $\ldots \ldots \ldots \ldots \ldots \ldots$

6.5 Maximum Voltage on each Solution Inverval $\ldots \ldots \ldots \ldots \ldots \ldots$. . . . . 74

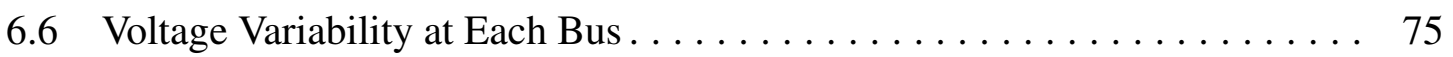

6.7 Average $\mathrm{LSF}$ at Each Bus $\ldots \ldots \ldots \ldots \ldots \ldots \ldots \ldots \ldots \ldots \ldots$

6.8 Minimum Voltage on each Solution Interval with RSVC Deployed . . . . . 78

6.9 Maximum Voltage on Each Solution Interval with RSVC Deployed . . . . 79

6.10 Voltage Variability with RSVCs Deployed $\ldots \ldots \ldots \ldots \ldots \ldots \ldots$

6.11 RSVC Output for Iteration $1 \ldots \ldots \ldots \ldots \ldots \ldots \ldots \ldots \ldots \ldots \ldots \ldots \ldots \ldots$

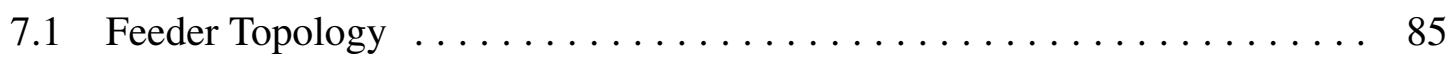

7.2 Simplified Distribution Feeder topology $\ldots \ldots \ldots \ldots \ldots \ldots$

7.3 Voltage at every customer meter without RSVCs deployed. . . . . . . . 87

7.4 Voltage at every customer meter with RSVC deployed $\ldots \ldots \ldots \ldots . \ldots 8$

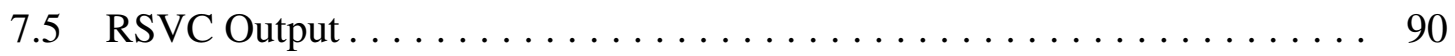

7.6 PV Sizing Algorithm Flow Chart $\ldots \ldots \ldots \ldots \ldots \ldots \ldots \ldots$

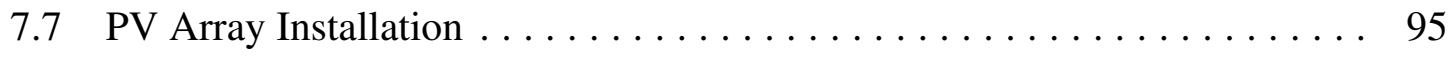

7.8 Voltage duration curves for Summer 2016, 2017, and $2018 \ldots \ldots \ldots \ldots$

7.9 Low-voltage occurrences plotted by time of day $\ldots \ldots \ldots \ldots \ldots \ldots \ldots$ 


\section{LIST OF ABBREVIATIONS}

AMI - Advanced Metering Infrastructure

AC - Alternating Current

ACSR - Aluminum Conductor Steel Reinforced

ATC - Automatic Tap Changer

AVR - Automatic Voltage Regulators

BSU - Boise State University

COM - Component Object Model

CVR - Conservation by Voltage Reduction

DER - Distributed Energy Resources

DG - Distributed Generation

DLL - Dynamic Link Libraries

EPRI - Electric Power Research Institute

FPGA - Field Programmable Gate Array

IEEE - Institute of Electrical and Electronics Engineers

IGBT - Insulated-Gate Bipolar Transistor

IOU - Investor Owned Utilities

LTC - Load Tap Changer 
LV - Low voltage

MOSFET - Metal-Oxide-Semiconductor Field-Effect Transistor

MCM - Thousand circular mils

NREL - National Renewable Energy Laboratory

$\mathbf{O} \& \mathbf{M}$ - Operations and Maintenance

OpenDSS - Open-Source Distribution System Simulator

PSO - Particle Swarm Optimization

PV - Photovoltaic

PCC - Point of Common Coupling

PF - Power Factor

PUC - Public Utility Commission

PWM - Pulse-width Modulation

QSTS - Quasi Steady-State Simulations

RMS - Root Mean Square

RSVC - Residential Static VAR Compensator

SGM - Smart Grid Monitor

SVC - Static VAR Compensation

VAR - Volt-Ampere Reactive

VBA - Visual Basic Applications

VER - Variable Generation Resources 


\section{CHAPTER 1}

\section{INTRODUCTION}

\subsection{Overview}

Distribution systems are experiencing a fast transformation from simple one-way radial feeders to complex networks with multiple sources and bidirectional power flows [1]. The rapid increase of Distributed Energy Resources (DER) connected to the distribution system over the last decade, especially Solar Photovoltaic (PV), has been key a element of this transformation.

The variable nature of PV-based DER has increased the complexity of voltage regulation in distribution systems. Electric utilities are facing an increasing number of voltage issues in the distribution system with the high penetration of DERs. This leads to customers experiencing voltage levels outside of range A of the American National Standard for Electric Power Systems and Equipment - Voltage Rating, ANSI C84.1 standard. Electric utilities have to expend resources, both human and economic, to mitigate the voltage issues caused by the interconnection of DERs. The economic impact of voltage issues can be considerable in some cases.

Conventional methods to mitigate voltage issues in distribution systems, such as the addition of voltage regulators and capacitor banks, could be ineffective in mitigating localized voltage issues caused by high levels of DER penetration. Other mitigation options, such as increasing the conductor size and the operational voltage level of the feeder, are capital 
intensive. There is a clear need in the industry to locally solve voltage issues economically.

Traditionally, distribution systems have been analyzed using snapshot tools and methods that may not be adequate to accurately analyze the fast variability and complex in-

teraction of high levels of DERs in distribution feeders. Snapshot study methods only analyze peak periods or a peak variability day, which makes determining the maximum and minimum voltage at the feeder complicated.

Radial feeders are simple and can be analyzed using peak load to find the minimum voltage and light load to find the maximum voltage. The addition of generation on the distribution feeder complicates the analysis of the distribution feeders. The maximum and minimum voltages are no longer found by using peak load and light load scenarios and a time-series analysis is necessary. [2].

In this dissertation, a new device, a Residential Static Volt-Ampere Reactive Compensator (RSVC), is proposed. The RSVC could be used to mitigate both low and high voltage issues by deploying them in a feeder with a high DER penetration level. This dissertation investigates the interaction between solar inverters, voltage regulators, and capacitor banks with the proposed RSVC. Loss sensitivity factors are used to determine the buses that will be candidates to host an RSVC, effectively reducing the search space and shortening the processing time. Quasi-static time-series simulations will be used to analyze the feeder during the hours of the year, covering most of the possible operating conditions the feeder experiences.

\subsection{Research Motivation}

The increased complexity of distribution systems has attracted the attention of many researchers to investigate methods to make distribution systems more efficient, reduce losses, 
maintain voltage within limits, and maintain reliability with the increased number of distributed generation connected to the distribution system.

The integration of renewable energy brings a new set of challenges to the way distribution systems are operated. One of the main issues with the integration of renewable energy is the voltage rise at the Point of Common Coupling (PCC) for each DER. The voltage rise limits the amount of DER that can be connected to the distribution system.

The work presented in this dissertation focuses on solving high and low voltage conditions in the distribution system by addressing the problem at the customer level. The continuous improvements in power electronics and Field Programmable Gate Arrays (FPGAs) in the last decade have made the realization of a single-phase RSVC possible. The single-phase RSVCs proposed in this dissertation implements a high frequency PulseWidth Modulation (PWM) switching technique, that produces a sinusoidal wave with negligible harmonics, eliminating the need for a filter.

The flexibility that the RSVC provides to control the voltage makes it possible to solve both high and low voltage conditions with the same device. The RSVC also increases the operational flexibility and the hosting capacity of a feeder.

\subsection{Proposed Method}

This work proposes the use of a new device to regulate voltage in distribution systems by controlling the voltage at the customer level. The proposed device, the RSVC, can be used to mitigate low and high voltage issues in distribution systems. The simulations presented in this proposal are based on the test feeder J1 from the Electric Power Research Institute (EPRI) [3]. 


\subsection{Dissertation Organization}

This dissertation is organized as follows. In Chapter 2, a review of the standards that regulate the voltage magnitudes in distribution systems is presented. Also, a detailed derivation of the voltage change at the load terminals is presented as a way to show how PV systems and RSVCs can change the voltage in distribution systems. A summary of the

current technologies employed by utilities to control voltage in their distribution systems is also presented.

In Chapter 3, the derivation of loss sensitivity factors is presented by using the same model as a publicly available published paper. The calculation of the sensivity factors obtained from OpenDSS are presented and compared to the published results.

In Chapter 4, the principles of operation of the RSVC developed at BSU are presented. A description of the method used for sizing the reactive components is also presented. The chapter includes the model developed in Simulink to represent the RSVC and the verification of its equivalent model used in OpenDSS.

Chapter 5 describes the test feeder used in this dissertation. The chapter shows the voltage impact that the current DG has in the feeder. An static analysis of the feeder is presented in this chapter. The effects of deploying RSVC in the feeder using a static mode are shown in this chapter.

Chapter 6 shows the time series analysis of the test feeder. The impact of the DG is presented and the results on voltage, voltage variability and voltage regulating devices number of operations by adding RSVCs in the feeder are presented.

Chapter 7 presents a case study performed on a distribution feeder.

Finally, Chapter 8 presents the conclusions obtained from this work and suggests areas for future research. 


\section{CHAPTER 2}

\section{BACKGROUND}

Residential customers are connected to the secondary side of a service transformer, which reduces the distribution voltage to the service voltage. The two Investor Own Utilities (IOU) in Idaho use typical distribution voltages of $12.47 \mathrm{kV}$ or $34.5 \mathrm{kV}$. Typically, service voltages are $120 \mathrm{~V}$ or $240 \mathrm{~V}$ at the meter terminals. The service voltage is the voltage used by home appliances and lighting. Electric utilities focus on regulating the voltage on the distribution side of the service transformer, rather than at the customer side. Designers and engineers usually apply a constant voltage drop across the service transformer to estimate the voltage at the service side of the residential customer during planning studies.

There are several factors that affect the voltage on a distribution feeder. Some of the most common factors are: 1) size of a primary feeder conductor; 2) loads on a primary feeder; 3) power factor of feeder loads; and 4) length of a primary feeder [4].

A residential customer connects to the main feeder via a tap along the main trunk of the feeder, drawing current through the line and causing the voltage to drop as successive customers get connected further away from the substation.

A typical distribution feeder is shown in Fig. 2.1. During heavy load conditions, the voltage at the feeder head will be increased (usually by using a Load Tap Changer (LTC)) to compensate for the voltage drop. The LTC will increase the voltage at the feeder head to ensure the customers at the end of feeder remain within the voltage limits. 


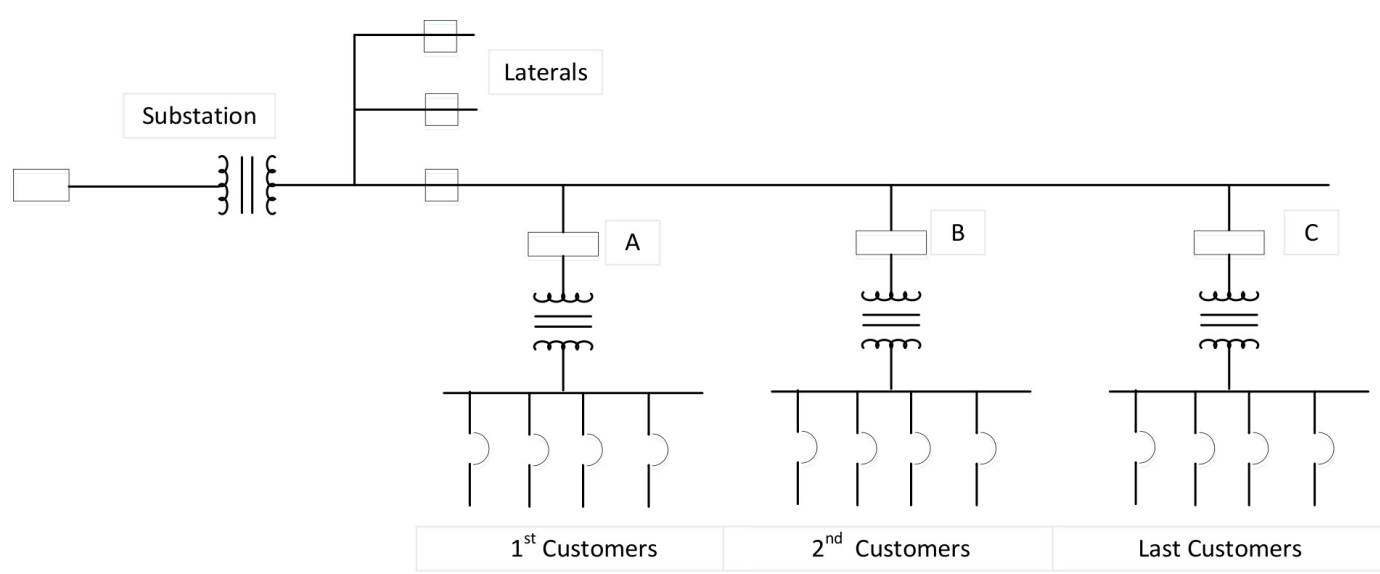

Figure 2.1: Representation of a typical distribution circuit

The high current, due to the heavy load, will cause a voltage drop along the feeder. As the customers connect to the feeder further along the substation, they will see a lower voltage. Figure 2.2 shows how customers experience lower voltage as they are connected further away from the substation.

For example, if the voltage at the feeder head is set at the nominal voltage, the customers situated toward the end of the feeder could experience low voltage. Also, if the voltage is set to ensure the customers at the end of the feeder receive nominal voltage under heavy load conditions, the customers near to the feeder head could experience high voltage during light load conditions.

Utilities use an LTC at the substation transformer to regulate the voltage at the feeder head according to the feeder loading and to ensure an adequate voltage for all customers. Voltage regulators and capacitor banks are also used as a way to regulate the voltage along the distribution feeder.

The addition of DERs complicates the regulation of the voltage profile along the feeder. DERs raise the voltage at their Point of Common Coupling (PCC) and decrease the current flowing through voltage regulators and LTCs. The reduction of the current through the LTC 


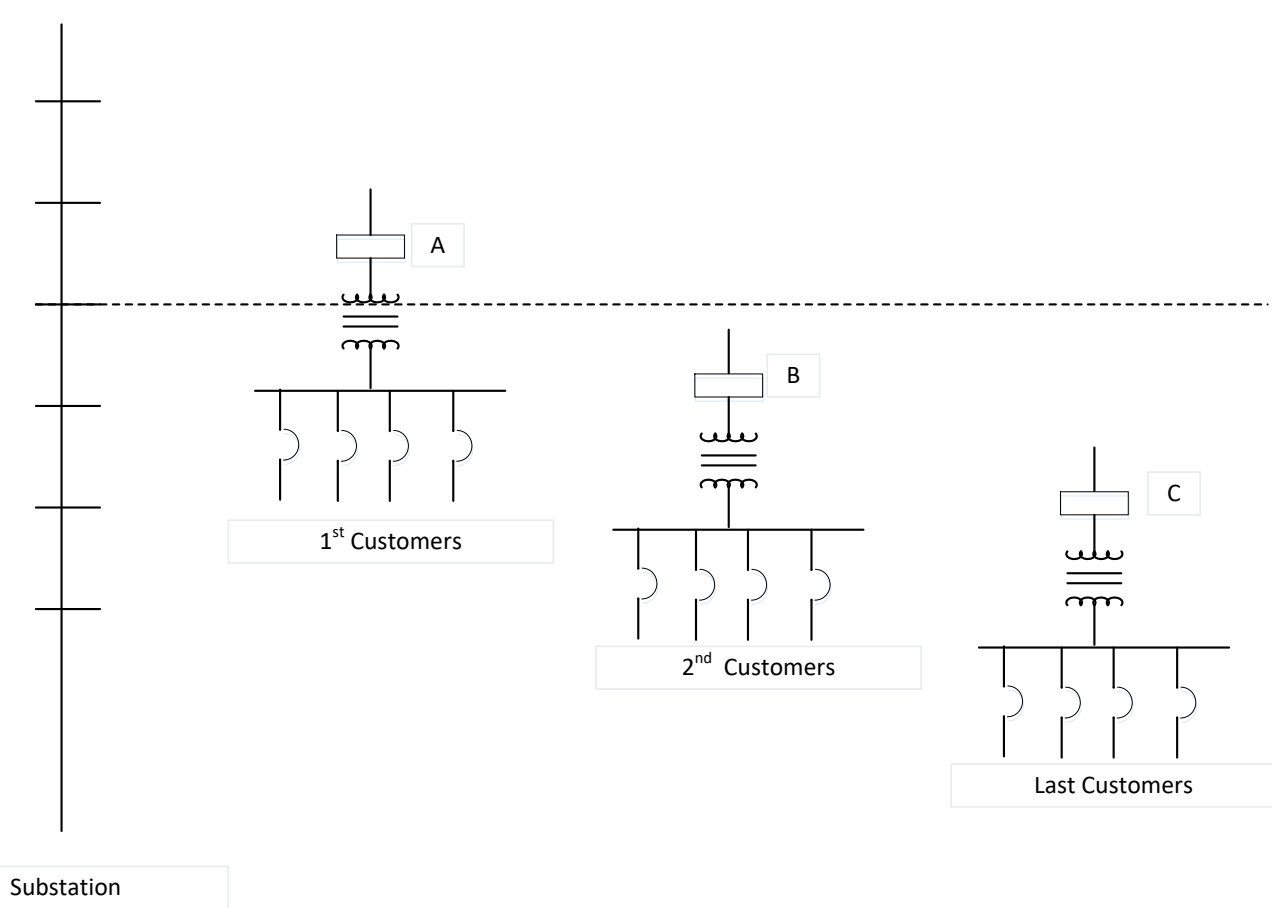

Figure 2.2: Typical Voltage Profile Under Heavy Load

could result in low voltage for adjacent feeders without DERs connected to them.

\subsection{ANSI C84.1 Voltage Ratings}

The American National Standard for Electric Power Systems and Equipment - Voltage Rating, ANSI C84.1 standard [5], establishes nominal voltage ratings and operating tolerances for $60 \mathrm{~Hz}$ electric power systems above $100 \mathrm{~V}$. Fig 2.3 shows the voltage range set by ANSI C84.1 [6].

Voltage regulation requirements are defined in two categories: Range A and Range B. Range $\mathrm{A}$ is for normal conditions, where the required regulation is $\pm 5 \%$ on a $120 \mathrm{~V}$ base at the service entrance. For services above $600 \mathrm{~V}$, the required regulation is $-2.5 \%$ to $+5 \%$.

This standard also distinguishes between service voltage and utilization voltage. Ser- 


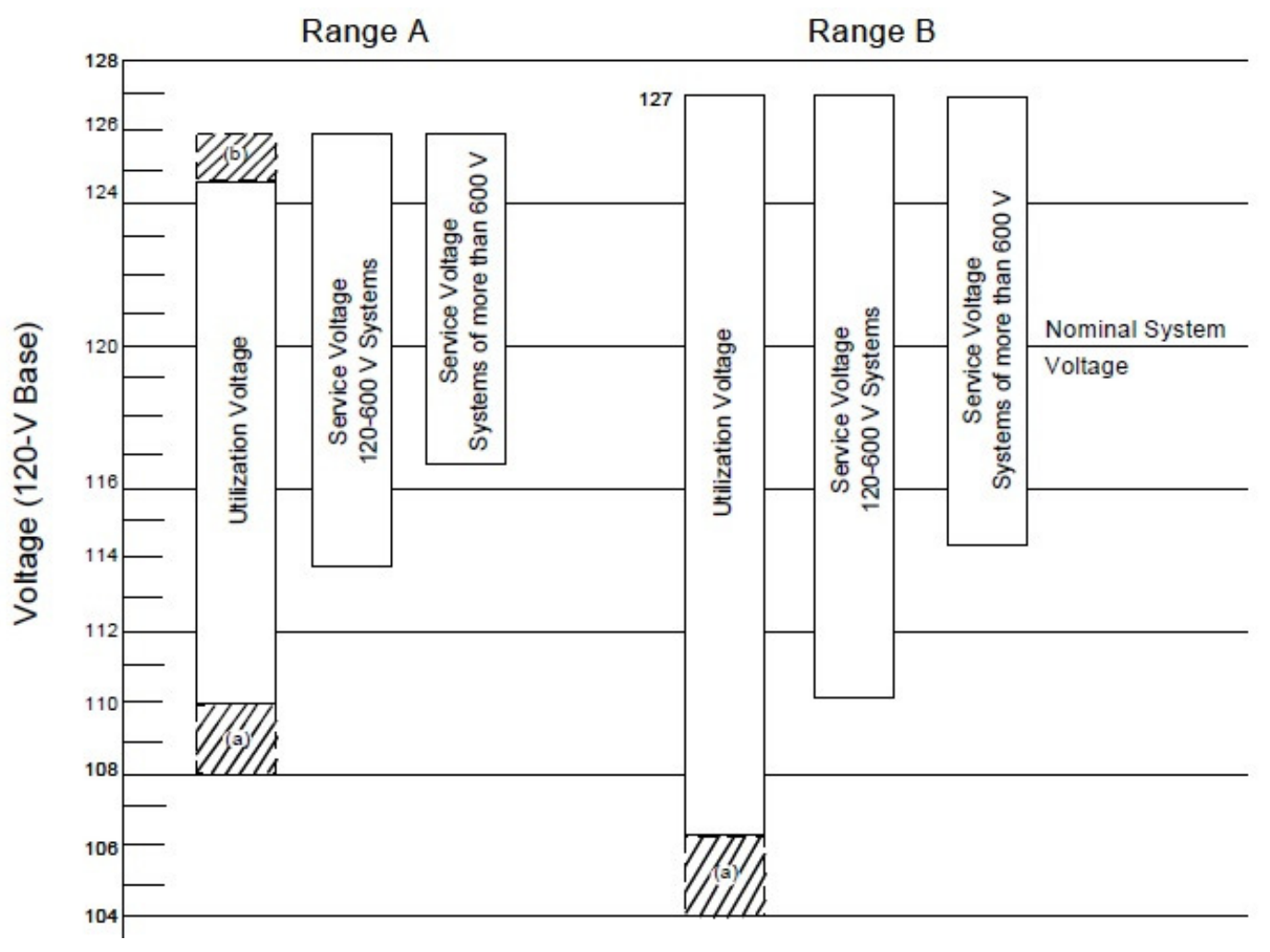

Figure 2.3: ANSI C84.1 Voltage Range

vice voltage is measured at the point of delivery, which is typically the utility meter. The utilization voltage is measured at the terminals of the utilization equipment. The difference between service and utilization voltage allows for voltage drop in the facility wiring between the point of utility delivery and the utilization equipment.

The occurrence of service voltages outside Range A limits should be infrequent. Range A must be the basis for the utilization equipment's design and rating. Range B should be limited in extent, duration and frequency. Range B results from the practical design and operations of the distribution system. For common nominal system voltage, the recommended service and utilization voltage ranges from $120 \mathrm{~V}$ to $600 \mathrm{~V}$ in the ANSI C84.1. 


\subsubsection{Range A Service Voltage}

Electric supply systems should be designed and operated so that most service voltages will be within the limits specified for Range A. The occurrence of service voltages outside of these limits should be infrequent.

\subsubsection{Range A Utilization Voltage}

User systems should be designed and operated so that with service voltages within Range A limits, most utilization voltages will be within the limits specified for this range. Utilization equipment should be designed and rated to give full performance throughout this range.

\subsubsection{Range B Service and Utilization Voltage}

Range B includes voltages above and below Range A limits that necessarily result from practical design and operating conditions on supply or user systems, or both. Although such conditions are a part of practical operations, they should be limited in frequency and duration. When they occur, corrective measures should be implemented within a reasonable time to improve voltages to meet Range A requirements.

\subsubsection{Outside Range B}

It should be recognized that because of conditions beyond the control of the supplier or user, there will be infrequent and limited periods when sustained voltages outside Range B limits will occur. Utilization equipment may not operate satisfactorily under these conditions and protective devices may operate to protect the equipment. 


\subsection{Voltage Variations}

Voltage variations can affect the performance of end-user equipment as well as shorten their lifetimes. High voltage increases the risk of insulation failure of transformers, cables, motors, and end-user equipment. Higher voltage during normal operation increases the base from which the transient high voltages start. Increasing the base increases the peak voltage and thus the risk of insulation failure. Higher than normal voltage at transformer terminals increases the magnetizing current of the transformers, distorting the magnetizing current.

Under voltage leads to reducing the starting torque of induction motors, increases the full-load temperature, and lowers the power factor which increases the voltage drop. The reduced starting torque increases the time it takes the motor to reach rated speed. In an extreme scenario, the low voltage might stall the motors, becoming a short-circuited transformer. A stalled motor will increase the reactive current and cause a greater voltage drop seen by the loads close to the motor. Low voltage increases the duty cycle for any equipment that uses a thermostat, such as heating, refrigerating, and air conditioning, resulting in the increase of the total current drawn by these devices [7].

\subsubsection{Changes in Voltage Due to Load}

The change in voltage at the load terminal due to the change of load could be explained using a Thevenin equivalent. Thevenin's theorem states that a linear circuit can be represented as an ideal voltage source behind a constant impedance. If one considers the Thevenin equivalent in Figure 2.4, a practical approximation, the voltage $E$ can be approximated by the voltage on the primary side of the service transformer and the impedance $Z$ can be approximated by the impedance of the service transformer [7]. 


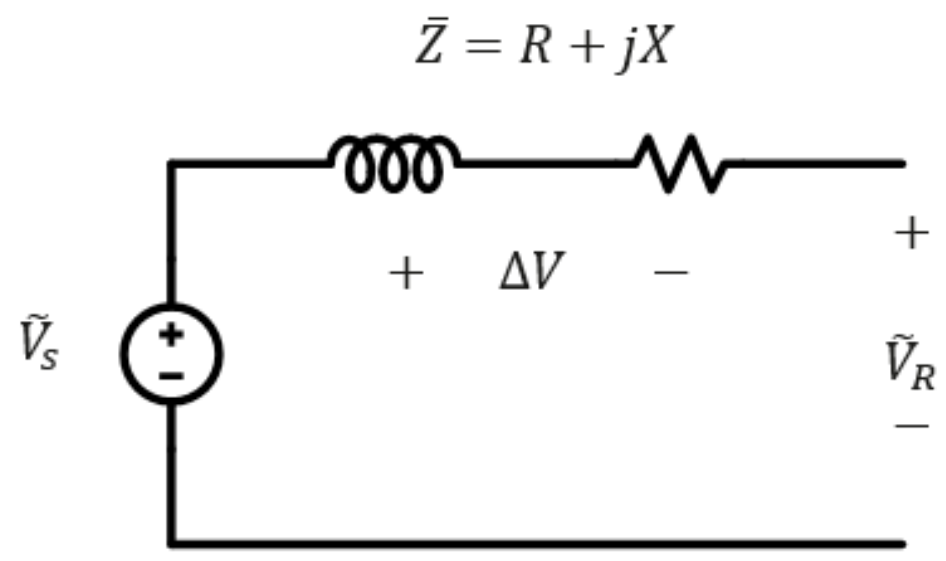

Figure 2.4: Thevenin representation of the power system

Consider the Thevenin equivalent from Figure 2.4. The voltage seen by the load, $\tilde{V}_{r}$, can be expressed as:

$$
\tilde{V}_{r}=\tilde{V}_{s}-\bar{Z} \tilde{I}
$$

The power delivered to the load is:

$$
\bar{S}=\tilde{V}_{r} \tilde{I}^{*}=P+j Q
$$

The voltage drop can be derived from (2.1) as:

$$
\Delta \tilde{V}=\tilde{V}_{s}-\tilde{V}_{r}=\bar{Z} \tilde{I}
$$


The load voltage can be used as the reference along the positive axis so that:

$$
\tilde{V}=V_{r}=V_{r} \not 0^{\circ}
$$

Using (2.2), the current as a function of the active and reactive power can be derived to obtain:

$$
\tilde{I}=\frac{P-j Q}{V_{r}}
$$

Plugging (2.5) into (2.3); the voltage drop can be expressed in terms of the power delivered to the load and the impedance seen by the load as:

$$
\Delta \tilde{V}=\bar{Z} \tilde{I}=(R+j X)\left(\frac{P-j Q}{V_{r}}\right)
$$

Substituting the real and imaginary components of the impedance, $\bar{Z}=R+j X$, the voltage drop can be expressed in terms of the load power, the impedance seen by the load, and the voltage at the load terminals as:

$$
\Delta \tilde{V}=\frac{(R P+X Q)+j(X P-R Q)}{V_{r}}
$$

The voltage drop is the difference on the absolute value between the source and load voltage and can be expressed as: 


$$
\Delta \tilde{V}=\left\|\tilde{V}_{s}-\tilde{V}_{r}\right\|
$$

Dividing both sides of the equation by $V_{r}$ gives:

$$
\frac{\Delta \tilde{V}}{V_{r}}=\left\|\frac{\tilde{V}_{s}-\tilde{V}_{r}}{\tilde{V}_{r}}\right\|
$$

$$
\frac{\Delta \tilde{V}}{V_{r}}=\left\|\frac{\tilde{V}_{s}}{\tilde{V}_{r}}-1\right\|
$$

Assuming that the angle between the $V_{s}$ and $V_{r}$ is small enough that it can be ignored, which is usually the case in distribution systems, equation (2.10) can be simplified to:

$$
\frac{\Delta \tilde{V}}{V_{r}}=\left\|\frac{\tilde{V}_{s}}{\tilde{V}_{r}}\right\|-1
$$

Solving for $V_{s}$ in equation (2.3) and substituting it in (2.11) gives:

$$
\frac{\Delta \tilde{V}}{V_{r}}=\left\|\frac{\tilde{V}_{r}+\Delta \tilde{V}}{V_{r}}\right\|-1
$$

Simplifying inside the absolute value gives: 


$$
\frac{\Delta \tilde{V}}{V_{r}}=\left\|1+\frac{\Delta \tilde{V}}{V_{r}}\right\|-1
$$

Substituting equation (2.7) into equation (2.13) gives:

$$
\frac{\Delta V}{V_{r}}=\left\|1+\frac{(R P+X Q)+j(X P-R Q)}{V_{r}^{2}}\right\|-1
$$

The magnitude of the absolute value is:

$$
\frac{\Delta V}{V_{r}}=\sqrt{\left(1+\frac{R P+X Q}{V_{r}^{2}}\right)^{2}+\left(\frac{X P-R Q}{V_{r}^{2}}\right)^{2}}-1
$$

Equation (2.15) cannot be used to easily calculate the actual voltage of the load, $V_{r}$, because the variable appears on both sides of the equal sign. However, the equation can be used to calculate the rise or reduction in voltage due to change in the load.

In distribution systems the angle between the sending end and the receiving end is very small. Equation (2.15) can be simplified assuming that:

$$
1+\frac{R P+X Q}{V_{r}^{2}} \gg \frac{X P-R Q}{V_{r}^{2}}
$$

The expression for the normalized voltage drop can be reduced to:

$$
\frac{\Delta V}{V_{r}} \cong \sqrt{\left(1+\frac{R P+X Q}{V_{r}^{2}}\right)^{2}}-1
$$


Simplifying the square root from 2.17 , the normalized voltage drop becomes:

$$
\frac{\Delta V}{V_{r}} \cong 1+\frac{R P+X Q}{V_{r}^{2}}-1
$$

Equation (2.18) can be further reduced to:

$$
\frac{\Delta V}{V_{r}} \cong \frac{R P+X Q}{V_{r}^{2}}
$$

The voltage drop can finally be expressed as:

$$
\Delta V \cong \frac{R P+X Q}{V_{r}}
$$

\subsection{Voltage Control Methods}

When the voltage provided by an electric utility is outside Range A of the ANSI C84.1 standard, electric utilities need to correct the voltage to ensure all customers are receiving voltage within Range A. If the voltage experienced by a customer is below the Range A limit, it needs to be increased. If it is above the high limit of range A, it needs to be reduced. Electric utilities use numerous ways to improve the distribution voltage profile along the feeder. The most common methods are listed below:

- Use of a generator voltage regulator

- Application of voltage-regulating equipment in the distribution substations

- Application of capacitors in the distribution substation 
- Balancing of the loads on the primary feeder

- Increasing feeder conductor size

- Changing of feeder sections from single-phase to multi-phase

- Transferring loads to new feeders

- Installing new substations and primary feeders

- Applications of voltage regulators out on the primary feeder

- Increasing the primary voltage level

- Application of shunt capacitors on the primary feeders

- Application of series capacitors on the primary feeders

This list covers a wide range of options to control the voltage in the distribution feeder: from building new facilities, to transferring load from one feeder to another. The complete list is given by [8].

The construction of new facilities, increasing the primary voltage level and increasing the conductor size, requires a big capital investment and are usually the last option considered. When possible, low capital options such as transferring load are the first option.

For over a century, distribution networks have been operated radially, with the substation as the only source in the circuit. In a radially-operated feeder, the voltage is regulated by a LTC situated at the feeder head. The voltage decreases as a function of the distance and the amount of load connected. The voltage regulation problem for radially-operated distribution systems is a problem that has been solved by utilities for several decades.

LTCs, Automatic Voltage Regulators (AVRs), and capacitor banks have been used by utilities for decades to regulate voltage in distribution systems. However, the increase of 
DG connected to the distribution system and the push from some regulatory bodies to implement Conservation by Voltage Reduction (CVR), has increased the complexity of voltage regulation in distribution systems. This requires more complex algorithms and smarter devices to control the voltage.

\subsubsection{Capacitor Banks}

The wide use of motors in every aspect of today's society causes most loads in a distribution feeder to have a lagging power factor as the motors absorb reactive power. The voltage drop of a feeder operating with a low power factor will be higher than a feeder with the same amount of load operating with a unity, or close to unity, power factor. A low power factor increases the apparent power, the magnitude of the current flowing through the distribution lines, and the voltage drop along the feeder. To reduce the magnitude of the apparent power, shunt capacitors are installed along the feeder to reduce the reactive power required at the head of the feeder, a common practice called power factor correction.

In addition to improving the power factor, capacitors provide voltage correction. The leading current that flows through the distribution system decreases the voltage drop due to the inductive reactance, causing a voltage rise. The voltage rise is proportional to the current of the capacitor, the imaginary part of the impedance between the voltage source, and the capacitor location, as shown in Eq. (2.21).

$$
\Delta V(V) \approx I_{c} * Z_{c}
$$

where $\Delta V$ is the voltage rise in Volts, $Z_{c}$, is the conductor reactance in Ohms, and $I_{c}$ is the capacitor current. 
The use of shunt capacitors to compensate for low voltage and low power factor is a common practice among electric utilities. The capacitor current can be calculated if the reactive power rating of the capacitor bank and the phase to neutral voltage are known, using Eq. (2.22).

$$
I_{c}=\frac{Q_{c}}{V_{L N}}
$$

where $Q_{c}$ is the rated kVAR per phase, $V_{L N}$ is the phase-to-neutral voltage in $\mathrm{kV}$.

\subsubsection{Load Tap Changers}

A common method to regulate voltage in a distribution network is the use of Load Tap Changers. Taps are connections on a transformer winding that slightly change the turn ratio of a transformer. Load Tap Changers can be manual or automatic.

Automatic Tap Changers (ATCs) or LTCs are widely used for voltage regulation in a distribution system with fluctuating loads. LTCs can change the voltage by tapping up or down, effectively changing the turn ratio of the transformer, without interrupting the load.

Figure 2.5 shows the typical diagram of an LTC. LTCs typically have a $10 \%$ voltage regulation range. The diagram shows a preventive auto-transformer connected to line $H_{1}$. The preventive auto-transformer has a high impedance between transfer contacts to prevent high circulating current from damaging the windings as the taps are changed, and a low impedance between $H_{1}$ and the transfer switch contacts. 


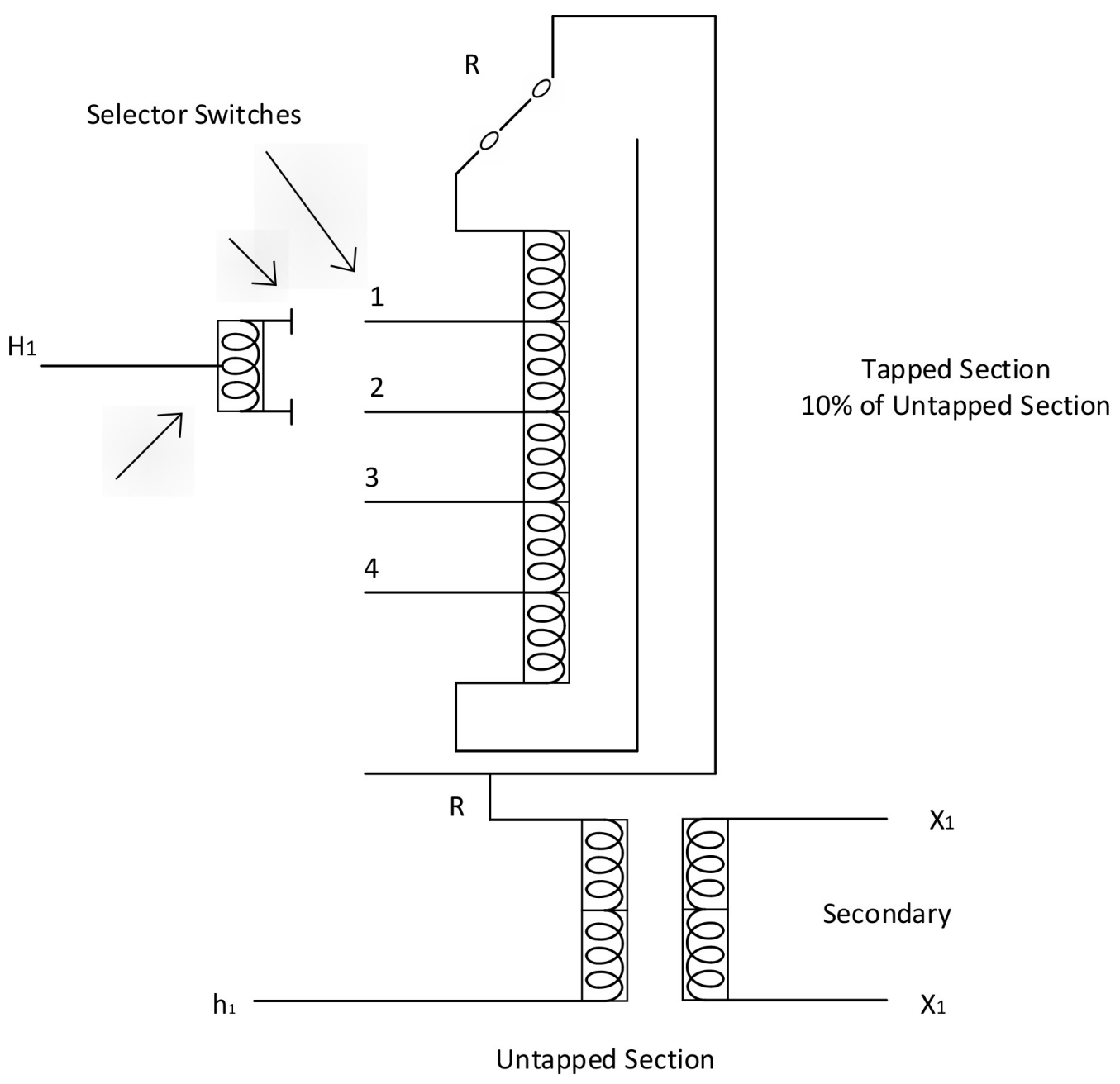

Figure 2.5: Typical diagram of an LTC

\subsubsection{Voltage Regulating Transformers}

A voltage regulator, sometimes also called a step-voltage regulator, is basically a $1: 1$ transformer with its source winding connected in shunt and its load winding connected in series. The voltage regulator can either aid (raise) or oppose (lower) the voltage in the feeder.

Voltage regulators used by utilities usually allow a $\pm 10 \%$ regulation range of the line voltage in 32 steps. Half of the steps, 16, are designated to buck (reduce) voltage and 
the other half to boost (increase) the voltage. Voltage regulators can be installed either at the feeder level or at the substation level, and they can be either three-phase units or single-phase units.

Most voltage regulators installed in the distribution system are single-phase because the loads are unbalanced and three independently-controlled voltage regulators can control the voltage better than a three-phase voltage regulator. A diagram of a single-phase voltage regulator is shown in Figure 2.6.

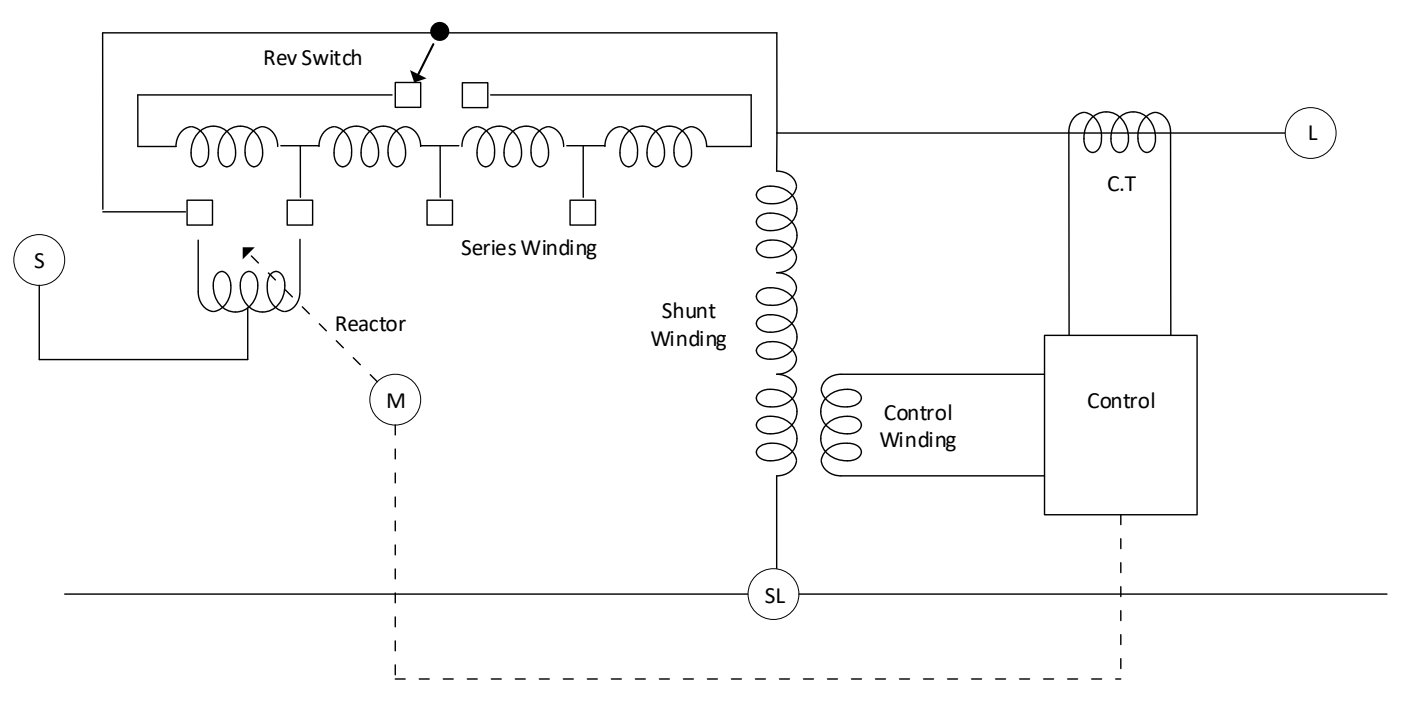

Figure 2.6: Single Phase Voltage Regulator

\subsubsection{Voltage Impact of Distributed Energy Resources}

The interconnection of DERs in the distribution system raises the voltage at the PCC. The voltage rise due to the interconnection of DER can be better understood by studying a simple radial circuit. Figure 2.7 shows a simplified feeder with one DER connected at the end of the feeder. 


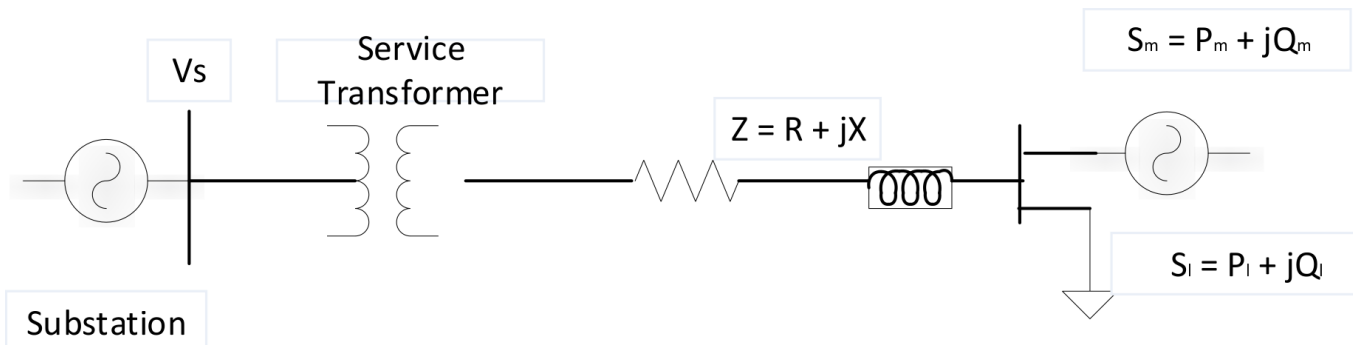

Figure 2.7: Single line diagram of a secondary feeder with a DER connected at the end of the feeder

The simplified power flow equation relating the voltage difference between the sending and receiving end is given by:

$$
V_{m}-V_{s} \approx \frac{R\left(P_{m}-P_{l}\right)+X\left(Q_{m}-Q_{l}\right)}{V_{m}}
$$

where $P_{m}$ is the active power output, $Q_{m}$ is the reactive power output, $P_{l}$ is the active power demand at the DER location, $Q_{l}$ is the reactive power demand at the DER location, and $R+j X$ is the supply impedance from the source to the DER location.

The supply impedance is composed of the utility source impedance, primary feeder impedance, distribution transformer impedance, and secondary system conductor impedance [9].

There are two components that affect the voltage at the customer terminals, the baseline voltage that is a function of the load and the impedance of the feeder, and the voltage rise due to the distributed generation. These two components can be separated from (2.23) and rearranged as: 


$$
V_{m} \approx\left[V_{s}-\frac{R P_{l}+X Q_{l}}{V_{m}}\right]+\left[\frac{R P_{m}+X Q_{m}}{V_{m}}\right]
$$

The first term of Eq. (2.24) represents the existing baseline voltage, $V_{b}$, without the presence of the DER. The base voltage is mainly affected by the load connected to the bus, the voltage in the primary feeder, and the position of the voltage regulator (in case there is one between the substation and the customer).

Equation (2.24) can be rewritten in a compact form as:

$$
V_{m} \approx V_{b}+\left[\frac{R P_{m}+X Q_{m}}{V_{m}}\right]
$$

Equation 2.25 shows that the voltage at the PCC can be affected by both the real and the reactive power of the DER. The work presented in this dissertation focuses on how to manage the voltage at the customer level (low side of the service transformer), rather than the typical distribution feeder level (high side of the service transformer).

\subsection{Voltage Control in Distribution Systems with Higher Penetration of DG}

Traditionally, the prevention of excessive voltage drops is the main design goal for distribution systems. Voltage drop sets a limit to the maximum feeder length. High voltages have traditionally been less of a concern during distribution system design. The introduction of Distribution Generation (DG) has changed the way distribution systems are operated, from simple radial circuits to systems that could have bidirectional power flow and multiple generation sources. The addition of DG to distribution systems has raised the complexity 
of controlling voltage along the feeder. There have been high voltages reported in feeders with a high penetration of DG, especially solar PV, and these high voltages are becoming a concern for electric utilities as described in [10].

The amount of DG, especially solar PV, connected to the distribution system has increased significantly over the past decade [1]. It is estimated that during 2015 alone, over $50 \mathrm{GW}$ of solar PV capacity was added in the US. The total PV capacity installed at the end of 2015 is estimated to be $228 \mathrm{GW}$, with most of the new installations being between $500 \mathrm{~kW}$ and $2 \mathrm{MW}$ and connecting directly to the distribution system [1] [11].

The ANSI C84.1 standard gives the suggested voltage at the customer meter. Readings of the voltage at the customer meter were not widely available less than a decade ago and the voltage control was performed at the feeder level. When the voltage at the meter is unknown, utilities estimate the voltage at the meter using a fixed voltage drop across the service transformer. The estimation of the voltage leads to either a conservative approach where the voltage at the feeder level was kept relatively high to ensure that the voltage at the customer meter was within the ANSI c84.1 standard or to an underestimation of the voltage drop across the service transformer, resulting in low voltage at the customer meter.

The widespread use of Advanced Metering Infrastructure (AMI) to obtain voltage and consumption data has increased the accuracy of voltage control algorithms. In [12], the author discusses three methods to measure the Low Voltage (LV) secondary voltage drop using AMI. The accurate knowledge of the voltage at the meter has increased the number of algorithms used to control the voltage at the feeder level. 


\subsection{Voltage Control in Feeders with Distributed Generation}

Researchers have long studied the voltage regulation control problem in distribution systems containing DG by coordinating the use of the LTC controller and the reactive power compensation. In [13], the authors proposed a control and coordination algorithm to manage the LTC and the reactive power compensation devices available in a feeder. The authors of [14] present a framework to assess the performance of different LTC-based strategies.

The authors in [15] address power quality issues associated with PV interconnection and propose to use reactive power compensation to mitigate the voltage issues due to DG by controlling the PV inverter using the Pulse Width Modulation (PWM) technique to drive the inverter. Their proposed control technique shows a reduction in voltage regulation in feeders with a high penetration of PV.

The slow response time of LTCs and AVRs and the limited flexibility of these devices to accommodate large amount of DG penetration have been investigated in [16] and [17]. The authors of [18] studied the impact of DG in distribution systems with multiple voltage regulation devices and proposed an on-line voltage control strategy for a distribution system containing a synchronous machine-based renewable DG and multiple voltage regulating devices.

In [19], the authors proposed a control coordination technique between the DG controller, the LTC controller and the AVR controller to utilize the DG as a voltage regulator to minimize the interaction with other active voltage control devices, like the LTC and the AVR controllers. The control technique proposed is based on the concept of a control zone, line drop compensation, dead band and manipulation of the controller parameters.

The authors in [15] demonstrated that reactive power compensation is effective in 
mitigating voltage issues due to high levels of DG penetration. However, not all electric utilities have the power of requiring PV installations to operate their PV systems in this mode. Reactive compensation is a recognized method for improving the voltage profile along the transmission and distribution systems as described by [20-22].

Electric utilities, specifically IOUs, are regulated by the state Public Utility Commissions (PUC). The state PUC sets the rules for the requirements that an IOU can set on a DG to interconnect to the IOU system. The local electric utility, Idaho Power, requires that utility scale DG to meet the reactive requirements set by the Institute of Electrical and Electronics Engineers (IEEE) 1547-2018 standard. Idaho Power currently does not require residential DG installations to provide reactive compensation.

There is a need for electric utilities to mitigate local voltage issues at the local level due to the increase in DG penetration. The RSVC presented in this dissertation aims to bridge the gap between currently installed DG that do not have reactive compensation capability, and future installations of DG that would be required to provide the reactive compensation.

\subsection{Reactive Compensation in Distribution Systems}

Reactive power compensation can be achieved as either series compensation or as a shunt compensation. Reactive series compensation changes the equivalent impedance of the transmission or distribution line. Reactive series compensation has been used in transmission lines to change the impedance and to change the power flow. Reactive shunt compensation changes the equivalent impedance of the load. Reactive shunt compensation is mainly used as a way to control the voltage in transmission systems [23].

In distribution systems, reactive power compensation is typically associated with the optimal adjustment of capacitor banks to satisfy operating constraints and minimize energy 
losses. The dynamic compensation of reactive power is usually achieved by using switched capacitor banks that turn on and off depending on a control variable. The control variable can be a localized measurement such as voltage or reactive power or it can be controlled by a remote measurement. Capacitor banks can also be independently controlled or can be part of a centralized control algorithm to minimize circuit losses and improve the power factor of the entire feeder [24].

Electric utilities limit the switching of the capacitor banks to extend their lifetime and to minimize the transient high voltage associated with the closing of a capacitor bank. A common way to limit extensive switching is to apply a delay in the capacitor controller, typically in the range of tens of seconds to minutes. The slow response of capacitor bank switching could lead to high and low voltage in feeders with high penetration of DG, as discussed later in this dissertation.

\subsubsection{Shunt Compensation}

In distribution systems, shunt compensation is used to compensate for the lagging current in the feeder due to inductive loads. Shunt devices, such as capacitor banks, inject VARs into the distribution system, improving the voltage regulation at the receiving end terminals [23].

The distribution system is compensated by the leading current injected by the capacitor banks reducing the lagging current supplied by the AC source [23]. The leading current injection can be modeled as current source, as shown in Fig. 2.8. Shunt compensation helps to improve the power factor and the voltage profile in a distribution system. 


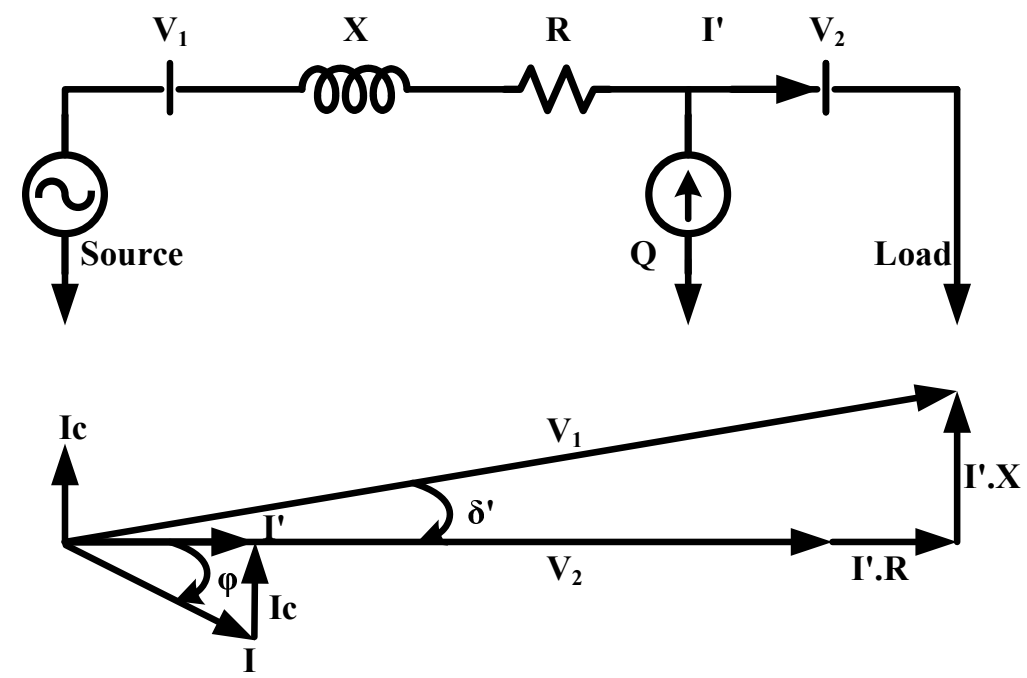

Figure 2.8: Reactive Shunt Compensation with phasor diagram

\subsubsection{Series Compensation}

Series compensation is achieved by decreasing or increasing the reactance of power lines by installing series capacitors or series inductors. The total reactance of the line can be modified and thus the amount of power flowing through the line can be increased or decreased [25]. 


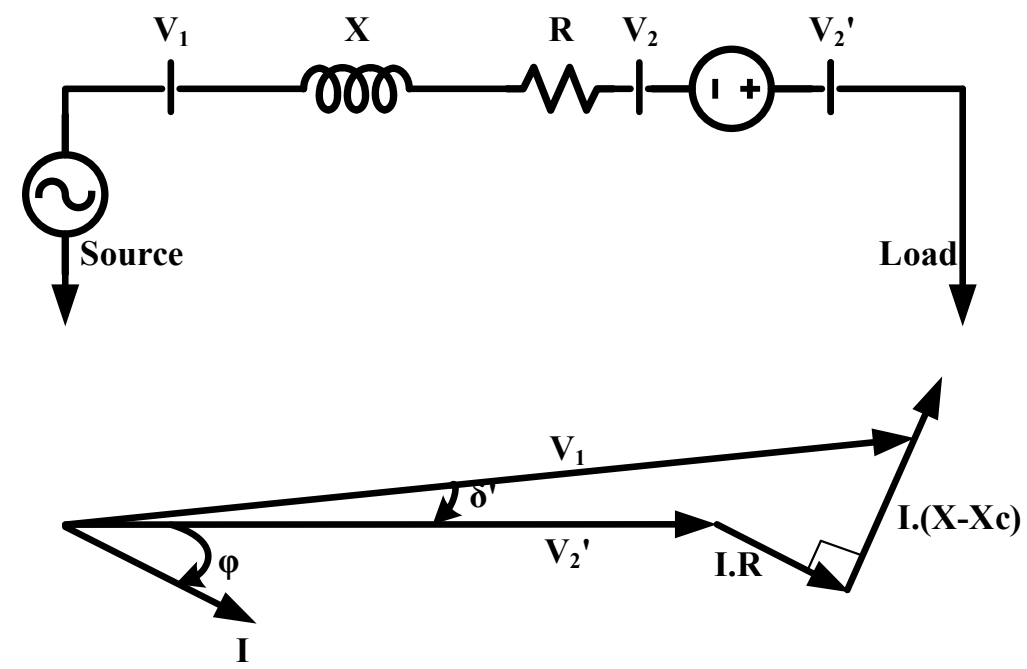

Figure 2.9: Reactive Series Compensation with phasor diagram 


\section{CHAPTER 3}

\section{LOSS SENSITIVITY FACTORS}

\subsection{Loss Sensitivity Factors}

Loss Sensitivity Factors (LSF) are defined as the change in the total real power loss with respect to the change in the injection of reactive power at a particular node or bus. LSF have been used by researchers as a way to limit the search space of different optimization algorithms [26]. LSF are used to determine which buses are sensitive to the change in reactive power and which buses are not. The buses with a low LSF could be removed from the search space of an algorithm. Having a smaller search space reduces the number of iterations that it takes an algorithm to arrive at the optimal solution [26,27].

The authors in [26] used LSF to find suitable candidate buses for reactive support, reducing the search space of their optimization algorithm. The authors in [27] used LSF to find the candidate nodes and then also used LSF to determine the sequence in which the nodes were considered to host a capacitor bank. In both cases, the number of iterations to arrive at the optimal solution was reduced. 


\subsection{Derivation of Loss Sensitivity Factors}

\subsubsection{Sensitivity Factors}

The Loss Sensitivity Factor (LSF) method is a technique that is based on the linearization of the nonlinear loss formula. The LSF determines how sensitive the system losses are to the real or reactive power injection at any given bus.

The LSF have been applied to allocate capacitor banks in distribution feeders in the past. However, the approaches only used the peak load of the feeder [28, 29]. A feeder operates at peak capacity only during a few hours out of the year and using only the peak load might not be accurate for identifying the optimal location of capacitors to reduce losses over a period of time such as a year. A more accurate way to determine the optimal location for the RSVCs would be to use a daily or annual load shape of the load and minimize the losses over an entire period of time, rather than only at peak.

\subsubsection{Derivation of Loss Sensitivity Factors}

Consider a distribution line connected between 'p' and 'q' buses as shown in Fig. 3.1.

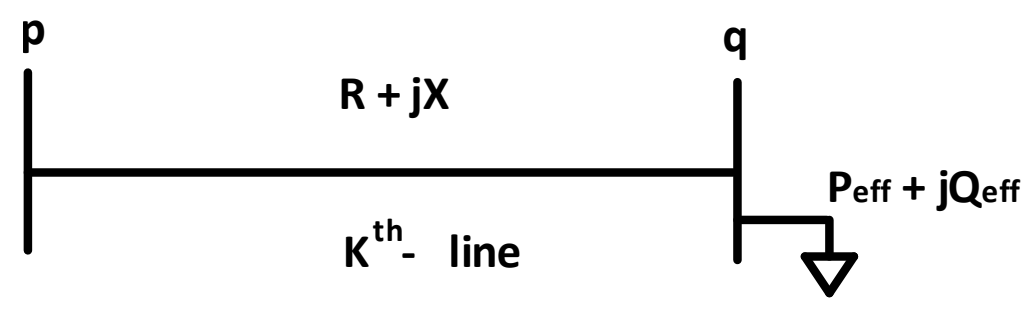

Figure 3.1: Distribution Line section

The active power loss in the line section " $k^{t h}$ " is given by 


$$
\text { Losses }_{\text {real }}=\left[I_{k}^{2}\right] * R[k]
$$

which can be expressed as:

$$
P_{\text {loss }}=\frac{\left(P_{\text {eff }}^{2}[q]+Q_{\text {eff }}^{2}[q] R[k]\right.}{(V[q])^{2}}
$$

Similarly, the reactive power loss in the " $k^{t h}$ " line is given by

$$
Q_{l o s s}=\frac{\left(P_{e f f}^{2}[q]+Q_{e f f}^{2}[q] X[k]\right.}{(V[q])^{2}}
$$

where $P_{e f f}[q]$ is the total effective active power supplied beyond the node 'q', $Q_{e f f}[q]$ is the total effective reactive power supplied beyond the node 'q', $R[k]$ is the real part of the impedance between nodes 'p' and 'q', $X[k]$ is the imaginary part of the impedance between nodes 'p' and 'q', and $V[q]$ is the voltage at node 'q'.

The loss sensitivity factors can be obtained as:

$$
\begin{gathered}
\frac{\delta P_{\text {loss }}}{\delta Q_{\text {eff }}}=\frac{2 * Q_{e f f}[q] R[k]}{(V[q])^{2}} \\
\frac{\delta Q_{\text {loss }}}{\delta Q_{\text {eff }}}=\frac{2 * Q_{\text {eff }}[q] X[k]}{(V[q])^{2}}
\end{gathered}
$$




\subsubsection{Loss Sensitivity Factors at Peak Load}

Large distribution feeders usually have thousands of nodes, with the majority of them not needing reactive compensation. Reducing the number of buses that could host an RSVC will reduce significantly the run time of the sizing algorithm. The use of loss sensitivity factors to reduce the potential nodes that require reactive compensation is presented in [28]. However, their analysis only focuses on the nodes with low voltage, excluding buses that could experience high voltage.

The recent increase in distribution connected solar PV could cause high voltage in the feeder and has been demonstrated to do so [30]. Traditional reactive compensation that is achieved via capacitor banks would not be able to reduce the voltage at the PCC of a customer with rooftop PV installed. However, the RSVC presented in this dissertation can

operate in inductive mode and hence it is able to reduce the voltage at the bus to which it is connected.

Buses with high voltage will also be considered as part of the set of potential buses to host an RSVC, given the capability of the RSVC to reduce high voltages.

\subsubsection{Loss Sensitivity Factors in OpenDSS}

The work presented in this dissertation uses OpenDSS as the main simulation platform. The authors in [28] published the LSF of a distribution feeder. The data of the distribution system used to calculate the LSF is available in [31]. The distribution feeder in [31] was built using OpenDSS and the power flow solution was compared to the published results. The LSF values in [28] were compared to the results obtained in the OpenDSS model and are shown in Table 3.1. The average error between the published results and the created OpenDSS model is only $0.47 \%$ with a maximum error of $1.669 \%$. The small error between 
the published paper and the results presented here can be attributed to the difference in the method of solving the power flow.

Table 3.1: Loss Sensitivity Factors Results Comparison

\begin{tabular}{|l|l|l|l|}
\hline Bus No & {$[31]$} & $\begin{array}{l}\text { Proposed } \\
\text { approach } \\
\text { (OpenDSS) }\end{array}$ & Error (pct) \\
\hline \hline Bus 2 & 0.029661 & 0.030098 & 1.4500 \\
\hline Bus 3 & 0.015485 & 0.015545 & 0.0700 \\
\hline Bus 4 & 0.006182 & 0.0061777 & 0.0923 \\
\hline Bus 5 & 0.001256 & 0.0012553 & 0.3290 \\
\hline Bus 6 & 0.016437 & 0.016452 & 0.3857 \\
\hline Bus 7 & 0.002811 & 0.0028107 & 0.3043 \\
\hline Bus 8 & 0.001613 & 0.001613 & 1.2169 \\
\hline Bus 9 & 0.004134 & 0.0041352 & 0.0018 \\
\hline Bus 10 & 0.001342 & 0.0013416 & 1.6694 \\
\hline Bus 11 & 0.008526 & 0.0085001 & 0.0528 \\
\hline Bus 12 & 0.005266 & 0.0052139 & 0.0100 \\
\hline Bus 13 & 0.001678 & 0.0016578 & 0.9998 \\
\hline Bus 14 & 0.002966 & 0.0029173 & 0.0286 \\
\hline Bus 15 & 0.003141 & 0.0031307 & 0.0300 \\
\hline
\end{tabular}

A sensitivity analysis is used to select the candidate locations for placing the RSVC in the distribution system. Loss Sensitivity Factors will be used to determine the candidate buses to host an RSVC. As an example, the LSF for the distribution system in [28] are shown in Fig. 3.2. Based on the figure, the first RSVC would be connected to Bus 2, the second one to Bus 6 and so on. The last bus to consider to host an RSVC would be Bus 5, since it has the lowest sensitivity factor value. The estimation of these candidate locations helps in reducing the numbers of buses that are candidates to host an RSVC. In earlier works heuristics and engineering judgment have been used to select the locations. The sensitivity analysis applied in this work is a systematic procedure to select those locations which have maximum impact on the system's real power losses. 


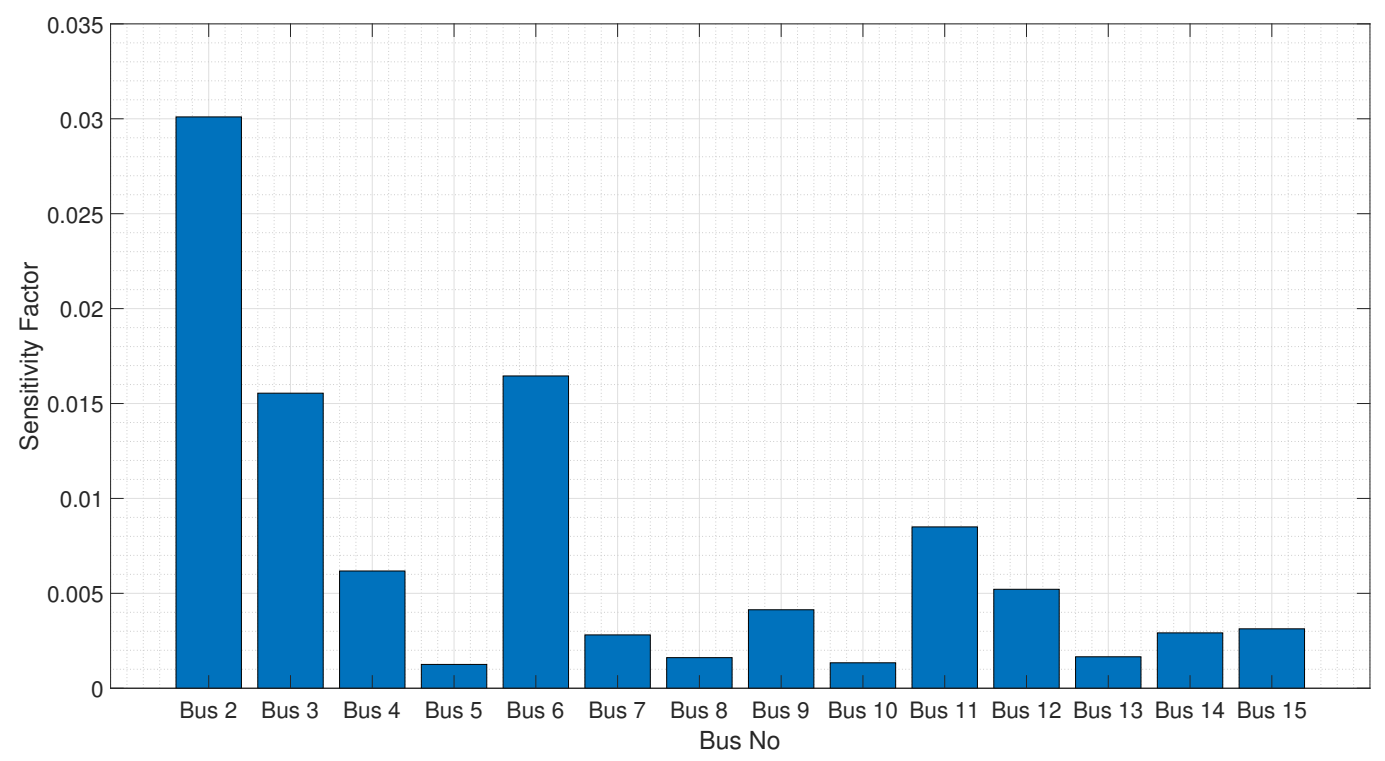

Figure 3.2: Loss Sensitivity Factors Using OpenDSS

\subsubsection{Daily Sensitivity Factors}

This dissertation introduces the concept of daily sensitivity factors to represent the sensitivity factor at each bus during each hour of the day. The daily sensitivity factors are then averaged. The LSF for each bus is the average value of the LSF calculated for each hour of the day. The daily LSF are more representative than a LSF calculated for a single loading condition because it reflects how the load changes in the feeder with respect to time.

Even though each customer could have a unique load shape during a 24-hr period, there are similarities between customer's classes. Residential customers tend to peak in the late afternoon, when most people get home from work, whereas industrial and commercial customers tend to peak earlier in the day when most people are working.

The Electric Power Research Institute (EPRI) has developed a load shape library under Project Set P170A Analytical Frameworks with the objective to facilitate the collection, 
use, and functionality of a library representative of electric load shapes by climate zone, geography or by utility [32]. A typical residential, commercial, and industrial load shape for the North-West United States was obtained from EPRI's library .

A typical distribution feeder has all types of customers connected to it, including residential, commercial, and industrial. Distribution engineers can get a good idea of the load profile of the feeder by looking at the current and voltage measurements that most feeders have at the feeder head. Some utilities have installed Advance Meter Infrastructure (AMI) that gives them access to hourly data of each customer.

The three load shapes, residential, commercial, and industrial, were assigned randomly to each of the loads in the sample feeder. The LSF at each hour of the day were calculated. The results are shown in Fig. 3.3.

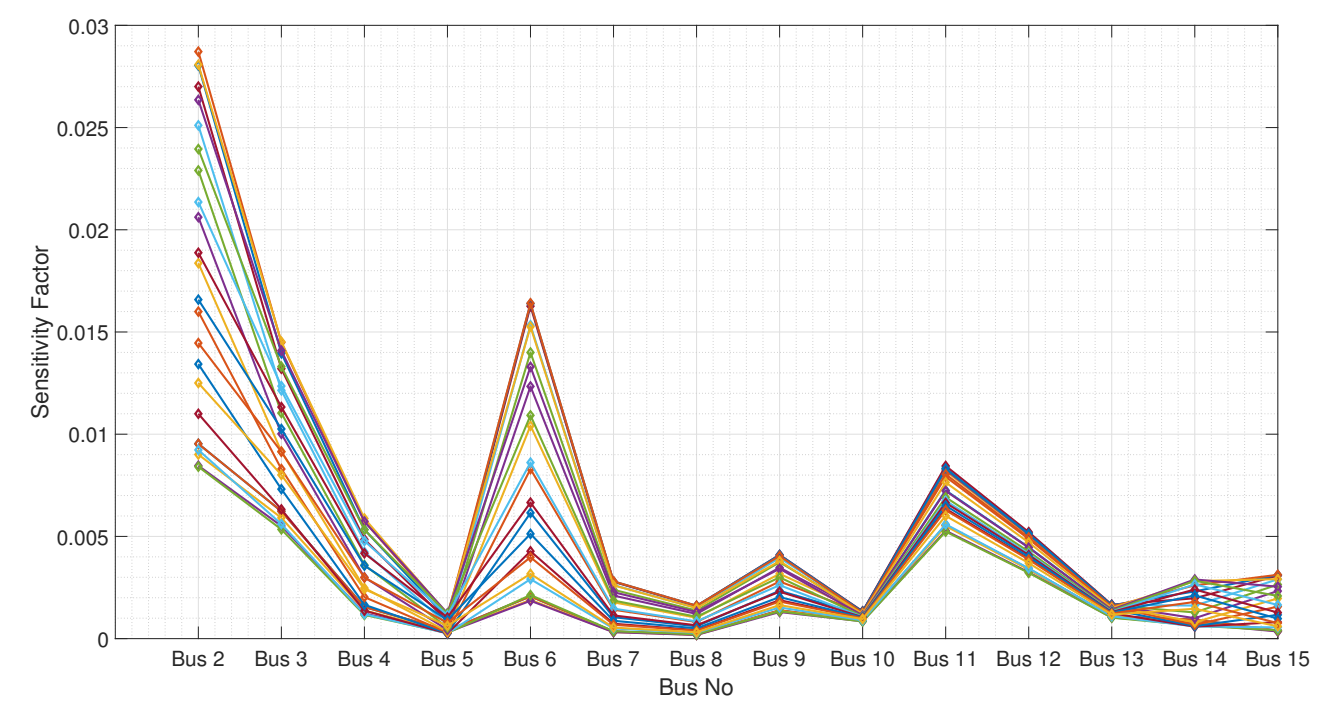

Figure 3.3: Hourly Loss Sensitivity Factors

The results shown in Fig. 3.3 show that the LSF for a bus are different depending on the loading of the feeder. It can also be seen which buses have a wide range of values of 
the LSF. Theses buses would be good candidates to host an RSVC, whereas the buses that do not change or barely change would not be impacted significantly by an RSVC.

\subsection{Similar Devices}

In recent years, companies have started to offer localized solutions to voltage problems. Other companies have been founded with the purpose of mitigating localized voltage issues due to the high penetration of DG. Two of the companies that have commercially available products with this objective in mind and already have a product commercially available are Varentec and the Gridco Systems.

Varectec offers a dynamic VAR source that can be mounted on a pole top service transformer or next to a pedestal type service transformer, while Gridco offers a low voltage, pole-mounted, $20 \mathrm{kVA}$ Static VAR Compensator.

\subsubsection{Varentec}

Varentec developed a 10-kVAR unit called ENGO in the past three years. The ENGO unit is a secondary-side voltage and VAR regulator that combines real-time voltage control with monitoring to implement Volt/VAR control. The ENGO unit has a range of 0-10 kVAR reactive power injection. The details of the how the switching of the power electronics is implemented in this device is protected and it is not publicly available [33].

\subsubsection{Gridco Systems}

Gridco Systems has recently launched a reactive support product called SVC-20. The SVC-20 has a rating of $23.2 \mathrm{kVAR}$ at 277 Volts and $17.4 \mathrm{kVAR}$ at 240 Volts. It is designed to be connected on the secondary side of a service transformer and its two main applications 
are voltage assurance and CVR. The switching technique used by the SVC-20 is also proprietary and it is not publicly available [34].

The RSVC presented in this dissertation aims to solve localized voltage issues in a feeder with high penetration of DG at an affordable price for the utility company. While the price of the two previous products is not available without a consultation of the application, it is believed by the author of this dissertation to be on the order of thousands of dollars, making the wide implementation of these products non-competitive with traditional solutions used by electric companies. 


\section{CHAPTER 4}

\section{RSVC DESIGN AND MODEL}

\subsection{Residential Static VAR Compensator}

The Power Research Group at Boise State University (BSU) has been working on developing an RSVC over the past three years. The RSVC has been designed as a device that can provide voltage regulation to enhance the implementation of Conservation by Voltage Reduction (CVR) and to mitigate low and high voltage issues due to high levels of PV penetration.

Static VAR Compensators (SVC) have been in operation for decades in transmission and distribution systems. In distribution systems SVCs are not widely utilized due to their cost. The SVCs are limited to special applications in distribution systems such as electric arc furnaces, car crushers, phase balancing and other specialized industries $[35,36]$.

The RSVC prototype was developed as a shunt device that could be mounted on a distribution pole and could be connected to the secondary side of a $25-\mathrm{kVA}$ pole-mounted service transformer. The service transformer reduces the voltage from distribution levels $(15 \mathrm{kV}-34 \mathrm{kV})$ to utilization voltages $(240 \mathrm{~V})$. Typically, a 25-kVA transformer will serve at least three different residential customers. The reactive components of the RSVC were sized to regulate the residential voltage according to the ANSI C84.1 Standard. The schematic of the RSVC is shown in Fig. 4.1. 


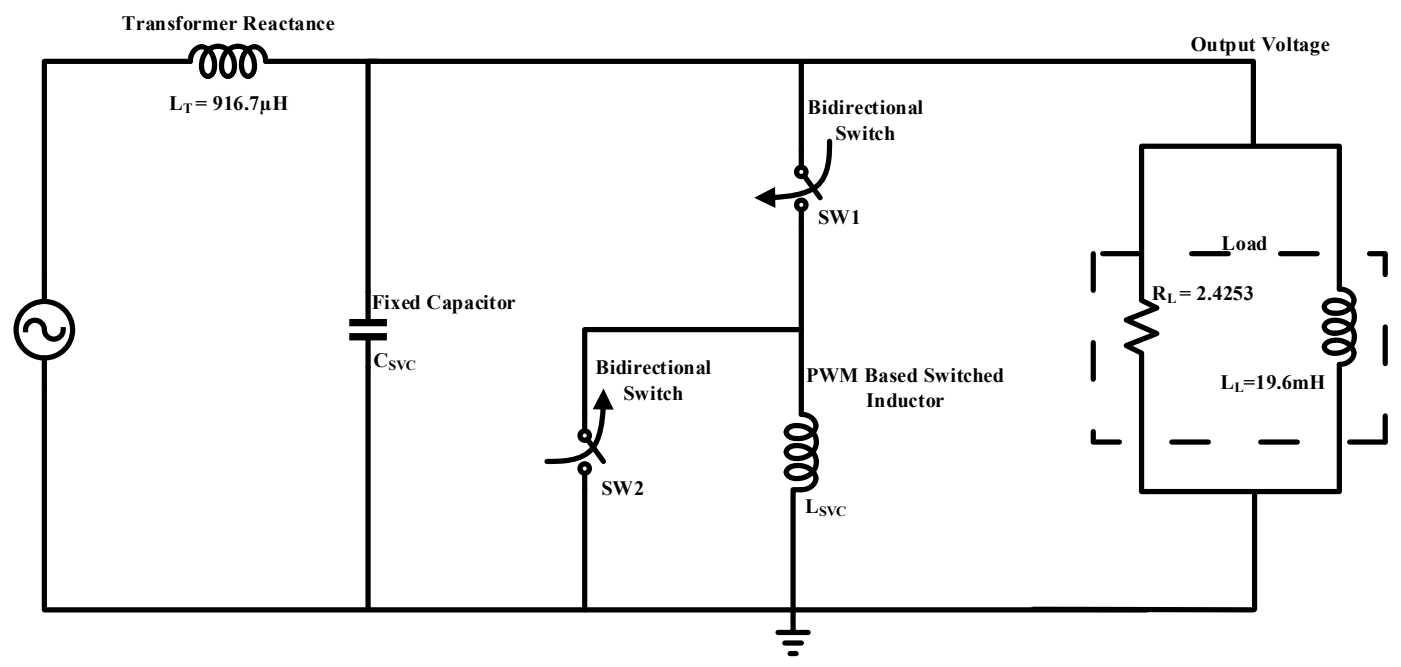

Figure 4.1: Residential Static VAR Compensator Schematic

\subsubsection{Distribution System Modeling}

The RSVC was developed as a single-phase device connected in shunt to the secondary side of a 25-kVA service transformer. To size the reactive components of the RSVC it is important to analyze the primary side of the service transformer. The modeling of the primary side of the service transformer is necessary to represent accurately the strength of the system as seen by the RSVC. The strength of the system can be thought of as the shortcircuit current available at any given point, the higher the short-circuit current available, the stronger the system.

A test feeder was created by building a simple feeder in PowerWorld. The source serves five uniformly distributed $1 \mathrm{MW}$ loads. The distribution conductor used for the simulation was a 397.5 MCM ACSR (Aluminum Conductor Steel Reinforce), a typical conductor used by Avista Corporation, a local utility in the state of Idaho.

Figure 4.2 shows the model created in PowerWorld ${ }^{\mathrm{TM}}$ of the distribution system. The substation is modeled as an ideal source that can generate any power, real and reactive, to 


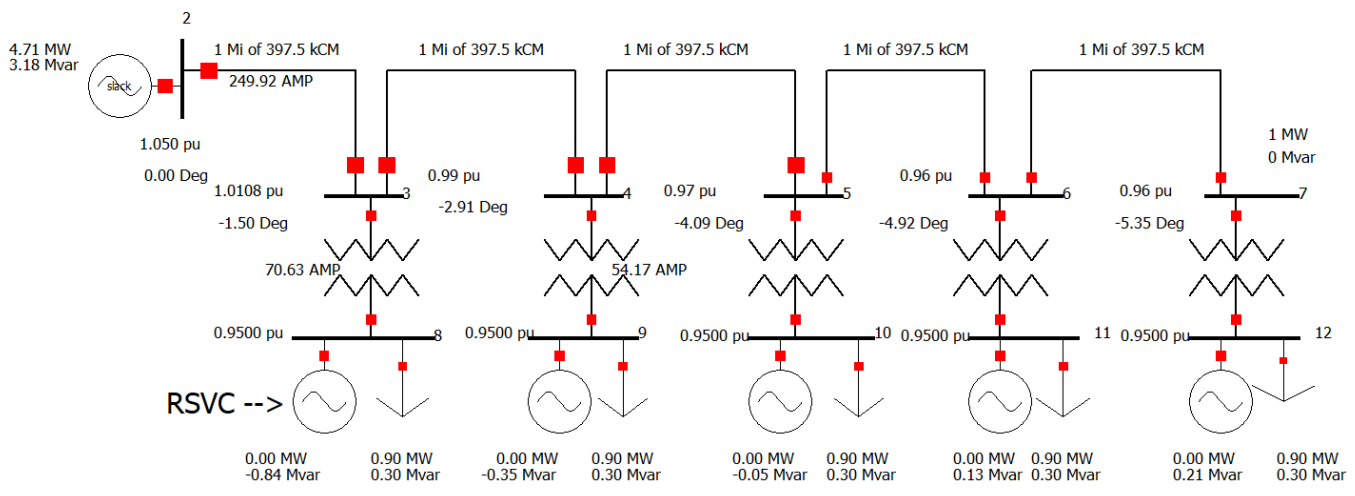

Figure 4.2: PowerWorld Model for a Distribution System with uniformly distributed loads

feed the load and to keep the voltage at a constant value.

The distribution system was modeled by using 5 distributed loads, of $1 \mathrm{MW}$ each, operating at unity power factor. A 100 MVA power base was used to calculate the Thevenin equivalent, as seen at the RSVC terminals. The voltage base used at the RSVC terminals was $240 \mathrm{~V}$. The RSVC was modeled as a generator with zero real power output. The generator was used to control the voltage at the low side of the service transformer. The leakage reactance of the service transformer was assumed to be $10 \%$ in a 2 MVA base.

The Thevenin equivalent as seen by the third RSVC from left to right in Fig. 4.2 was calculated to determine the strength of the distribution system at the RSVC terminals. The impedance diagram of the distribution system is shown in Fig. 4.3.

Solving the circuit in Fig. 4.3 for the Thevenin equivalent, the impedance seen by the $\operatorname{RSVC}\left(\mathrm{Z}_{\mathrm{TH}}\right)$ is $0.051+j 0.0086 p u$. Using this result, it can be safely assumed that the distribution system appears as an infinite bus to the RSVC.

The ability of the RSVC to increase or decrease the voltage can be explained using Eq. (2.20). By increasing or decreasing the reactive power at the load terminals, the voltage can increase or decrease. 


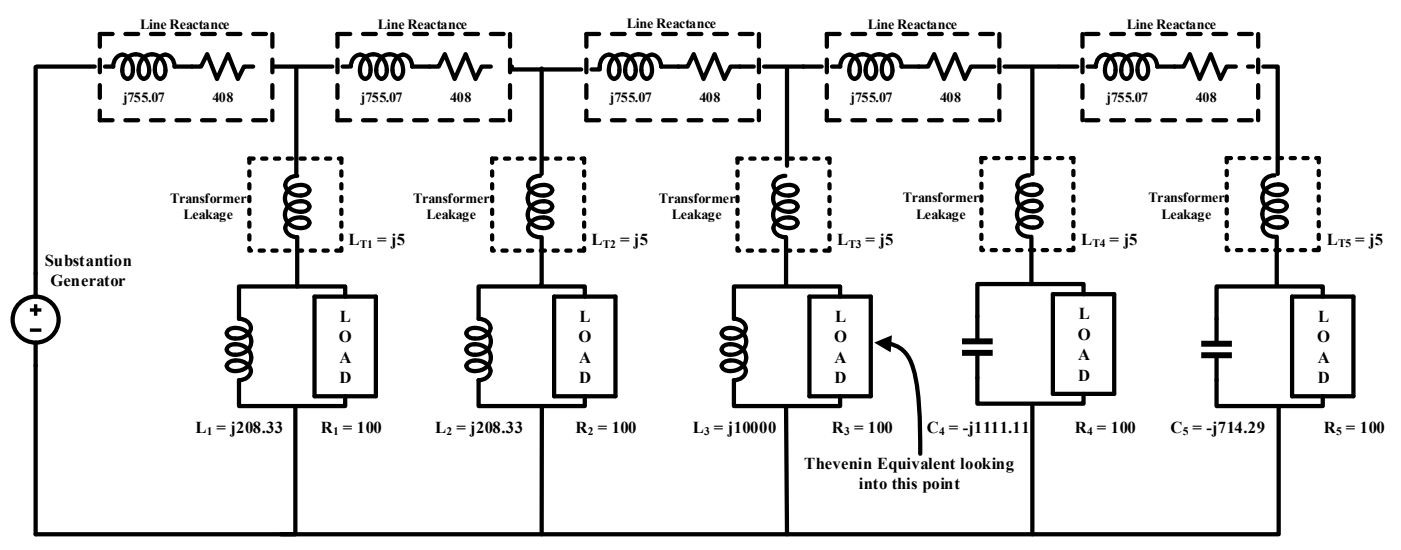

Figure 4.3: Impedance Circuit of the distribution system to calculate Thevenin impedance

The leakage reactance of the service transformer needs to be modeled accurately given that the RSVC will be connected to the load side of the service transformer. The leakage reactance is the amount of flux that leaks from the flux link between the primary and secondary windings in the service transformer. Ideally, this reactance will be zero, but in practice, it is impossible to have a zero leakage reactance. The leakage reactance of the service transformer was assumed to vary between $10 \%$ and $20 \%$ of the rated transformer reactance. The amount of reactive power that the RSVC can inject or absorb depends on the size of the reactive components used to build the RSVC.

\subsubsection{Sizing of RSVC components}

Conservation by Voltage Reduction (CVR) is the implementation of a voltage strategy that is based on the observation that some types of loads consume less power when they are fed with a voltage lower than the rated voltage [37-39].

The RSVC was designed with the goal to enhance the implementation of CVR. To enhance the implementation of CVR, the RSVC would be matched with a 25-kVA pole mounted transformer, one of the most common sizes serving residential loads at the local 
utility. The RSVC was designed to operate at 240-V, allowing the prototype to be tested in a laboratory.

A test circuit was developed in Simulink ${ }^{\mathrm{TM}}$ to determine the size of the reactive components. The high side of the service transformer was modeled using an ideal voltage source, the service transformer was modeled as having no resistance and a $10 \%$ leakage reactance. The transformer was assumed to be operating at rated nameplate capacity, in other words, the load was considered to be $25-\mathrm{kVA}$ operating at a 0.95 lagging power factor. The test circuit is shown in Fig. 4.4.

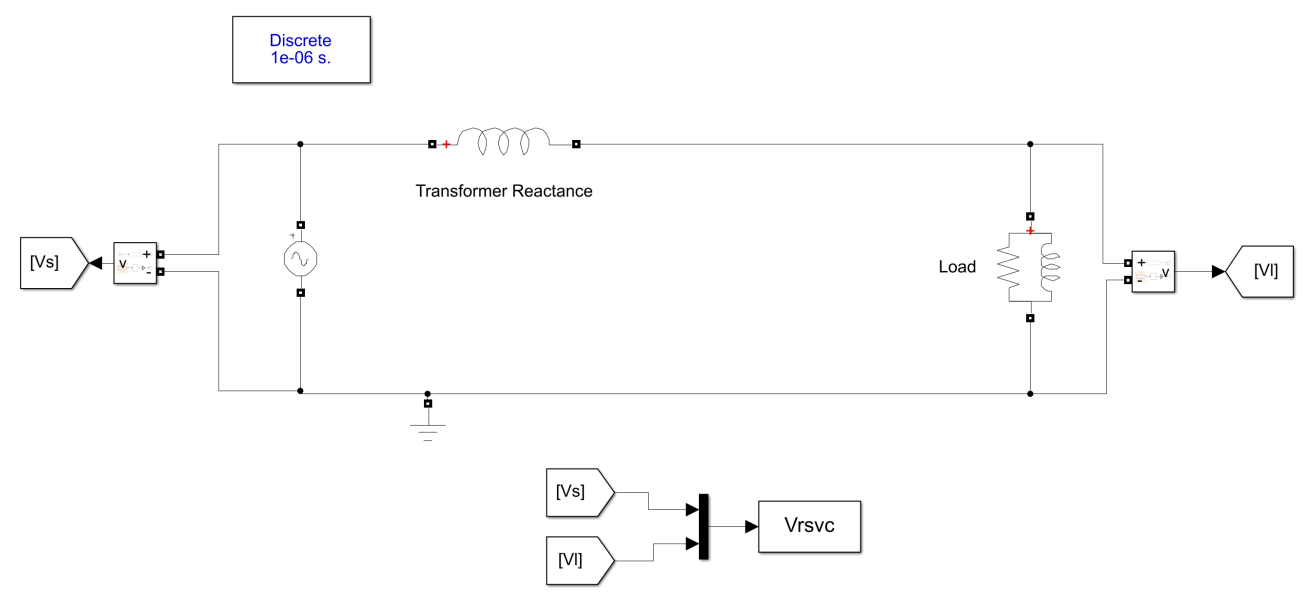

Figure 4.4: Circuit to size the capacitive component of the RSVC

\section{Capacitor Sizing}

The size of the RSVC capacitor was determined by first setting the voltage at the high side of the service transformer at $228 \mathrm{~V}(0.95 \mathrm{pu})$. The RSVC reactor is controlled by a pair of ideal bidirectional switches. If the top switch is left open, the reactor will have no contribution to the reactive power of the RSVC and there is no need to take it into 
consideration when sizing the capacitive element of the RSVC. The circuit to determine the capacitor size is shown in Fig. 4.5.

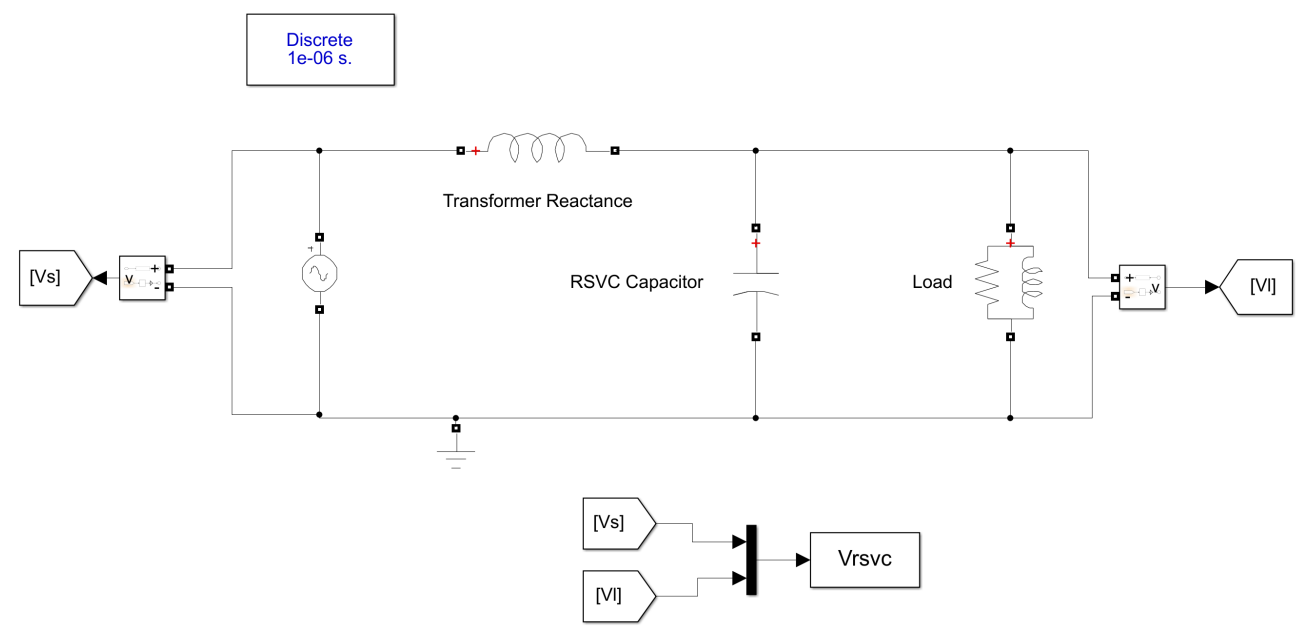

Figure 4.5: Circuit to size the capacitive component of the RSVC

The size of the RSVC capacitor was increased until the voltage at the load terminals was equal to $228 \mathrm{~V}(0.95 \mathrm{pu})$. This test will ensure that the RSVC has enough reactive capability to maintain the load voltage within limits when the feeder head voltage is lowered for CVR purposes.

The results obtained from the simulation suggest that in order to raise the voltage on the low side of the service transformer to $228 \mathrm{~V}(0.95 \mathrm{pu})$ when the voltage at the feeder, the high side of the service transformer, is kept at $228 \mathrm{~V}(0.95 \mathrm{pu})$, the capacitor of the RSVC needs to be at least $10 \mathrm{kVAR}$ with at a nominal voltage of $240 \mathrm{~V}$. The results of the simulations are shown in Fig. 4.6. The figure shows that the voltage at the high side of the service transformer, $V_{s}$, is the same as the voltage at the load terminals, $V_{l}$. The RSVC capacitor in this case is compensating for any voltage drop across the transformer, given that the service transformer is an inductive voltage drop, the capacitance of the RSVC is 


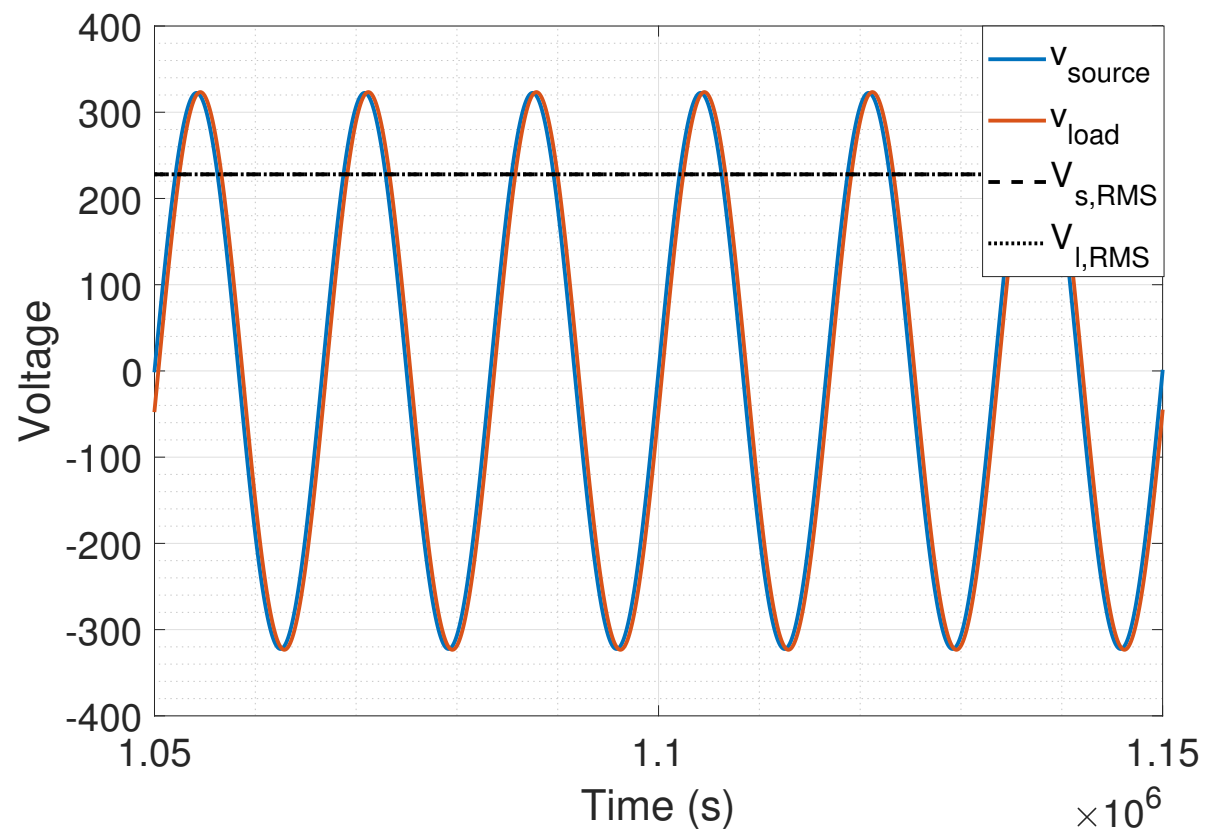

Figure 4.6: Source and Load Voltage with RSVC

able to mitigate the voltage drop and maintain the voltage at the terminals of the load within range.

\section{Inductor Sizing}

The inductor size of the RSVC was determined after the capacitor size was calculated for the RSVC. The capacitor in the RSVC is going to be operated in a fixed mode, meaning, it will always be connected, with no switch to take the capacitor out of service. A model was created in Simulink, where the capacitor was modeled at $10 \mathrm{kVAR}$ at $240 \mathrm{~V}$ in parallel with the load and in parallel with the inductor. The Simulink circuit is shown in Fig. 4.7.

The inductor size of the RSVC was determined by first setting the high side of the service transformer to $240 \mathrm{~V}(1 \mathrm{pu})$. Then, the size of the inductor was increased until the voltage at the load terminals was equal to $228 \mathrm{~V}(0.95 \mathrm{pu})$. 


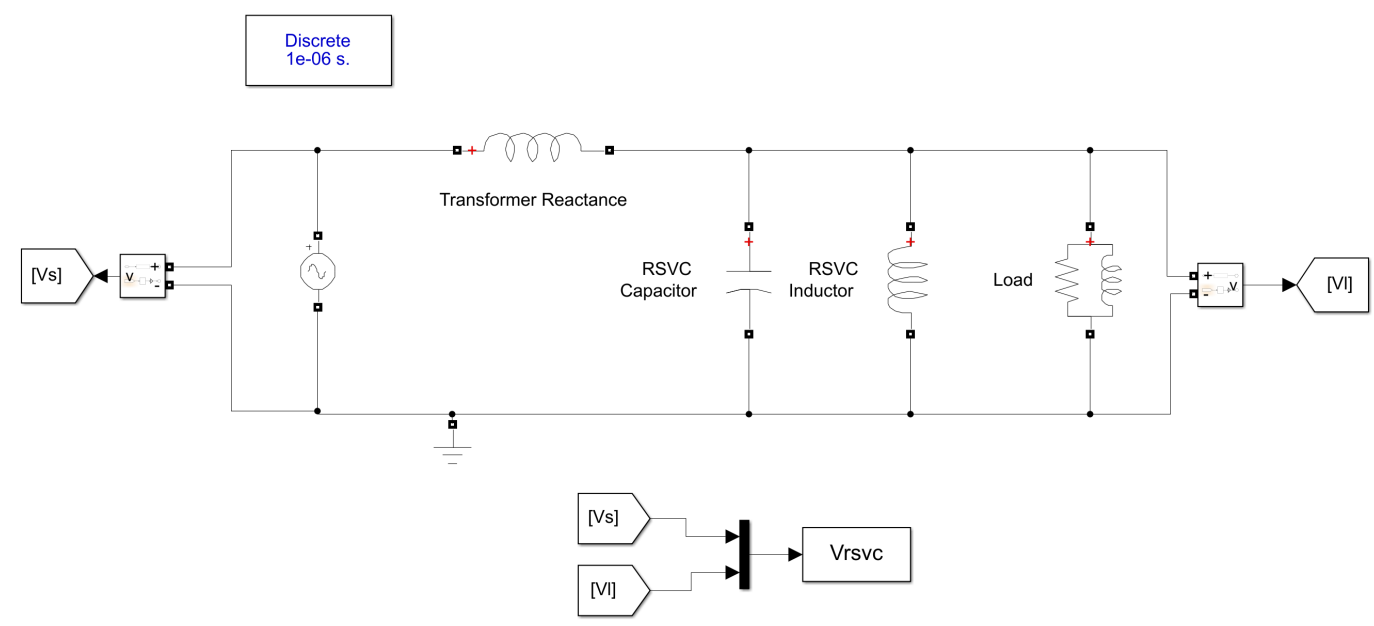

Figure 4.7: Circuit to size the inductive component of the RSVC

The waveform and Root Mean Square (RMS) value of the voltage at the high side of the service transformer, $V_{s}$, and the voltage at the low side of the service transformer, $V_{l}$, are shown in Fig. 4.8.

The final sizing of the RSVC was determined to be $10 \mathrm{kVAR}$ for the capacitive component and $11.75 \mathrm{kVAR}$ for the inductive component at $240 \mathrm{~V}$.

\subsubsection{Model of RSVC}

The model of the RSVC was first developed in Simulink due to its high speed and powerful solver. The model initially used ideal complementary switches instead of real switches. Fig. 4.9 shows the initial circuit implemented in Simulink. Another Simulink model using an IGBT switch and the proposed PWM switching technique was later implemented.

The model implemented in Simulink has a time step set in the order of milliseconds to microseconds. The milliseconds timescale is appropriate to analyze low order harmonic 


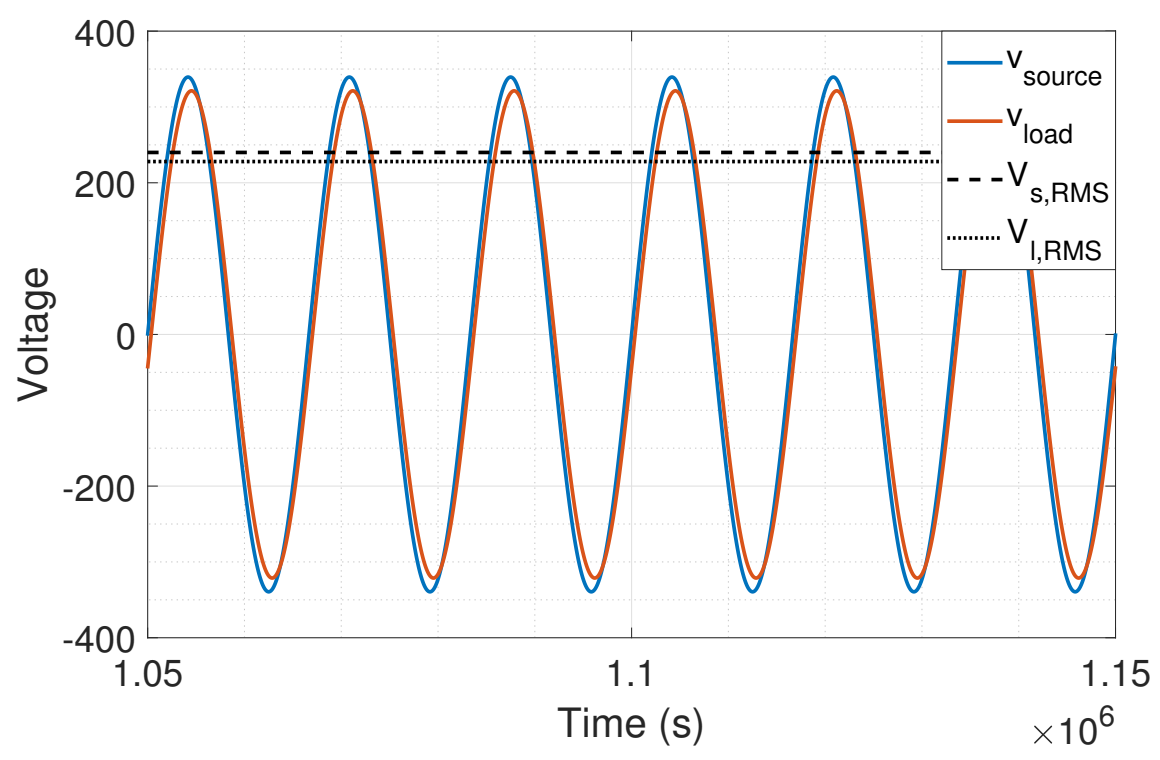

Figure 4.8: Source and Load Voltage with RSVC

issues and stability inside the RSVC control algorithm. However, it is not suitable to perform yearly simulations, where a time step in the hours range is more appropriate.

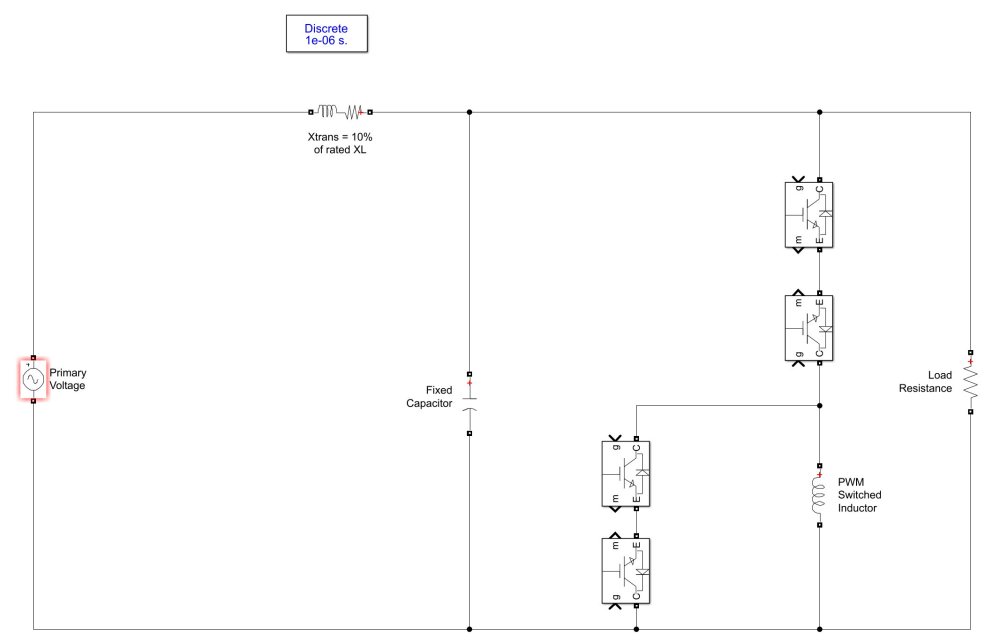

Figure 4.9: Residential Static VAR Compensator Circuit Implemented in Simulink

An appropriate model that could represent the RSVC behavior accurately and that could 
be used in yearly simulations was needed. So a model was developed in OpenDSS to represent the behavior of the RSVC. The model was verified by comparing the reactive power output of the RSVC model in OpenDSS with the reactive power output of the model created in Simulink. The model in OpenDSS requires an active power output to compile. The active power of the OpenDSS model was set to consume $0.01 \mathrm{~W}$ instead of $0.0 \mathrm{~W}$ to avoid computational issues. The real power set point represents the losses in the RSVC.

The reactive power obtained from the RSVC model implemented in Simulink was compared to the reactive power output of the model in OpenDSS. The two models were compared to show that the output of the model in OpenDSS is comparable to the detailed model developed in Simulink. A variable voltage data set provided by Avista was used as an input to the Simulink model of the RSVC. The RSVC would react to the changes in the input voltage and apply the required reactive power to keep the voltage at the RSVC terminals at $0.95 \mathrm{pu}$.
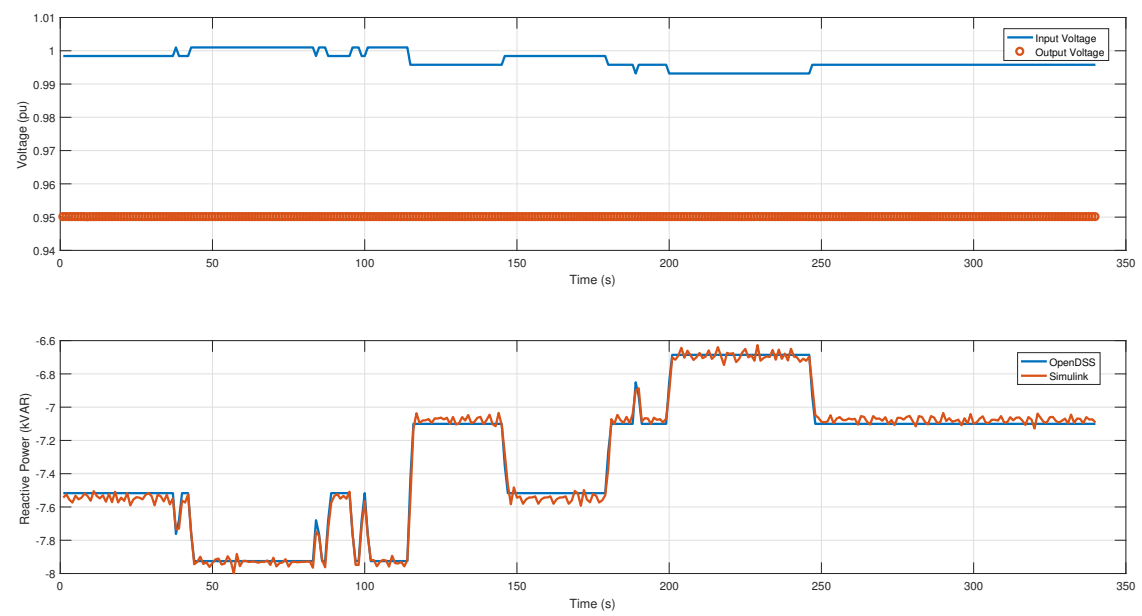

Figure 4.10: Simulink vs OpenDSS (a) input voltage; (b) reactive power

The same voltage data set was used as an input to the model built in OpenDSS. The 
OpenDSS model has the same reactive limits as the RSVC and it will output the necessary reactive power to maintain the voltage constant. The reactive power output of the model in OpenDSS was compared to the reactive power obtained from the RSVC model in Simulink. Fig. 4.10 (a) shows the input voltage and the output voltage used for the simulation and (b) shows the reactive power output of the Simulink model and the OpenDSS model.

The model in OpenDSS is able to represent the behavior of the RSVC with an acceptable level of accuracy. The advantage of using the OpenDSS model is the time it takes to simulate a years worth of data, while Simulink runs on the milliseconds to microseconds time step, OpenDSS could be used in yearly simulations with time steps that can range from minutes to hours. 


\section{CHAPTER 5}

\section{RSVC DEPLOYMENT}

\subsection{Description of Test Feeder}

The feeder $\mathrm{J} 1$ is a real feeder located in the northeastern part of the US [32]. It was selected for modeling in this dissertation because 1.7 MW of customer-owned PV systems already exist on this feeder and there is high voltage at times in this feeder that is suspected to be caused by the customer-owned PV systems.

The peak load of the feeder is approximately $6 \mathrm{MW}$. The feeder operates at the $12-\mathrm{kV}$ level and it serves approximately 1,300 residential, commercial, and industrial customers. The feeder has a total of 58 miles of primary line. The distribution substation is located at the southern-most edge of the feeder. The 1.7-MW PV systems are located near the center of the feeder, approximately 5 circuit-miles from the distribution substation.

The voltage regulation of the feeder is carried out by the use of an LTC, feeder voltage regulators and switched capacitor banks. There are four voltage regulators installed in the feeder, along with five capacitor banks, three of which are voltage controlled.

There is a small town located at the crossroads west of the PV arrays. The town has a population of less than 1,000. The town and the surrounding areas and farms are served by this feeder. Currently, the voltage regulators are used to mitigate voltage issues caused by the PV arrays. While voltage regulators are effective in mitigating the voltage fluctuations, the time delay programmed within the voltage regulators prevents them from operating in 
less than 45-90 seconds. The delay is intentionally programmed in the voltage regulators and capacitor banks to reduce wear and tear of these devices.

A PV array can ramp fast enough to cause voltage violations before the voltage regulators operate. The fast PV ramp is believed to be the cause of the high voltage violations in the feeder. The feeder model developed by EPRI in OpenDSS was used as the base case for this dissertation due to its data being publicly available and the results being published [3].

Figure 5.1 shows the geographic topology of the feeder. The yellow stars show the location of the existing PV in the feeder. The green squares and diamonds show the capacitor banks in the feeder and the red diamonds show the voltage regulators present in the feeder. The black thicker lines indicate all three phases are available while the gray lines indicate single-phase branches in the feeder. All of the PV installations are beyond the first voltage regulator and there are some PV installations that are beyond two stages of regulation and a few are beyond three stages of regulation.

A common way to display the voltage in a feeder is to plot its voltage profile versus location. The voltage plot is a voltage where the $\mathrm{x}$-axis is the distance away from the substation and the $\mathrm{y}$-axis is the normalized voltage, usually expressed in the $120-\mathrm{V}$ base. Using the voltage profile plot it is easier to identify where the voltage regulating devices are located and how far from the substation they are located. The voltage profile of the test feeder with no solar PV added to the feeder is shown in Figure 5.2

Figure 5.2 shows that under peak load conditions over the summer the feeder does not show any voltage violations. The dotted lines in the figure reflect the service voltage and the solid lines represent the medium voltage lines. The location of the voltage regulators can be seen by the sharp raise in voltage. The sharp voltage rise represents the source side of the voltage regulator has a low voltage and the load side of the voltage regulator being 


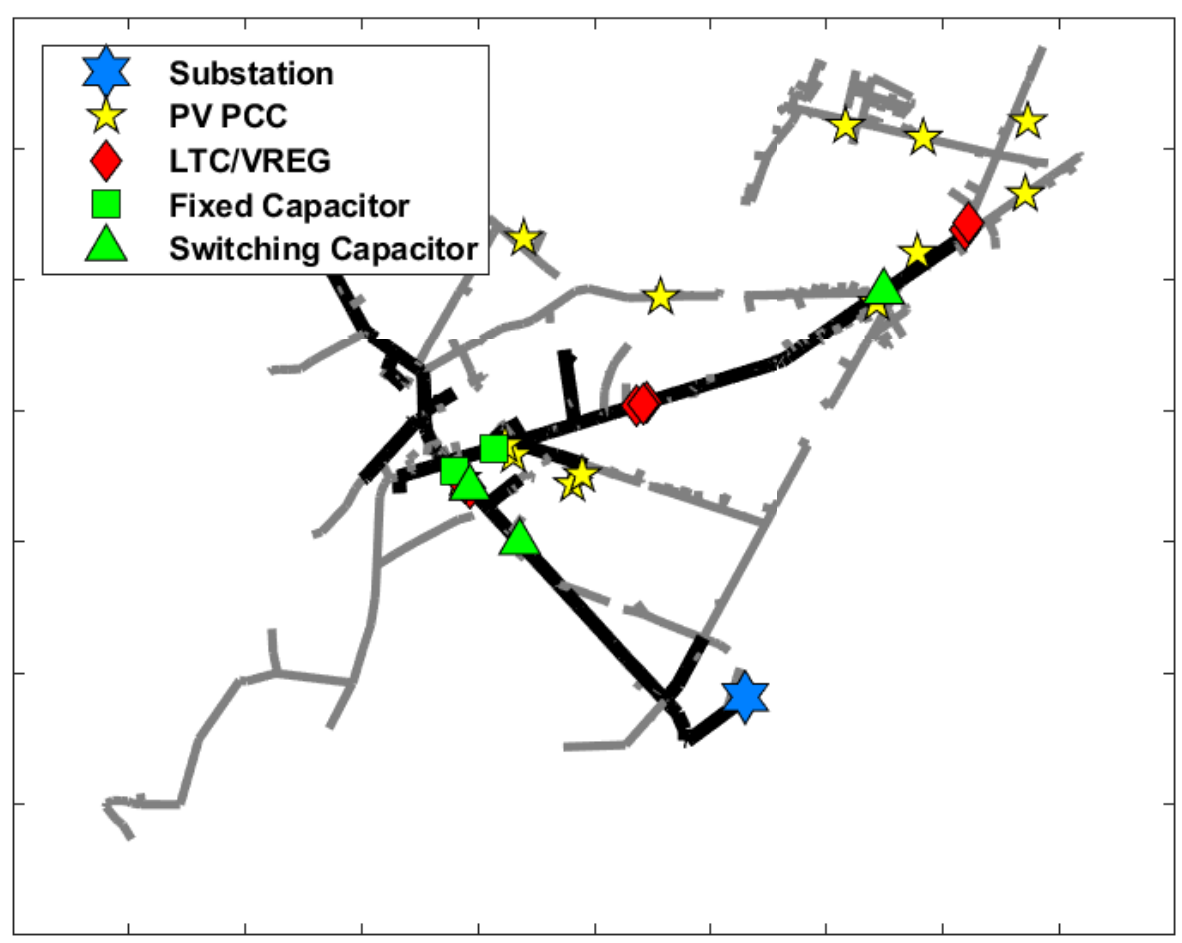

Figure 5.1: Topology of the Test Feeder

regulated to a higher voltage.

The solar PV available in the feeder was turned on at rated capacity, representing midday on a summer day. During steady-state conditions, the solar PV in the feeder does not cause any voltage violations in the feeder. The voltage regulating equipment is able to operate to maintain the voltage within the limits. Figure 5.3 shows the voltage profile with the solar PV operating at rated output power. The stars in the voltage profile show the location of the PV systems in the feeder.

A common test to determine whether or not variable generation, especially solar PV, could cause voltage violations on the grid is to perform a voltage change test. The volt- 


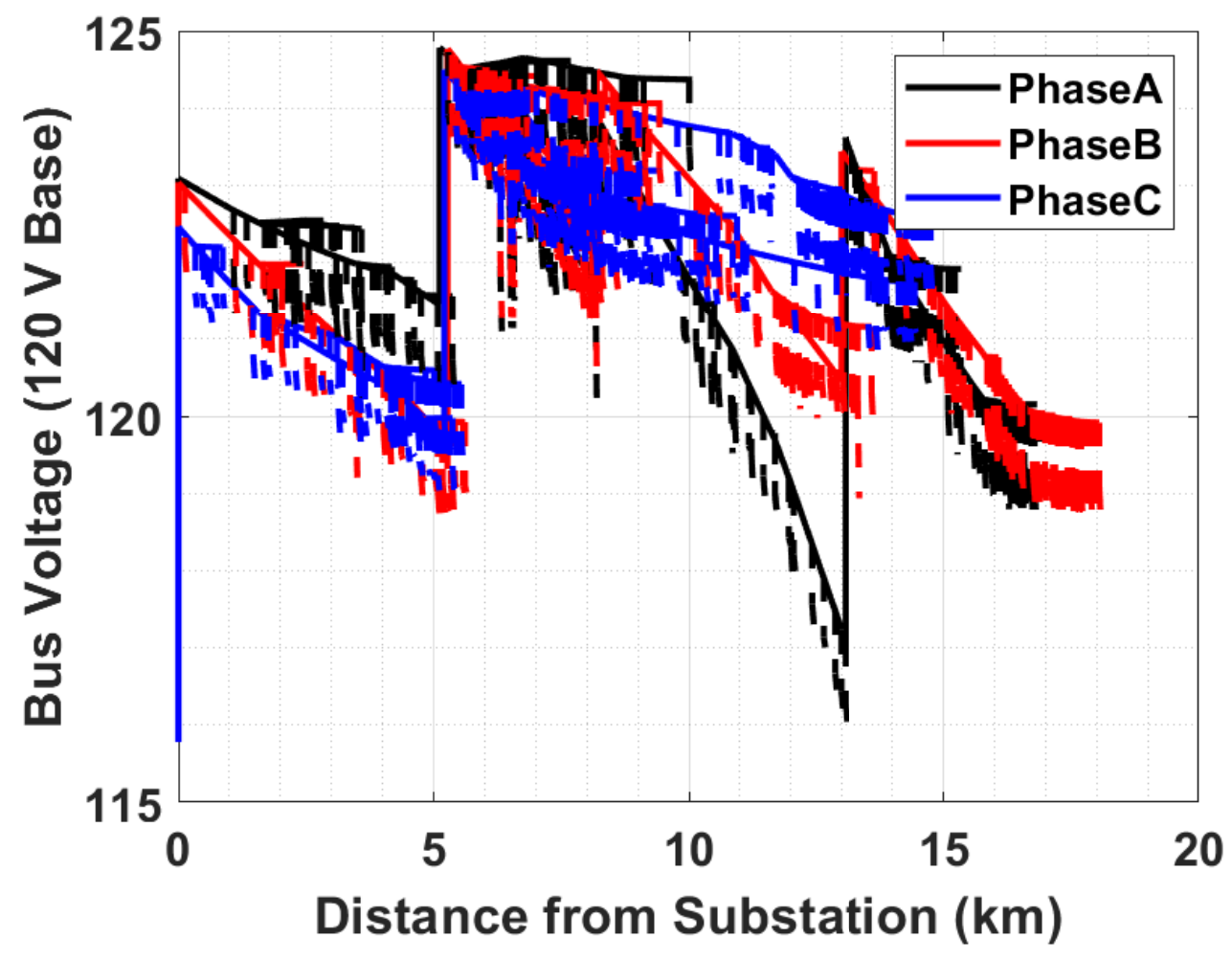

Figure 5.2: Voltage Profile with no feeder PV

age change test consists of solving the circuit without any generation online, then all the regulation equipment (i.e. voltage regulators, LTCs, capacitors, etc.) is locked so they do not operate. After all the regulation equipment is locked, the solar PV, or any other generation, is added to the model and the model is solved again. The resulting voltage is the voltage expected to be experienced on the grid before the regulation equipment operates. During partly cloudy days, solar PV can change its output faster than the voltage regulating equipment operates, making this test an easy way to check potential violations when granular data for solar PV and/or data is not available.

The voltage change test was applied to the test feeder by first solving the feeder with no generation turned on. Then, the regulating equipment was locked in OpenDSS so it did not 


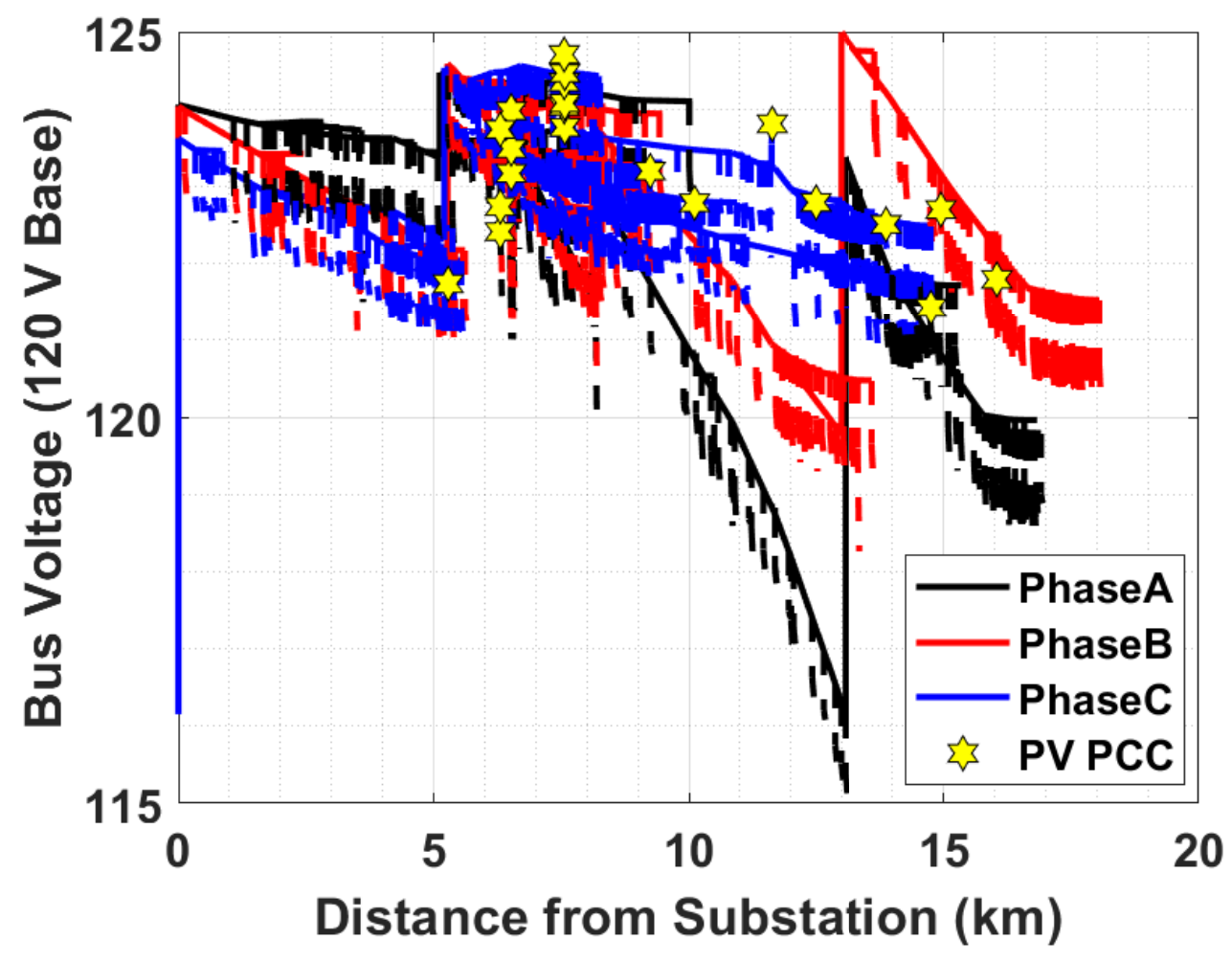

Figure 5.3: Voltage Profile with PV

operate. The generation was turned on and the feeder was solved again. Figure 5.4 shows the results of the test.

The test can also be performed starting with the feeder and all the PV operating at rated capacity, locking all the regulating equipment, setting the output power of all the PV systems equal to zero and solving the model again. This test will simulate a trip on the PV system or a cloud coverage that reduces the output of the PV system significantly. The results of this test is shown in Figure 5.5.

Figures 5.4 and 5.5 show that several locations on the feeder could experience high and low voltage due to the high penetration of PV in the feeder. The high voltage occurs when the generation ramps up before the regulating equipment is able to operate. The low voltage 


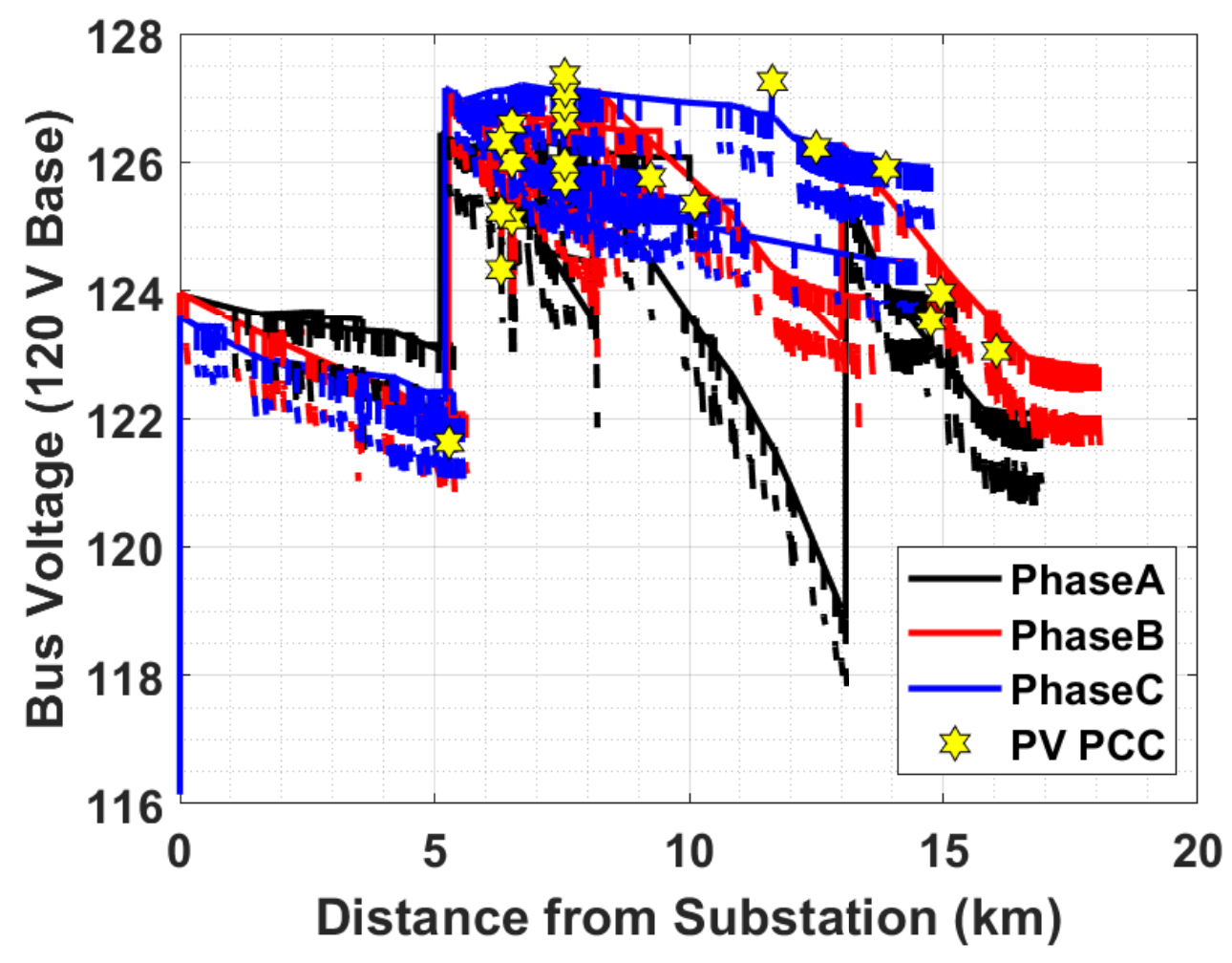

Figure 5.4: Voltage Profile During Voltage Change Test 1

was observed when the generation is taken off-line before the regulating equipment is able to adjust for the loss of generation. During a highly variable day, this condition could be present multiple times in a single day.

\subsection{Voltage Rise due to Distributed Generation}

The interconnection of a distributed generation source to the distribution system will result in a voltage rise at the Point of Common Coupling (PCC). The voltage rise can be approximated by: 


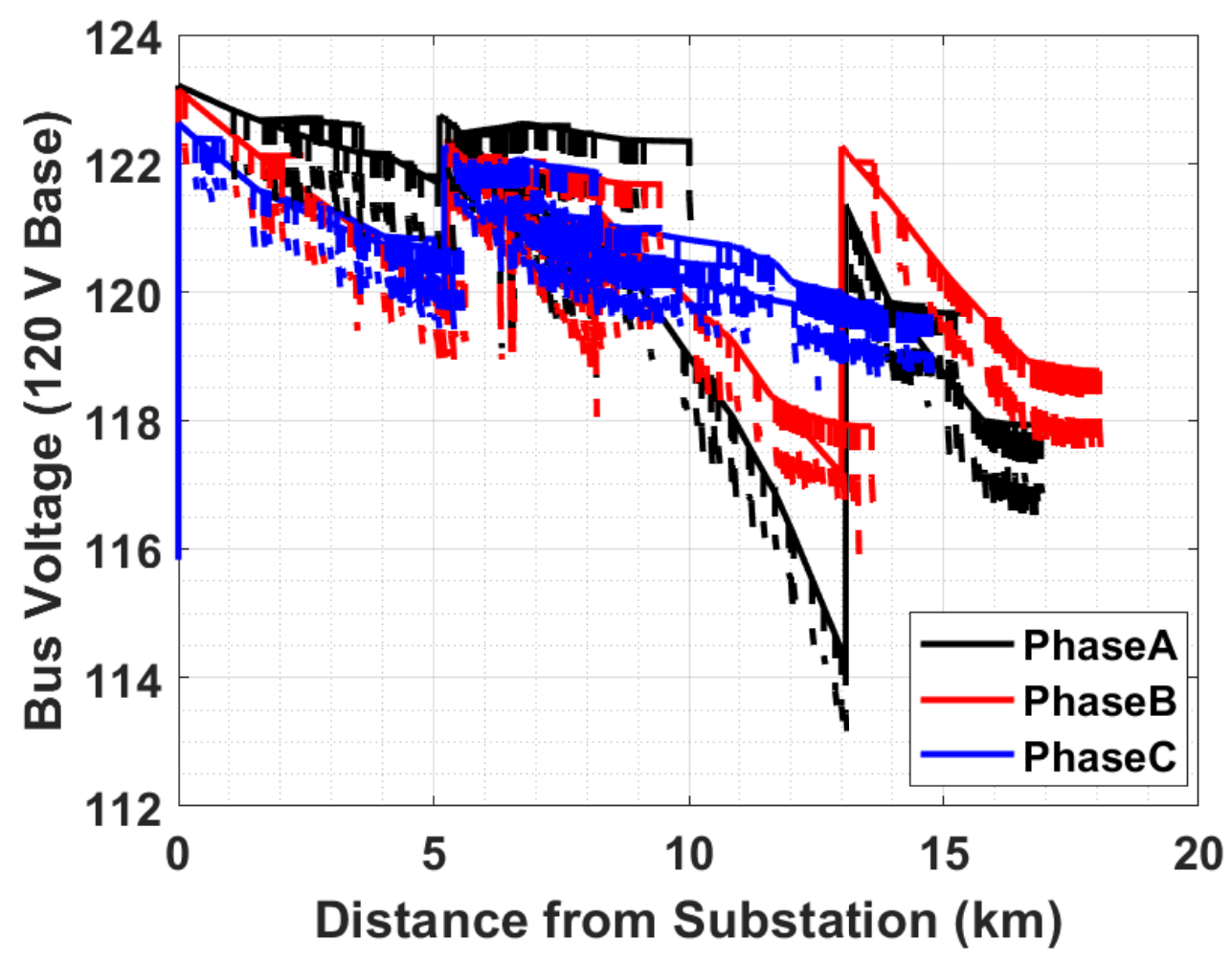

Figure 5.5: Voltage Profile During Voltage Change Test 2

$$
\frac{\Delta V}{V}=\frac{R * P_{D G}}{V^{2}}
$$

Where $R$ is the source resistance at the DG terminals, $P_{D G}$ is the injected active power, and $V$ is the nominal voltage. This approximation holds for most practical cases in distribution systems. The complete expression and derivation can be found in Chapter 2.

Equation 5.1 assumes the DG only injects active power, in other words, the DG is operating at unity power factor and no reactive power is absorbed from the distribution system, a typical mode of operation of solar PV generators since currently there is no revenue for reactive power.

When the DG is operating at a power factor different than unity, the voltage rise will 
depend on the amount of reactive power being injected or absorbed at the PCC. Assuming maximum real power injection results in maximum voltage rise, the reactive power will be a fraction of the real power:

$$
Q_{\max }=\alpha * P_{\max }
$$

The voltage rise at maximum production is equal to

$$
\Delta V_{\max }=R * P_{\max }-X * Q_{\max }
$$

Rearranging eq. (5.3), the voltage rise can also be expressed as follows

$$
\Delta V_{\max }=R\left(1-\alpha \frac{X}{R}\right) P_{\max }
$$

\subsection{Loss Sensitivity Factors}

The test feeder has over 2,500 buses and adding an RSVC to each bus would be cost prohibitive. To reduce the number of buses that can host an RSVC, the LSF are calculated for the test feeder.

First, the LSF are calculated for the feeder when no PV generation is online. The LSF for all the buses of the test feeder are shown in Fig. 5.6.

Second, all the PV systems in the test feeder were set to rated capacity at unity power factor and the load flow was solved again. The LSF for the feeder with the PV systems is 


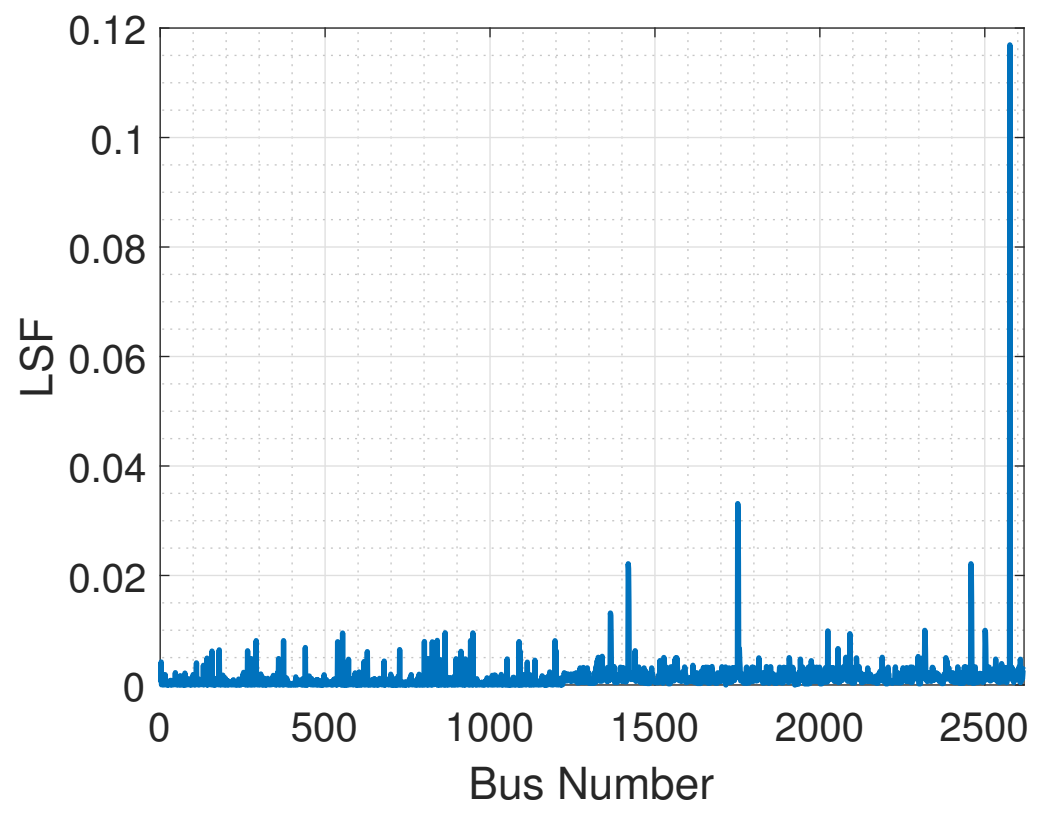

Figure 5.6: Loss Sensitivity Factors with no Solar PV

shown in Fig. 5.7.

The impact of the PV systems on the LSF can be calculated by comparing the LSF obtained from the feeder without the PV systems with the feeder with the PV systems operating at rated capacity. The difference in the LSF value at each bus with and without the PV systems is shown in Fig. 5.8

The maximum difference between the two cases is minimal, in the order of $10^{-4}$, as seen in Fig. 5.8. One of the main reasons for the small difference is that all the PV systems in the feeder are operating at unity power factor, meaning the PV systems are not absorbing or injecting any reactive power into the system.

The LSF can be sorted from high to low, making the identification of the candidate buses to host an RSVC easier. Fig. 5.9 shows the largest 100 LSF sorted from high to low when the feeder is operating with the PV systems at rated output. 


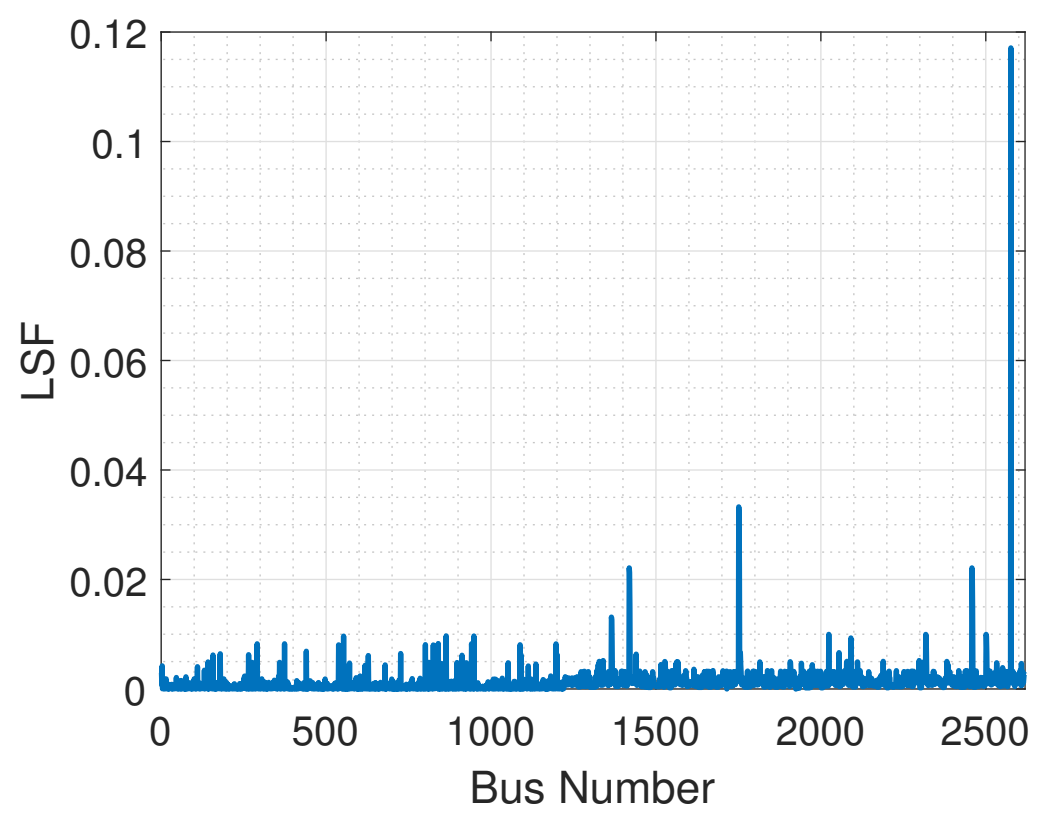

Figure 5.7: Loss Sensitivity Factors with Solar PV

\subsection{RSVC Deployment}

The feeder can experience low and high voltage due to the high penetration of DG in the feeder, as previously shown. In order to mitigate the high and low voltage issues, multiple RSVCs can be deployed in the feeder. The short-time response of the RSVC makes it an ideal mitigation option to solve voltage issues due to DG. While mechanically operated voltage regulating devices such as LTCs, capacitor banks, and voltage regulators have a time delay in the range of 30 seconds to several minutes, the RSVC can react in less than a second to change its operating point and lower or raise the voltage, depending on the feeder necessities. 


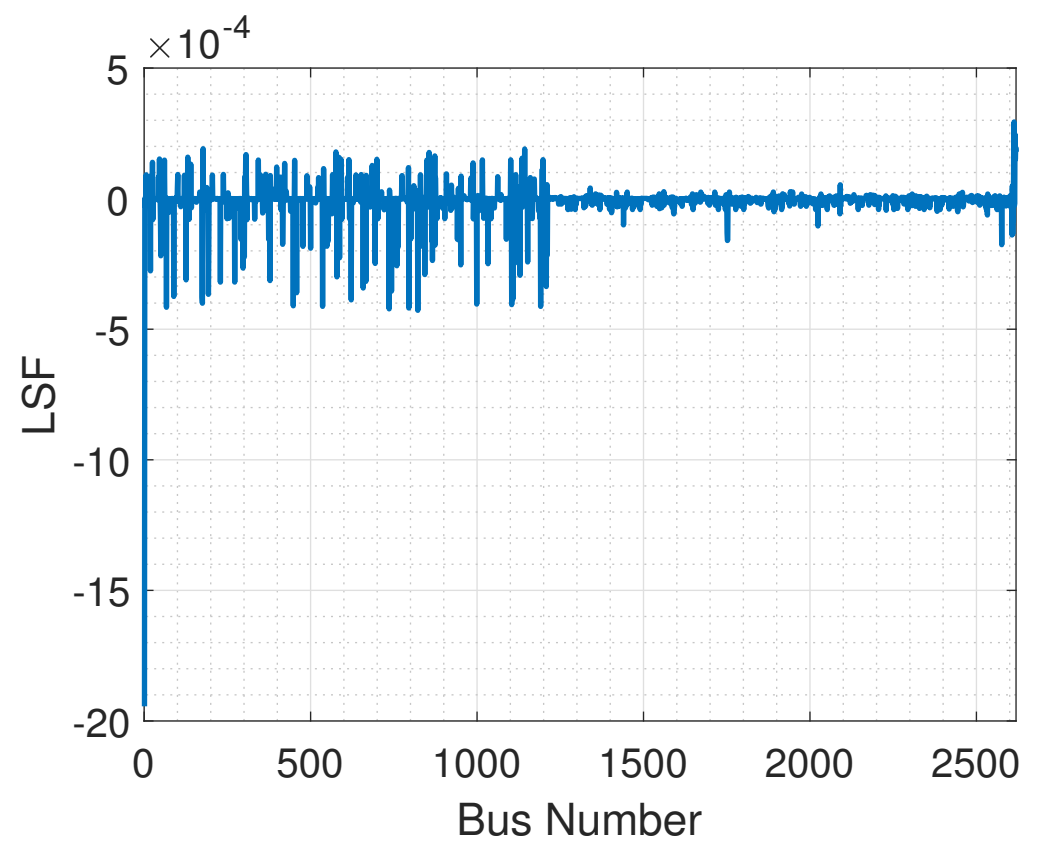

Figure 5.8: Difference in Loss Sensitivity Factors

\subsubsection{Low Voltage Mitigation}

Low voltage can be experienced in the feeder when all PV generation disappears or is lowered rapidly, as previously shown. One of the most common reasons for the PV generation to be reduced quickly is due to weather. PV generation can also be tripped off-line due to a voltage or frequency deviation.

To test if locations on the feeder experience low voltage due to sudden reduction on the PV output generation, the feeder steady-state operating points were solved with the PV systems operating at rated output, then the PV systems were taken off line, the regulating devices were locked in their current position and the power flow was solved again. Taking the PV offline is the equivalent to incrementing the load in the feeder, causing a low voltage in the feeder during the time it takes the voltage regulating devices to operate. The RSVCs deployed in the feeder can act in a matter of seconds to inject reactive power and raise the 


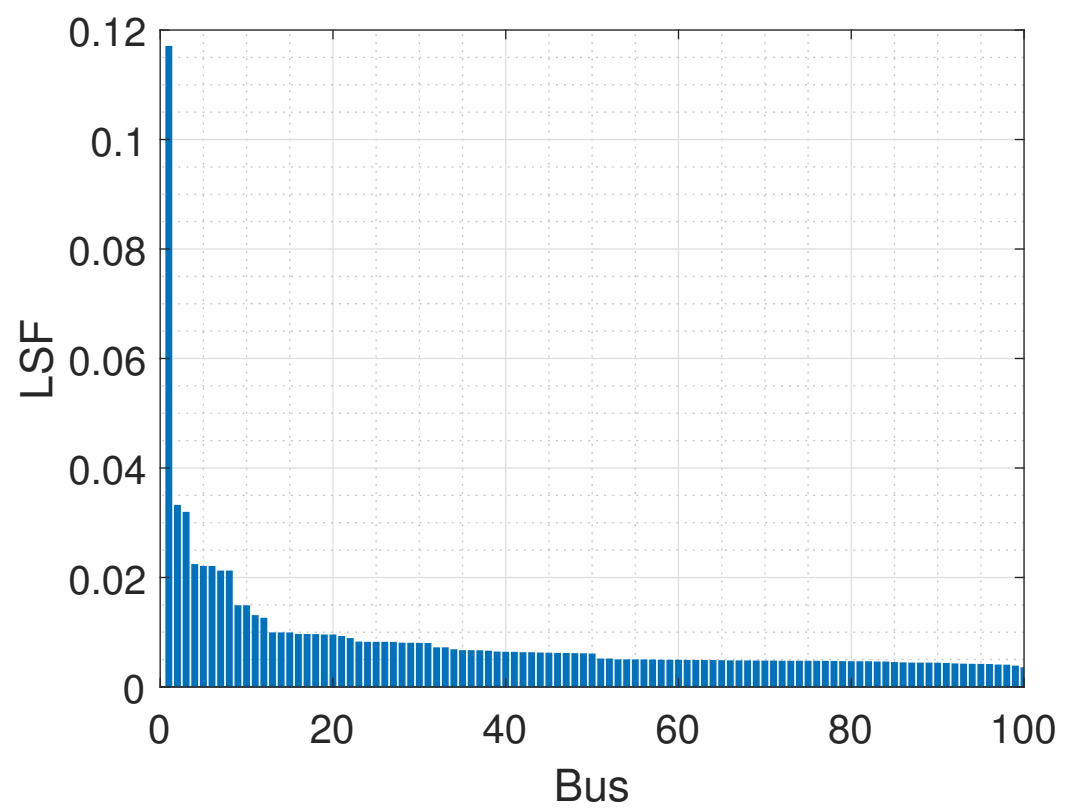

Figure 5.9: First 100 LSF Sorted from High to Low

voltage, effectively mitigating the low voltage.

The LSF for the feeder were calculated with the PV operating at rated capacity. Then, the LSF were sorted from high to low to obtain the buses with the highest LSF. An RSVC was attached to the first bus in the sorted LSF list and the circuit was solved with all the controllers locked to the previous position. Once the circuit was solved, the minimum voltage in the feeder was plotted and the process was repeated for a total of 25 times.

Figure 5.10 shows the minimum voltage as a function of the number of RSVC deployed in the feeder. It can be seen that the minimum voltage in the feeder raises as more RSVC are added to the feeder. The first couple of RSVCs have the biggest impact on the minimum voltage of the feeder. The LSF method shows that it is efficient at finding the buses where adding an RSVC would be the most effective.

The voltage profile for the feeder with 20 RSVCs added is shown in Figure 5.11. It can 


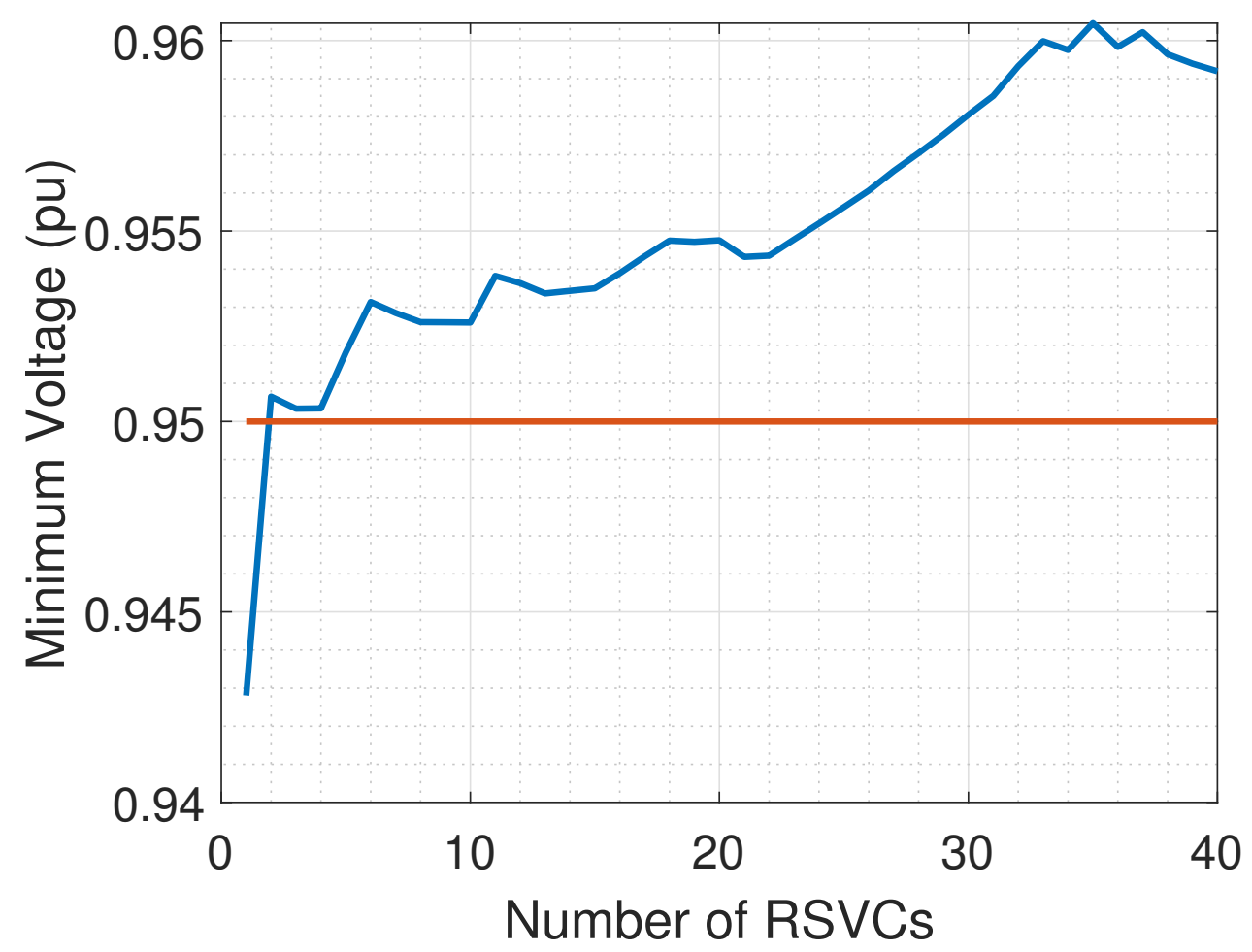

Figure 5.10: Minimum Voltage vs Number of RSVCs Deployed for sudden loss of PV generation

be seen that all the voltages are within the limits of Range A of the ANSI C84.1 standard.

The output of each of the RSVCs is shown in Fig. 5.12. All of the RSVCs in this test were set to control the voltage at $1.0 \mathrm{pu}$. If the voltage at the node where the RSVC is connected is higher than $1.0 \mathrm{pu}$, the RSVC will operate in the inductive mode, lowering the voltage, and if the voltage is lower than $1.0 \mathrm{pu}$, the RSVC will operate in the capacitive mode, raising the voltage. The results show that the first RSVC is operating in the inductive mode, bringing the voltage down at the node where it is connected, an indication that the bus with the highest LSF is not the node with the lowest voltage in the feeder. However, the second and third RSVCs are operating in the capacitive mode. The output of the RSVCs 


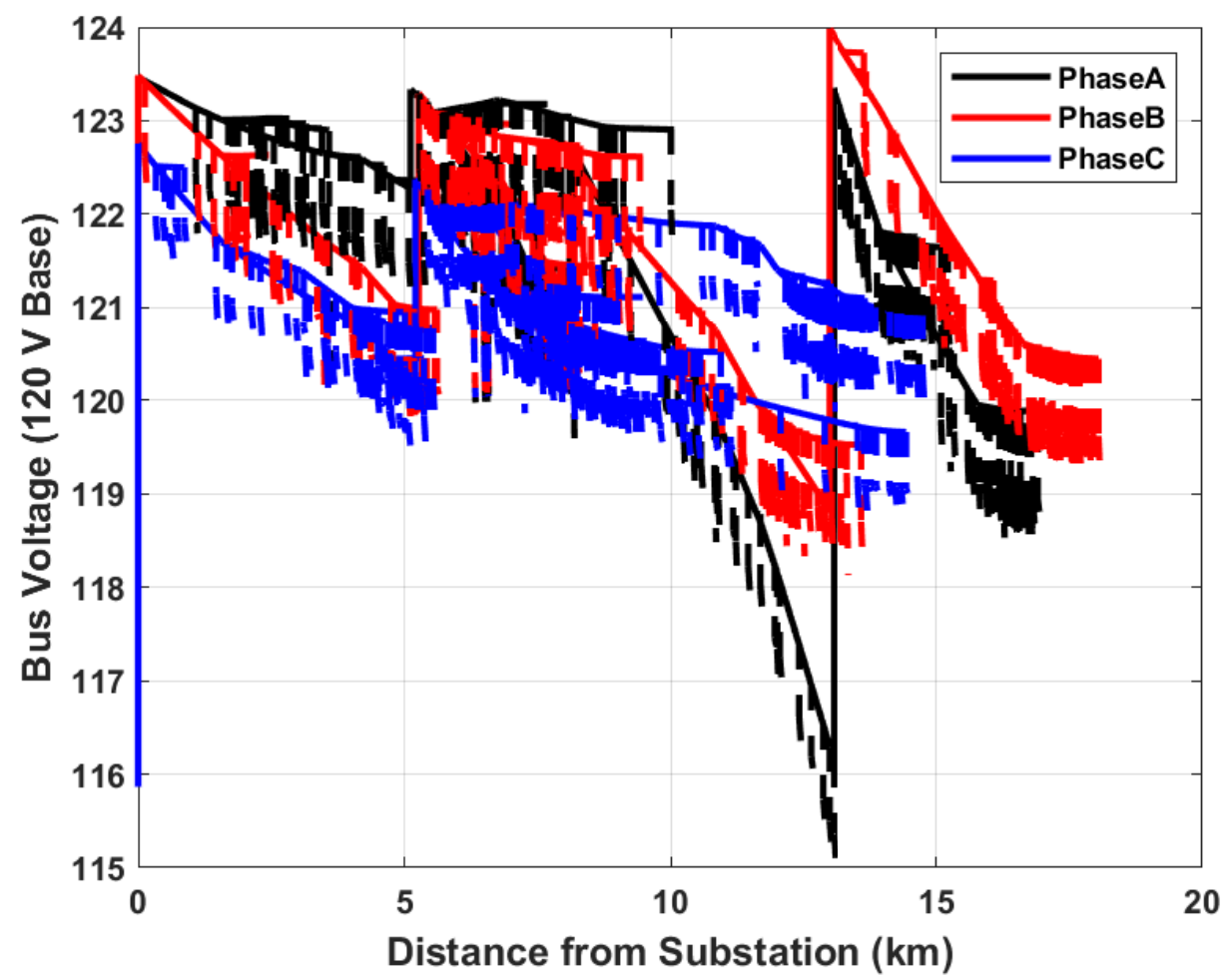

Figure 5.11: Voltage Profile with 20 RSVCs Deployed in the Feeder

are shown in Fig. 5.12, explaining the raise in voltage at the locations of the second and third RSVC.

\subsubsection{High Voltage Mitigation}

High voltage can be experienced in the feeder when the PV generation is suddenly added to the feeder, most commonly after a cloud passes by and the generation goes from nearly zero to rated capacity in matter of seconds. Mechanical devices are slow to react to bring the voltage down and customers can experience high voltage.

A similar test to the one previously performed to check for low voltage can be performed to determine if high voltage is experienced in the feeder. The test is performed by 


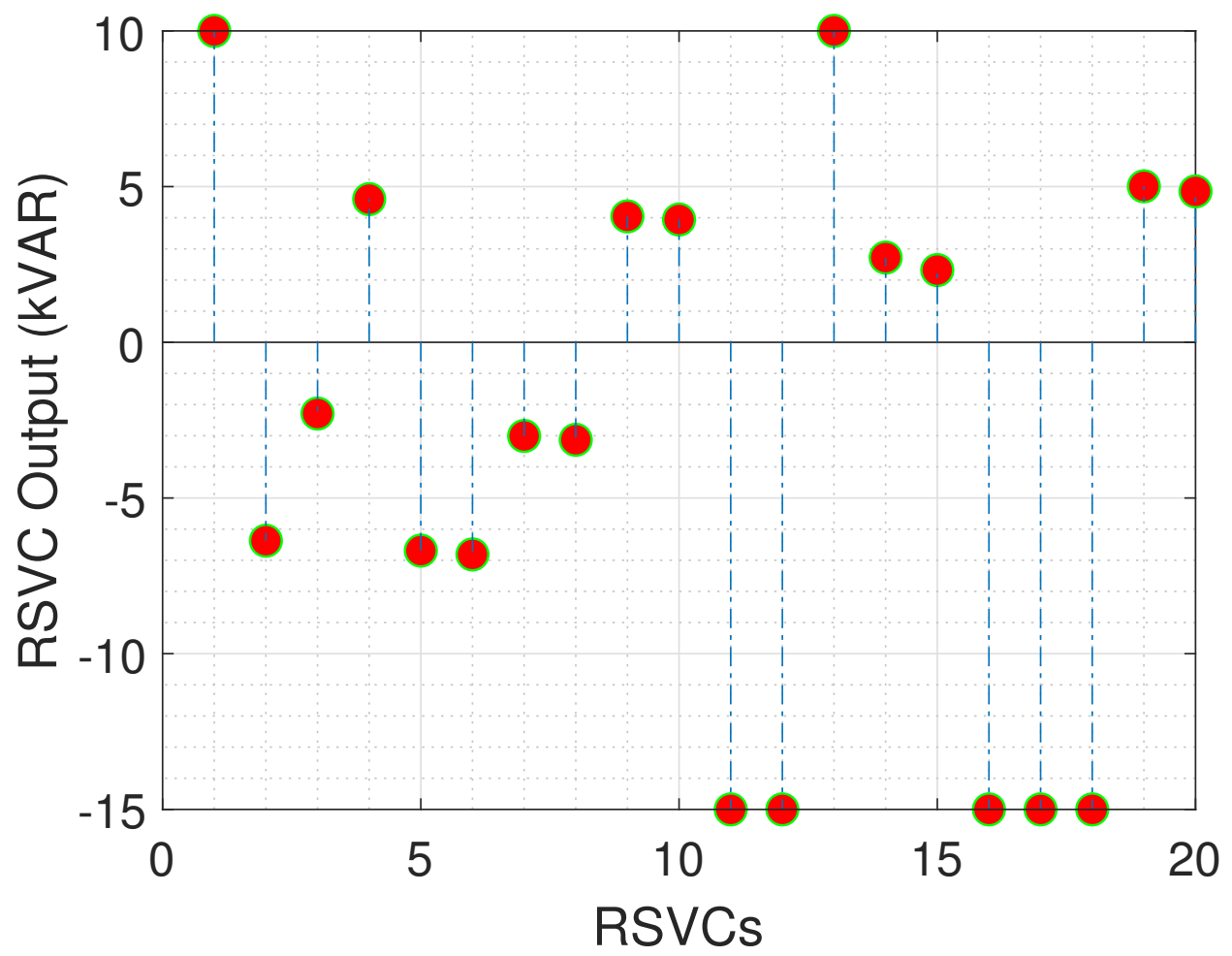

Figure 5.12: RSVC Output for Voltage Change Test 1

solving for the feeder voltage without any PV connected. Then the regulating devices are all locked to their current position. The PV generation is then brought online at rated capacity and the power flow is solved again. Bringing the PV online is equivalent to suddenly reducing the load in the feeder, causing a high voltage in the feeder. The RSVCs can be deployed in the feeder to mitigate the high voltage by operating in the inductive mode and bringing the voltage down.

The same LSFs used for the low voltage test are used in this test, reducing the simulation time. The maximum voltage in the feeder as a function of the number of RSVCs deployed in the feeder is shown in Fig. 5.13. It can be seen that the high voltage is more severe than the low voltage and it requires more RSVCs to mitigate the high voltage in the feeder. 


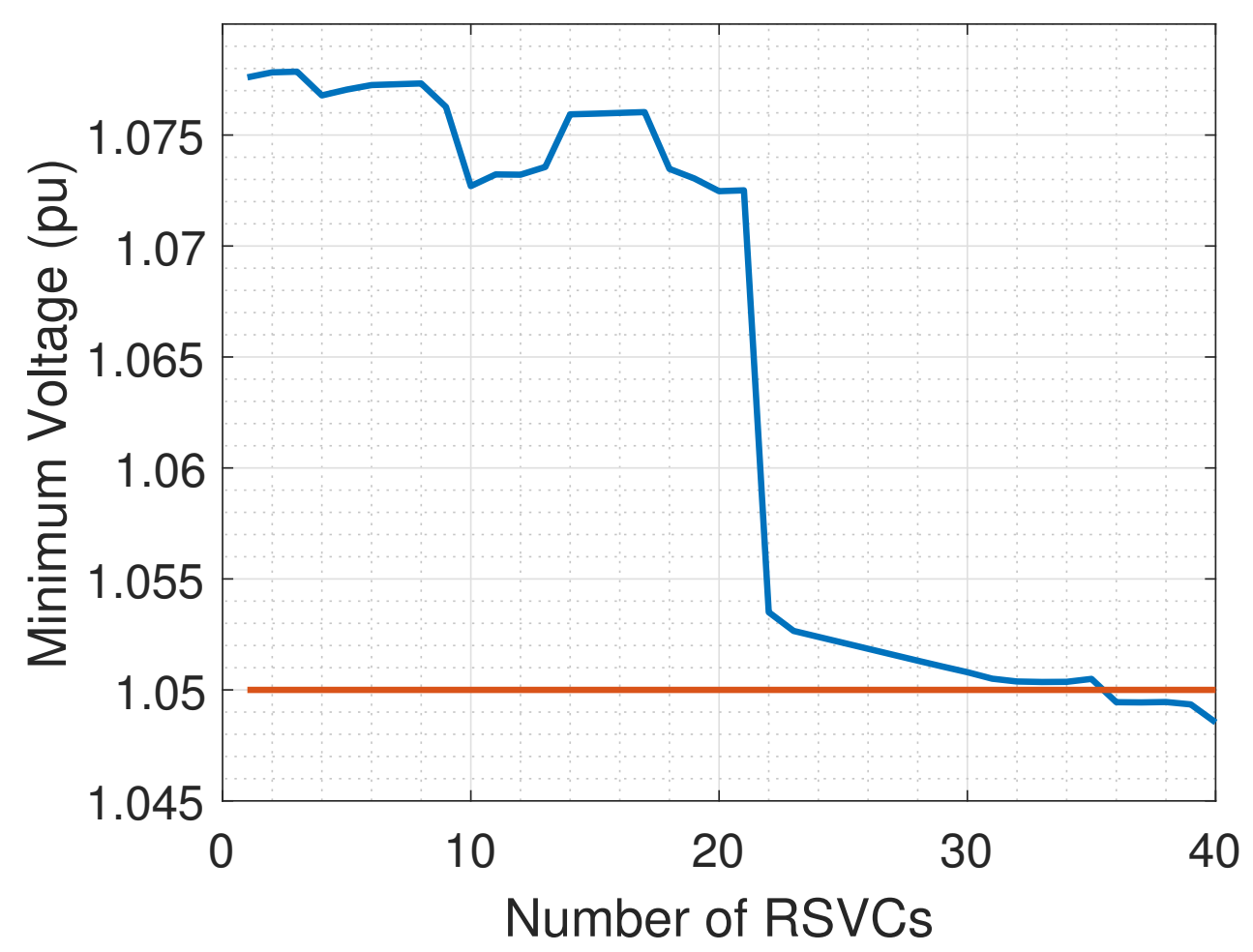

Figure 5.13: Maximum Voltage vs Number of RSVCs Deployed

The voltage profile for the feeder with 40 RSVCs is shown in Figure 5.14. It can be seen that all the voltages are within the limits of Range A of the ANSI C84.1 standard after the RSVCs have been deployed in the feeder.

The output of each of the RSVCs is shown in Fig. 5.15. All the RSVCs in this test were set to control the voltage at $1.0 \mathrm{pu}$. If the voltage at the node that is connected is higher than $1.0 \mathrm{pu}$, the RSVC will operate in the inductive mode, lowering the voltage, and if the voltage is lower than $1.0 \mathrm{pu}$, the RSVC will operate in the capacitive mode, raising the voltage. The results show that the first twenty RSVCs are operating in the inductive mode, bringing the voltage down at the node that they are connected to respectively.

The results of the static tests show that the RSVCs are effective in mitigating both 


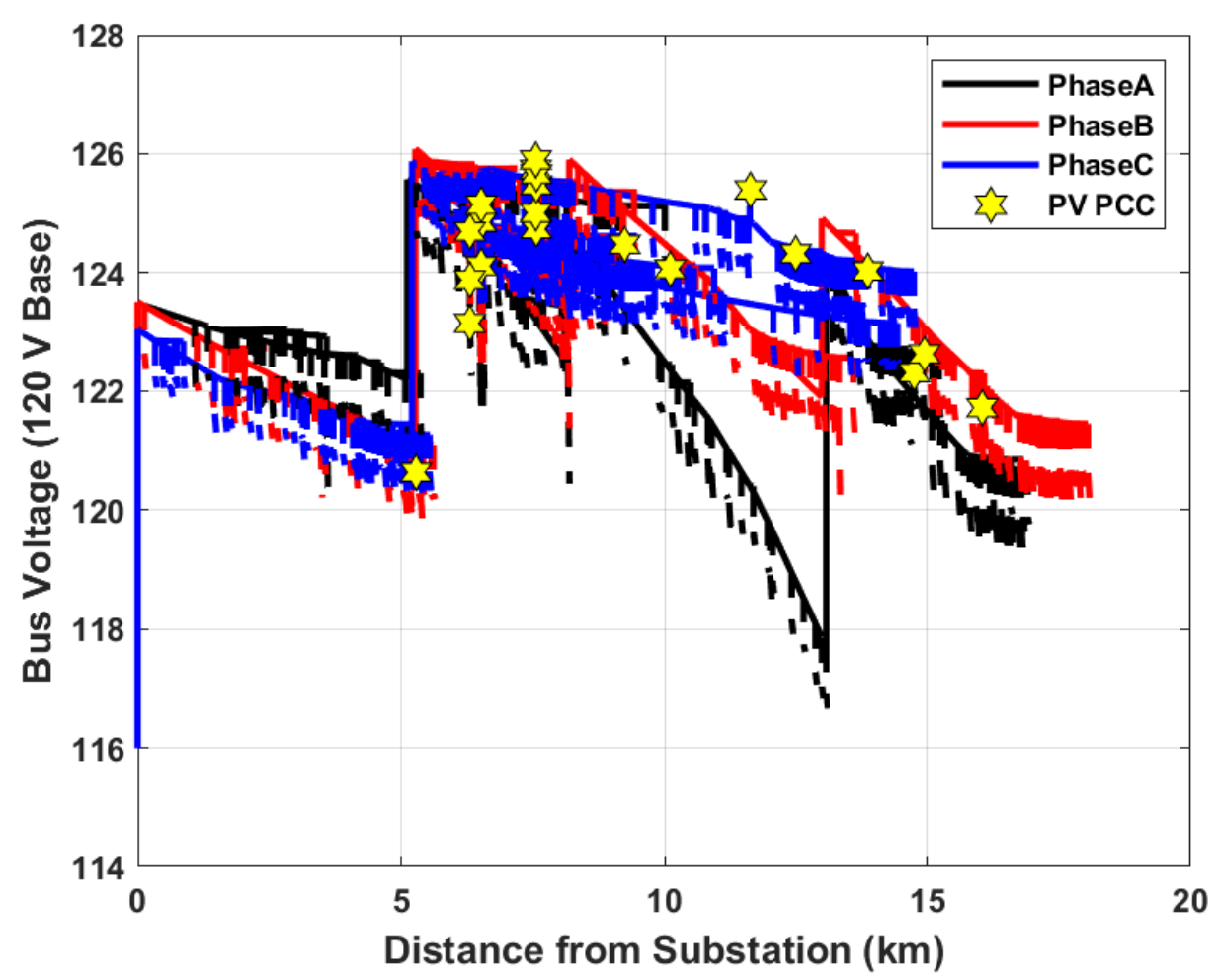

Figure 5.14: Voltage Profile with RSVC Deployed in the Feeder

high and low voltage caused by DG in the distribution feeder. The results also show that the LSF method is effective in identifying the buses that need reactive compensation to mitigate voltage issues, reducing the search space and thus reducing the time it takes to perform a simulation.

Recent updates to the IEEE 1547 interconnection standard allow residential DG to actively control the voltage at their PCC [40]. A common way to mitigate high voltage due to high penetration of solar PV is to operate the inverter at non-unity power factor. An interesting result of this dissertation is that for this feeder the LSF method identified buses that are not hosting a PV system. Residential customers that experienced high or low voltage due to the high penetration of DG in the feeder but do not actually host a PV system 


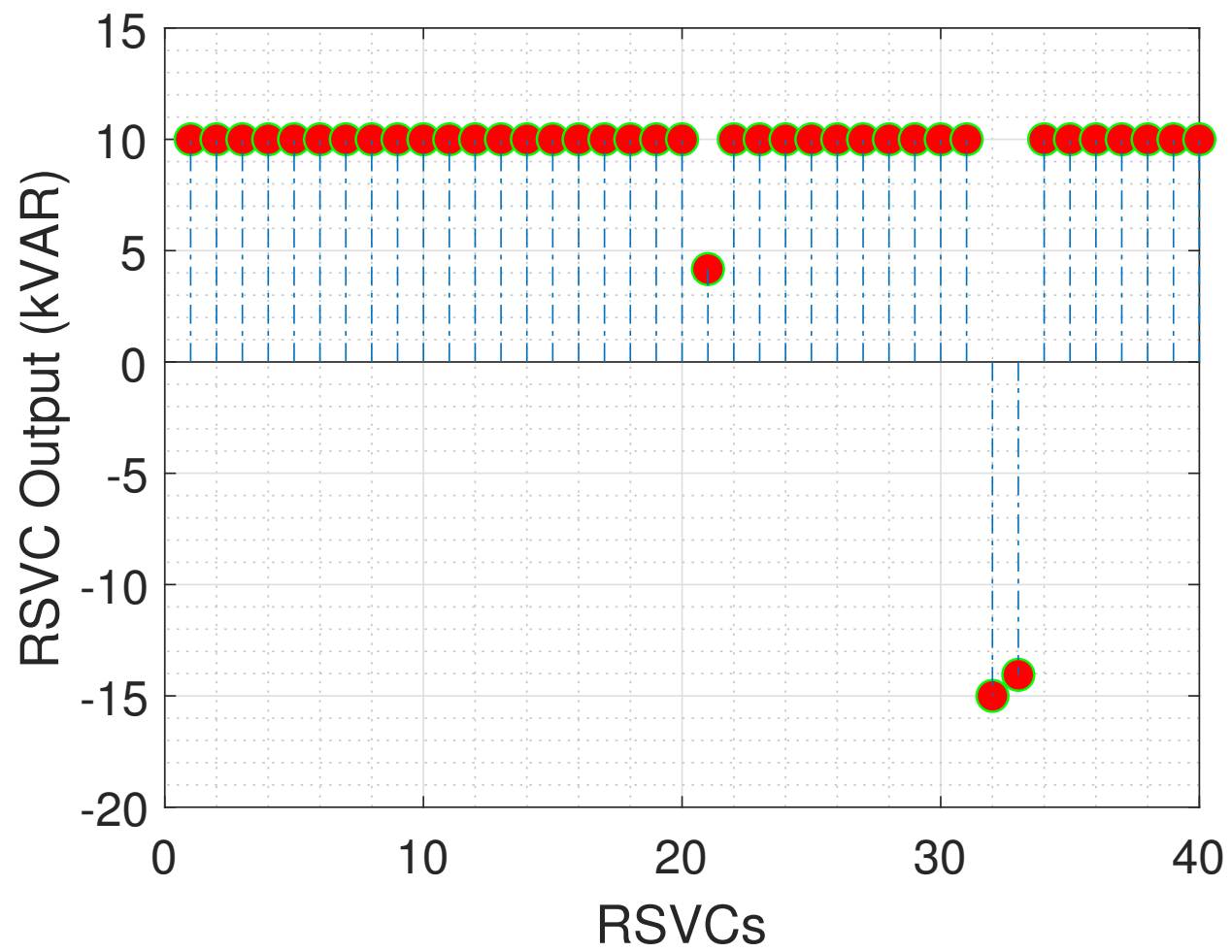

Figure 5.15: RSVC Output for Voltage Change Test 2

cannot make use of the advance capabilities of inverters. The RSVCs location and the PV system locations are shown in Fig. 5.16.

The RSVC deployment shows that the RSVCs are mainly distributed before the voltage regulator and on the edges of the feeder. The distribution of the RSVCs are expected, given that the edges of the feeder are usually the weakest point in a feeder. 


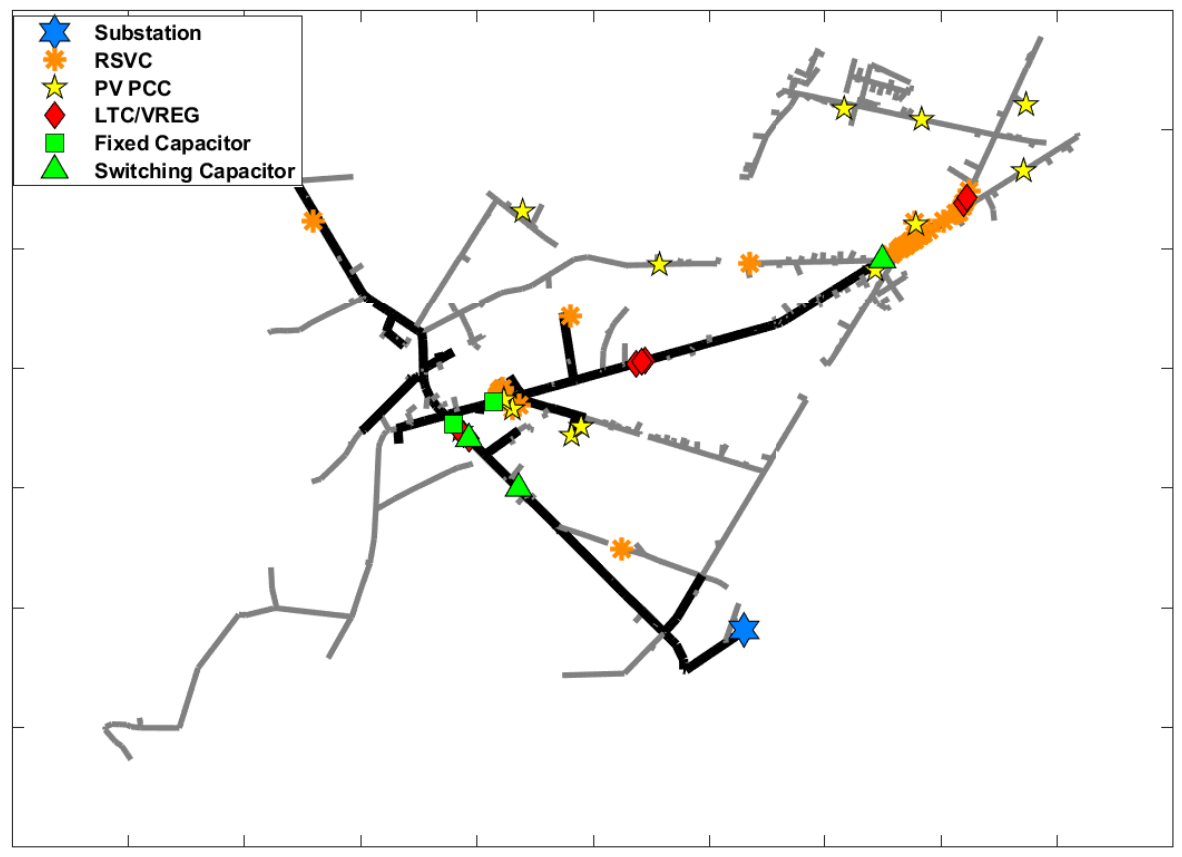

Figure 5.16: RSVC and PV Location 


\section{CHAPTER 6}

\section{TIME SERIES ANALYSIS}

Commercially available distribution analysis tools have only provided the capability to analyze the circuits at a specific snapshot in time. In recent years, simulation platforms have been developed with the capability to perform Quasi State-Steady Simulations (QSTS). One of the main advantages of using QSTS is its capability to properly assess and capture the time-dependent aspects of the distribution system. QSTS produces sequential steady state power flow solutions where the converged state of each time-step is used as the beginning state of the next. Some examples of time-dependent aspects of power flow include the interaction between the daily changes in load and the PV output and the effect on voltage regulation device controls. Another important advantage of QSTS is the ability to quantify both the magnitude of an impact as well as the frequency and the duration of such impact [41].

The use of QSTS simulation in distribution systems requires the use of significant amounts of data to accurately represent the time-varying PV output and the the timevarying load in the feeder and their interaction. The time series data is often difficult to obtain as measurement equipment at the feeder or at the PV site will not be available, or it won't be available at the desired time resolution. It is common for utilities to record feeder level load data at 15-minutes or at 1-hour resolution. When feeder level load data is only available for 15-minutes or 1-hour, interpolation may be the best option for obtaining 
higher resolution data [41].

The data necessary to perform QSTS can become very large, depending on the desired resolution and length of simulation time. Data obtained from utilities can be interpolated to run QSTS, but a 15-minute average data does not capture the necessary variability to accurately model voltage regulation equipment operations that require time steps on the order of seconds.

The solar PV output also needs to be represented as a time-series. Unfortunately, this data is typically not available for the scenarios of interest and an estimated PV output is usually synthesized from either irradiance sensors or proxy data from similar plants [41].

\subsection{Photovoltaic (PV) Data}

Given the lack of data for the individual PV systems, a normalized PV output from a single site that does collect data with 1-second resolution was used for all the PV systems in the feeder. The PV data has a duration of 30 minutes and was taken from a highly variable day. The data is shown in Fig. 6.1.

The PV data shows a highly variable day where the output goes from nearly rated output to $20 \%$ of the rated name plate in matter of seconds. The data shows a highly variable output, especially during the middle part of the simulation where the output goes from rated output to $40 \%$ of name plate and back to rated nameplate several times during the span of a few minutes.

The impact of generation on the voltage can be better observed running a QSTS and recording the voltage at one of the PV site's PCC. The normalized PV generation shape shown in Fig. 6.2 was applied to all the PV systems in the feeder. Given that the PV systems cover a small footprint, it is safe to assume all the PV systems will receive almost 


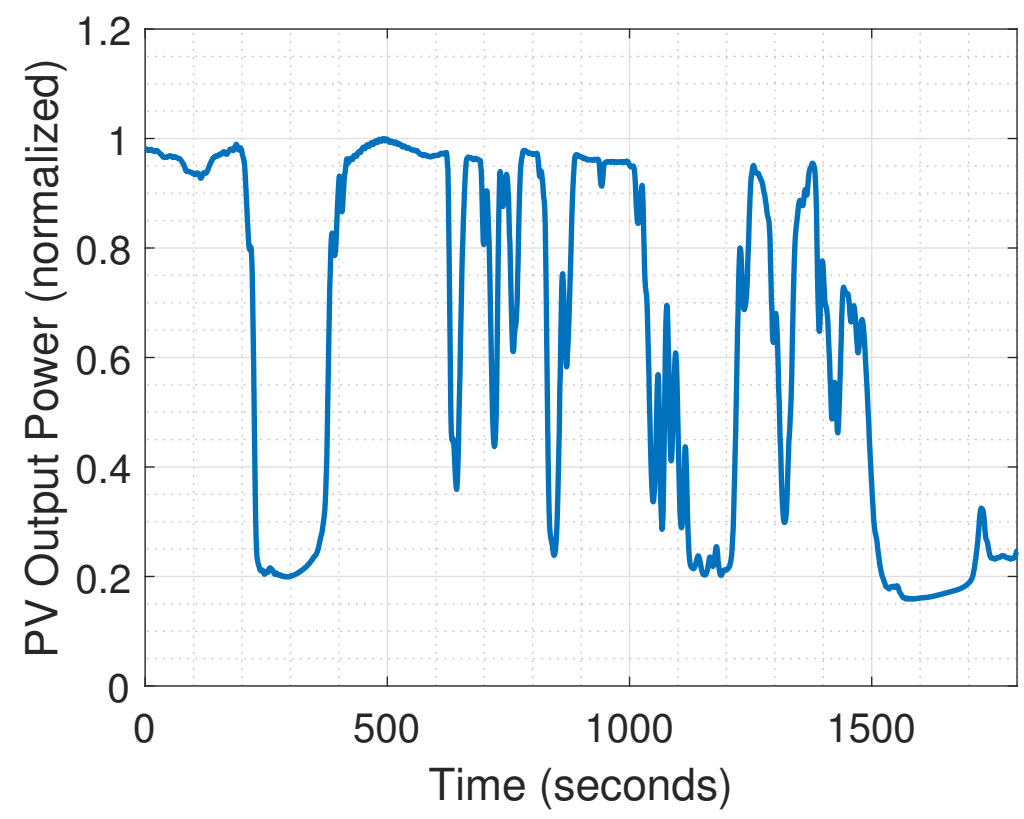

Figure 6.1: Normalized PV Output for Site 1

the same irradiance. The impact on the generation power output and on the voltage at the terminals of the PV system can be seen in Figs. 6.2 and 6.3

\subsection{Time-Series Analysis}

The time-series simulation was set for a 30 minute span with a 1 second time-step. There are several variables of interest when performing a time-series simulation. First, the number of LTC operations can be tracked by monitoring the tap position on the secondary side of the substation transformer. Second, the minimum voltage experienced on the feeder at each solution interval is also important, to make sure the voltage is within range. The variability of the voltage at any given node with respect to time is also important. A high variability on a node can cause voltage flicker, even if the voltage is always within range. 


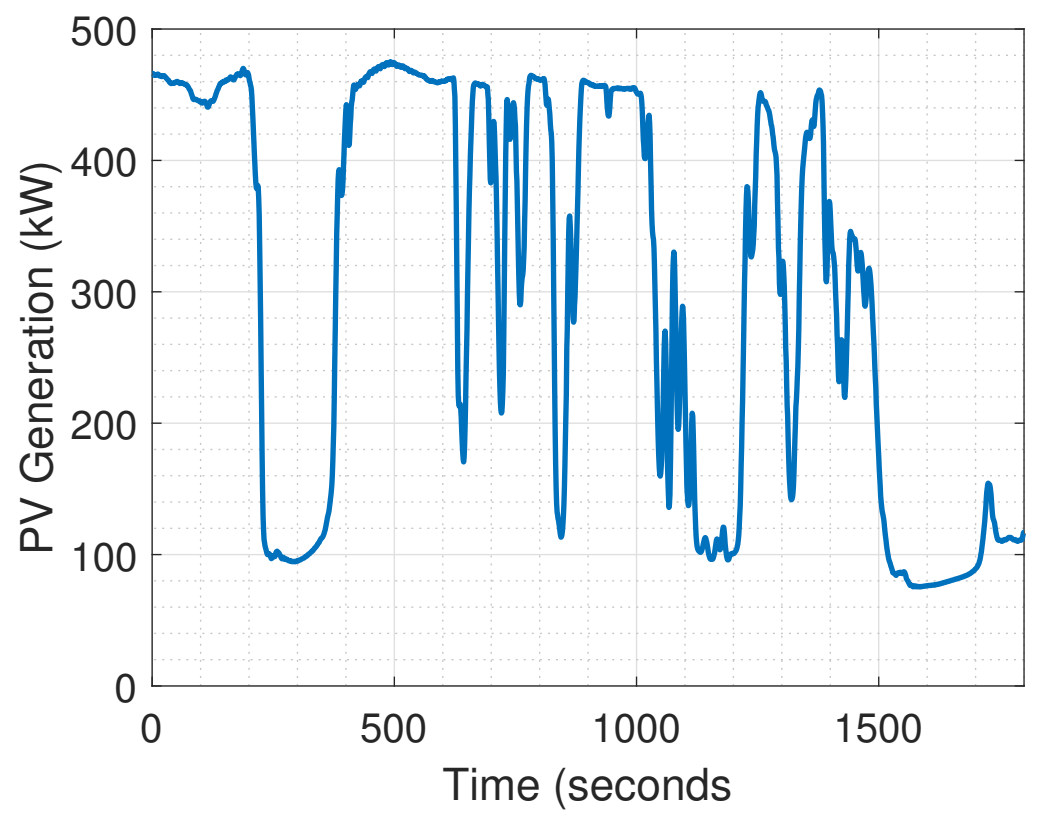

Figure 6.2: Power Output of PV System Site 1

\subsubsection{Minimum Voltage}

The minimum voltage experienced on the feeder at each solution interval is shown in Fig. 6.4. It can be seen that the minimum voltage follows a similar shape to the PV output shape used for the PV systems, an indication that the PV systems have a strong relationship with the voltage in the feeder. The data also shows the impact of voltage regulators and LTCs in the feeder, the sharp changes in voltage are due to a tap change in the voltage regulator either tapping up or tapping down.

The minimum voltage at the feeder during the 30-min span does not go below the minimum allowed by ANSI C84.1, keeping all the customers within acceptable range. However, this does not mean no customers will experience low voltage, as shown in the previous chapter, a day with higher variability or a tripping event on the PV systems can result in low voltage experienced by customers on the feeder. 


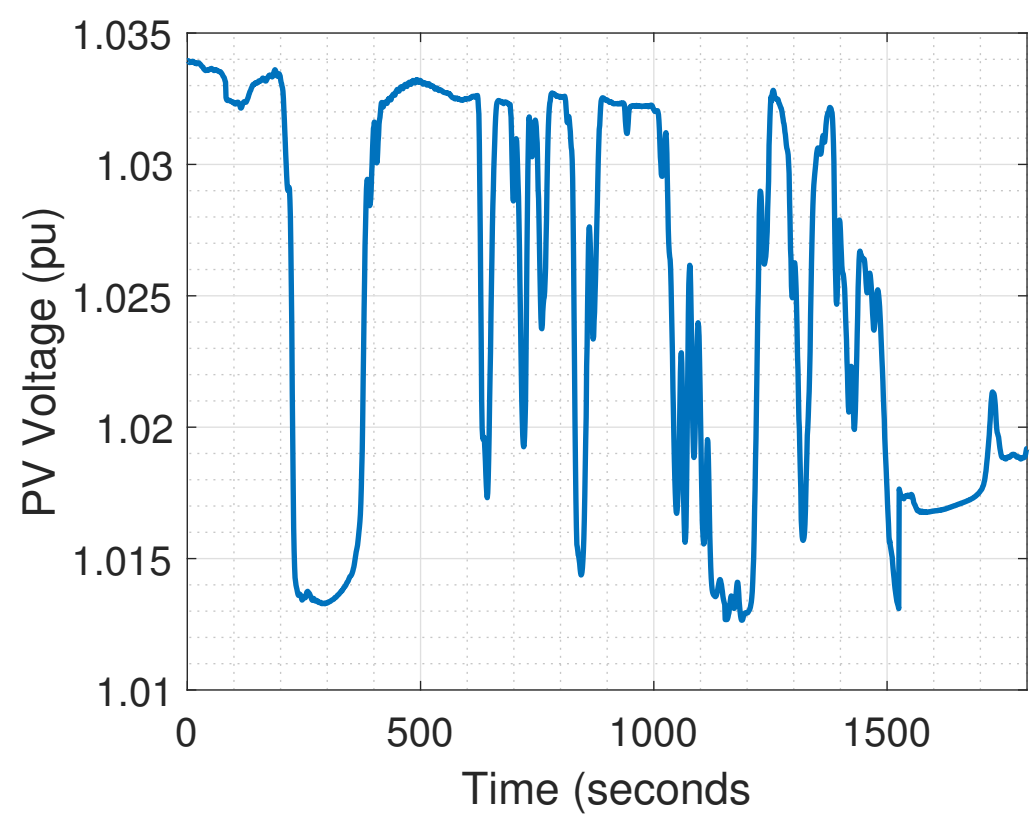

Figure 6.3: Voltage at PV System Site 1 Terminals

\subsubsection{Maximum Voltage}

The maximum voltage experienced on the feeder at each iteration is shown in Fig. 6.5. The data shows how the maximum voltage changes at each solution interval, and in some iterations the change is significant. The sharp changes in the maximum voltage can be attributed to the operation of the voltage regulators and the LTC on the feeder. The maximum voltage in the feeder seems to be affected more by the position of the voltage regulators and the LTC than the PV output, as was the case for low voltage.

The highest voltage in the feeder for each iteration was below the upper limit of the ANSI C84.1 standard. The highest voltage is above $1.04 \mathrm{pu}$, which is close to the upper limit of $1.05 \mathrm{pu}$. A day with a higher variability of lower load would result in high voltage experienced by the customers on the feeder. 


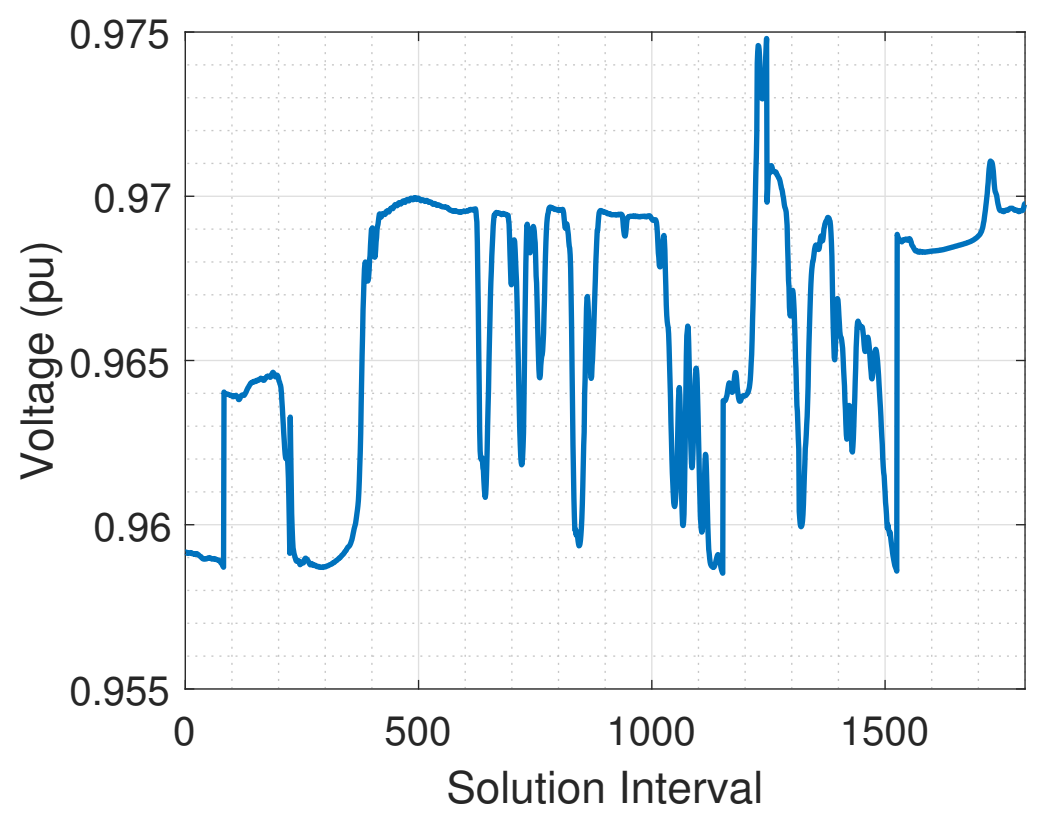

Figure 6.4: Minimum Voltage at Each Solution Interval

\subsubsection{Voltage Variability}

The IEEE Standard 1250-2011, the IEEE Guide for Identifying and Improving Voltage Quality in Power Systems [42], limits the individual step changes in voltage to less than 4\%. The step change is hard to calculate with traditional simulating tools, given that only a snapshot in time is solved.

One of the advantages of using OpenDSS and its time-series capabilities is that the voltage variability on the feeder can be simulated, saving time and money for power quality engineers that otherwise would have to go and install meters to gather data, return to collect the data and then analyze it. The 1 second step-size is small enough that the simulation is able to capture the impact of PV output variability and also the tap changes in the voltage regulators, switched capacitor banks, and the LTC.

The variability for each node was calculated by calculating the percent difference from 


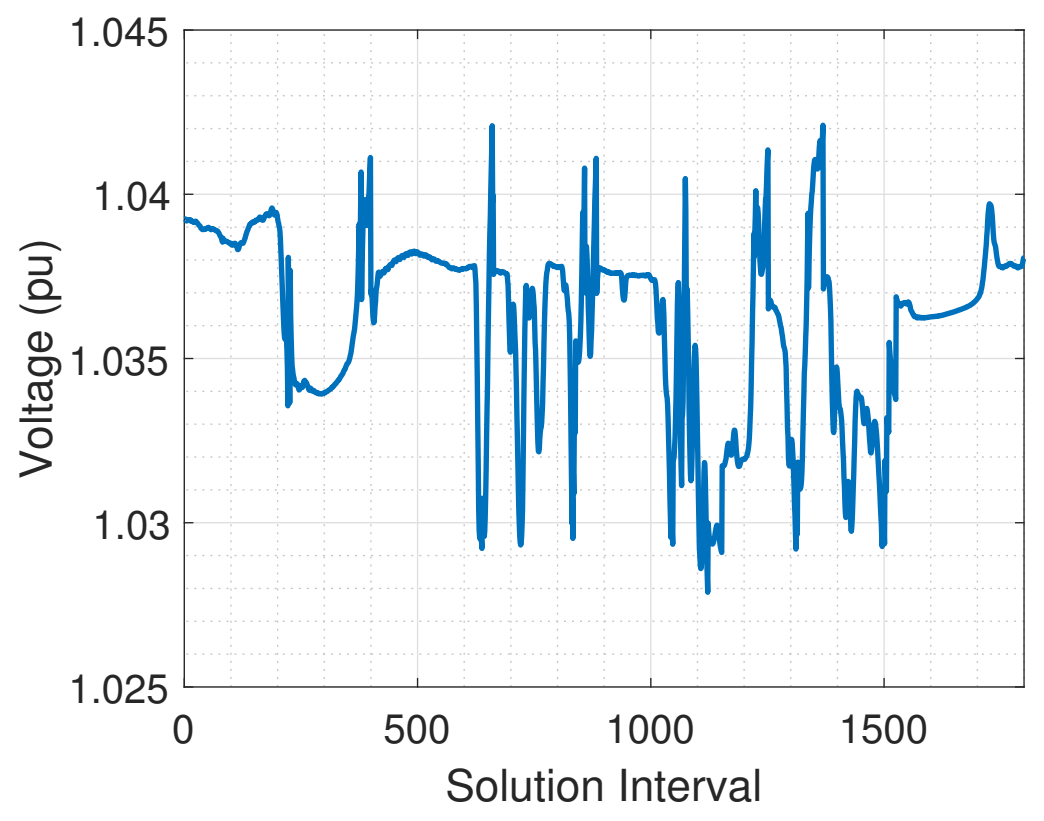

Figure 6.5: Maximum Voltage on each Solution Inverval

one solution interval to the next. The variability calculation can determine whether or not the system is in compliance with IEEE 1250-2011. The maximum variability of each node for the entire 30 minute simulation is shown in Fig. 6.6. The simulation results were sorted for readability purposes. The results show that the maximum voltage variability experienced in the feeder is around 1.1\%, meeting the requirements of the IEEE 1250-2011 standard.

\subsubsection{Number of Operations of Voltage Regulating Devices}

As is the case with the voltage variability, the number of operations of voltage regulating devices is hard to obtain with static simulation tools. Electric utilities keep track of the number of operations of the voltage regulating devices by driving to the site and recording manually the number of operations directly from the device itself. Keeping track of the 


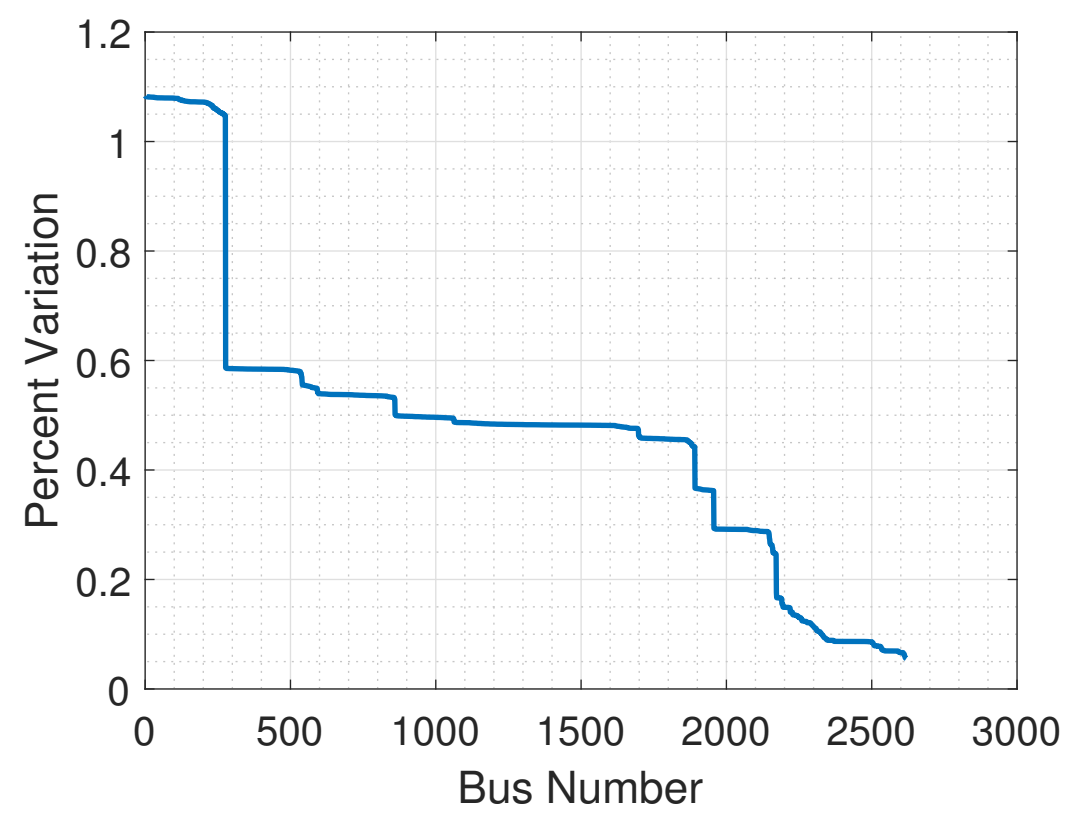

Figure 6.6: Voltage Variability at Each Bus

operations helps electric utilities to manage their $O \& M$ plan. Using QSTS, the number of operations can be simulated, helping utilities to optimize their $O \& M$ plans and also to consider the impact that DG has on the equipment.

Table 6.1: Number of Voltage Regulator Operations

\begin{tabular}{|l|l|l|}
\hline Regulator & Phase & $\begin{array}{l}\text { Number of } \\
\text { Operations }\end{array}$ \\
\hline \hline B18865 & Phase C & 12 \\
\hline B19008 & Phase B & 11 \\
\hline B18863 & Phase A & 5 \\
\hline B19010 & Phase A & 2 \\
\hline B4873 & Phase A & 1 \\
\hline B18864 & Phase B & 10 \\
\hline B4872 & Phase C & 7 \\
\hline B4868 & Phase B & 7 \\
\hline
\end{tabular}

Voltage regulating devices, as explained in Chapter 2, are connected in series with the 
feeder. When the equipment is taken out of service by utilities to perform maintenance, the customers downstream of the piece of equipment experience an outage while the utility workers bypass the piece of equipment and power is restored again. Reducing the number of operations in these pieces of equipment can reduce the $O \& M$ and avoid unnecessary outages for customers.

The number of tap transitions for the LTC and the voltage regulators was calculated by analyzing the tap position at each iteration for the substation transformer and for the voltage regulators. Table 6.1 shows the number of operations during the 30 minute analysis for each of the voltage regulating devices in the feeder.

In a span of only 30 minutes, three regulators operated over ten times. The increase in operations can be attributed to the DG in the feeder and their high variable output in this scenario. The load in the feeder is modeled as static given the lack of high resolution data available for the simulated feeder.

\subsubsection{Loss Sensitivity Factors}

The LSFs of the feeder were calculated in the same manner as shown in Chapter 4. The LSFs were calculated during each iteration of the simulation. At the end of the simulation, each node had a total of 1,800 LSFs. The average LSF was taken for each node to form an array of LSFs. The LSF were used to select the buses where the RSVCs will be deployed. The LSF at each node during the 30 minute analysis is shown Fig. 6.7, the LSFs are almost identical to the previously calculated LSF during the static analysis. The LSFs were expected to be similar given the small difference calculated between the LSF without any $\mathrm{PV}$ in the feeder and the LSF with the PV operating at rated capacity. 


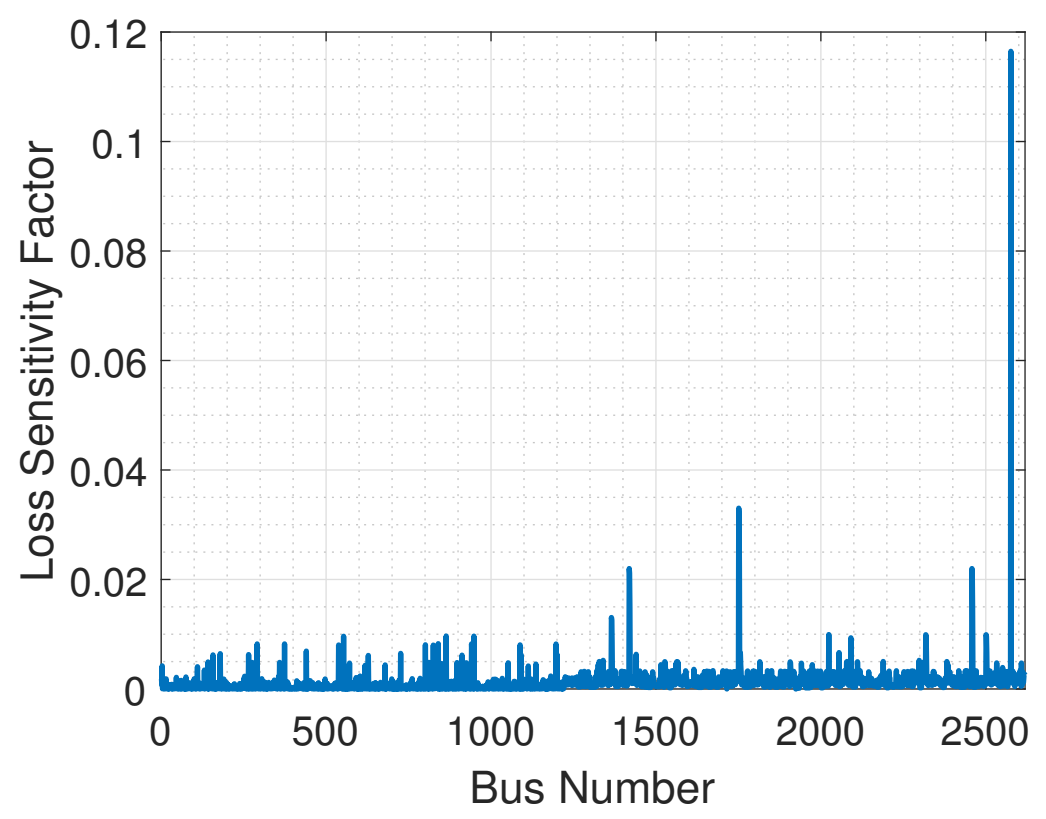

Figure 6.7: Average LSF at Each Bus

\subsection{RSVC Deployment}

The RSVC were deployed based on the LSFs calculated in the last section. The number of RSVCs deployed in the feeder was obtained from the static analysis, where 40 RSVC were required to mitigate the high voltage experienced in the feeder under the step change test. The voltage step change test performed in the last section is a conservative approach given that the PV goes from full output to zero in a one time-step.

The simulation was run for the same 30 minutes and using the same PV output profile as in the previous section. The impact of deploying the RSVC was captured for low and high voltage, voltage variability and number of voltage regulating device operations. 


\subsubsection{Minimum Voltage}

The minimum voltage experienced on the feeder at each solution interval with the RSVCs deployed in the feeder is shown in Fig. 6.8. The minimum voltage does not follow the same shape as in the previous case as seen in Fig 6.4. The RSVCs are able to modify the voltage on the feeder by injecting or absorbing reactive power. It can also be seen that there are less sharp changes than in Fig. 6.4, a result of the reduction of the number of operations of the voltage regulating devices. The minimum voltage also varies less than in the case without RSVCs.

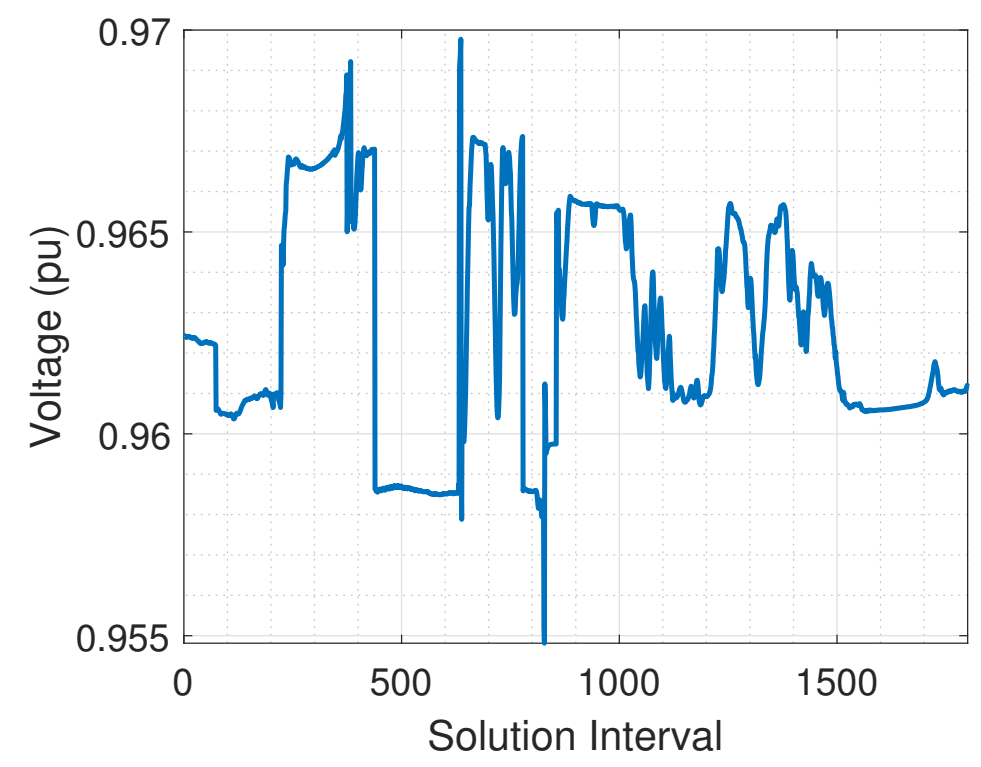

Figure 6.8: Minimum Voltage on each Solution Interval with RSVC Deployed

\subsubsection{Maximum Voltage}

The maximum voltage experienced on the feeder at each solution interval is shown in Fig. 6.9. The maximum voltage is lower than in the previous case, a result of the addition of the RSVCs in the feeder. There are still a few tap position changes of the voltage regulating 
devices. The range of the voltage, the minimum of the maximum values and the maximum of the maximum steady-state values is also decreased from the previous case.

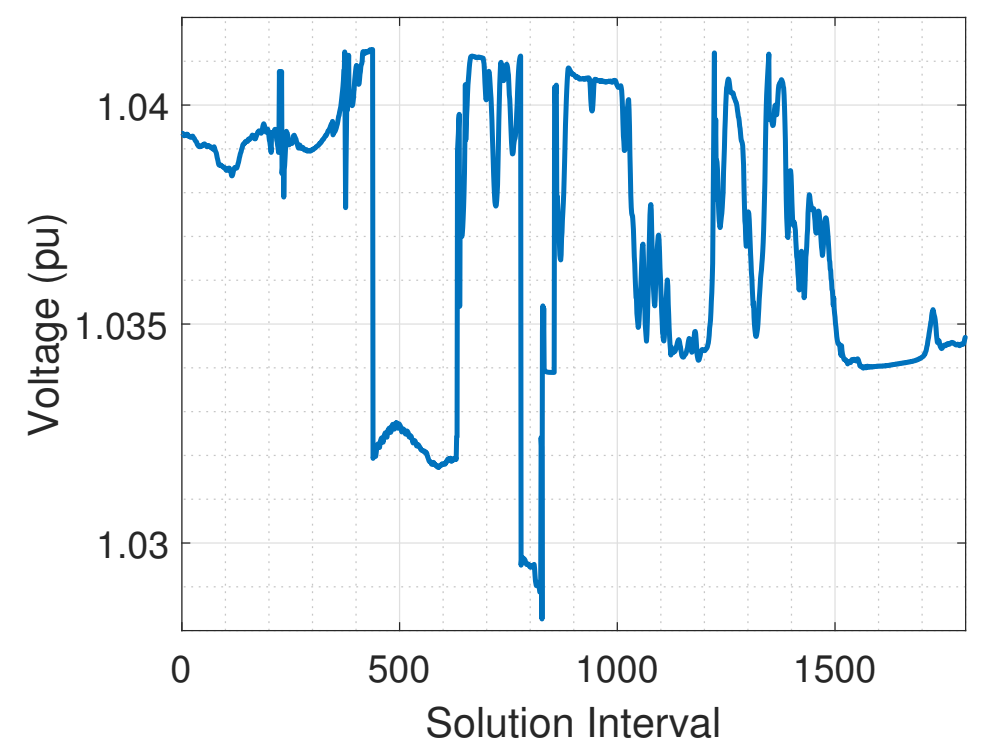

Figure 6.9: Maximum Voltage on Each Solution Interval with RSVC Deployed

\subsubsection{Voltage Variability}

The voltage variability for the 30 minute simulation was calculated using the same principle as in section 6.2. The highest voltage variability observed in the feeder with the RSVC deployed is less than half as the highest voltage variability observed in the case without the RSVCs. Fig. 6.10 shows the voltage variability sorted from high to low for readability.

\subsubsection{Number of Operations of Voltage Regulating Devices}

The number of operations of the voltage regulating devices was reduced with the addition of the RSVCs. The quick reaction time of the RSVCs are able to keep the voltage within limits before the voltage regulating devices need to change positions to correct the voltage. 


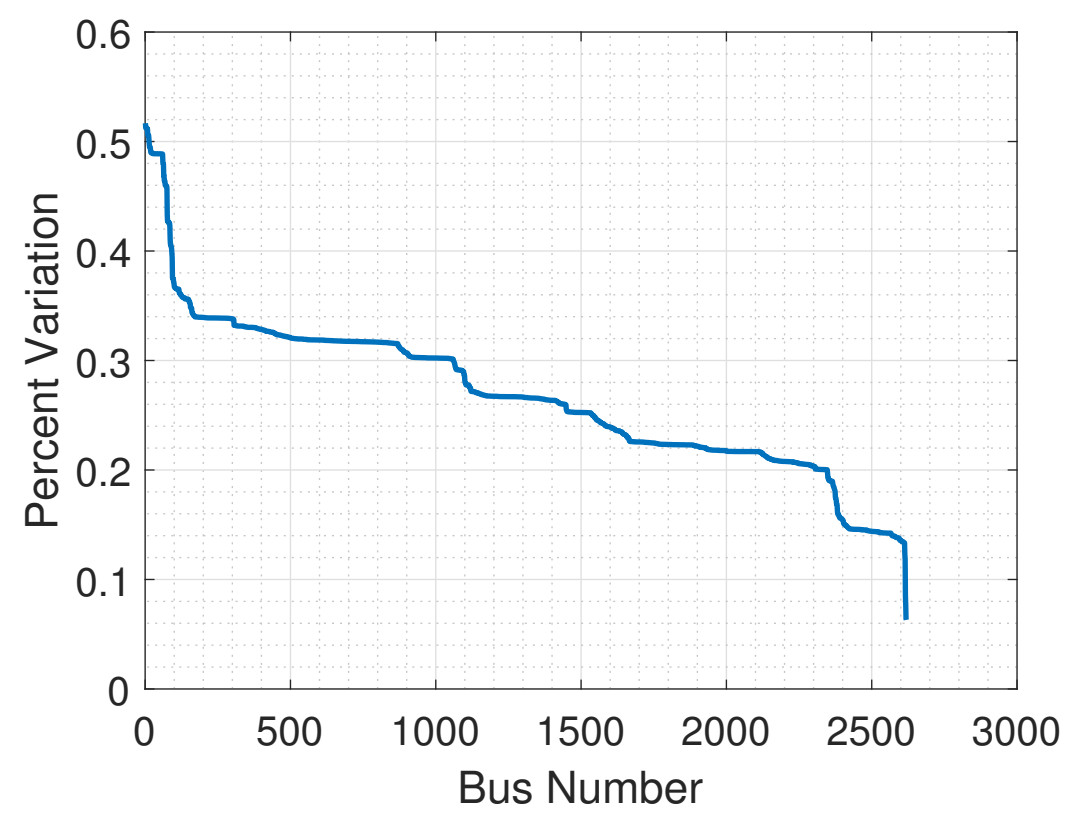

Figure 6.10: Voltage Variability with RSVCs Deployed

Table 6.2 shows the number of operations with the RSVCs deployed in the feeder. The number of operations was significantly reduced for all the regulators.

Table 6.2: Number of Voltage Regulator Operations with the RSVCs Deployed

\begin{tabular}{|l|l|l|}
\hline Regulator & Phase & $\begin{array}{l}\text { Number of } \\
\text { Operations }\end{array}$ \\
\hline \hline B18865 & Phase C & 8 \\
\hline B19008 & Phase B & 0 \\
\hline B18863 & Phase A & 0 \\
\hline B19010 & Phase A & 0 \\
\hline B4873 & Phase A & 0 \\
\hline B18864 & Phase B & 1 \\
\hline B4872 & Phase C & 0 \\
\hline B4868 & Phase B & 0 \\
\hline
\end{tabular}




\subsubsection{RSVC Output}

The output of each of the RSVCs was recorded for each of the solution intervals. All of the RSVCs are set to control the voltage at $1.0 \mathrm{pu}$. The RSVC could change its output to adjust for any voltage variations in the feeder, due to the relatively high penetration of DG.

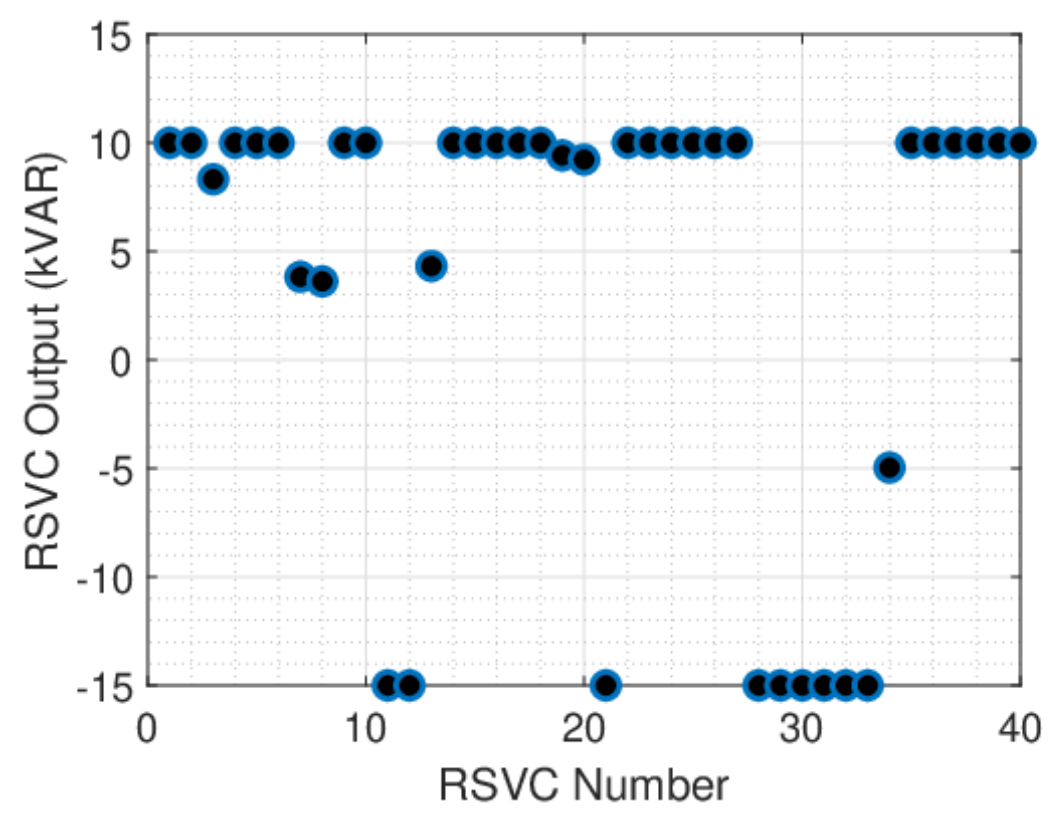

Figure 6.11: RSVC Output for Iteration 1

The output for all forty RSVCs during the first solution interval of the time-series analysis is shown in Fig. 6.11. The data shows how some of the RSVCs operate in the capacitive mode, boosting the voltage of the node they are connected to, while other RSVCs operate in the inductive mode, lowering the voltage of the node.

The time-series analysis shows the versatility of the RSVC in controlling the voltage, both high voltage and low voltage in a distribution feeder with high penetration of DG. The analysis also shows the efficiency of using LSF to identify the nodes that require reactive support. 


\subsubsection{Conclusion}

The deployment of RSVCs in the feeder during a time-series solution shows an improvement in the voltage profile by raising the minimum voltage at each solution interval and decreasing the maximum voltage during each solution interval. The deployment of RSVCs also improved the voltage variability, by reducing the maximum steady-state variability experienced during the 30 minute simulation by more than half.

The RSVCs operate faster than the voltage regulating devices already in the feeder. The fast time of operation of the RSVC allows the RSVC to react to the change in PV output before the voltage regulating devices need to change their tap position to maintain the voltage within the band of the voltage regulating devices. 


\section{CHAPTER 7}

\section{LOW VOLTAGE MITIGATION: CASE STUDY}

A case study is presented in this chapter where a remote rural feeder of the local utility experienced low voltage during certain times over the summer. The electric substation that serves the feeder and the feeder itself are located in a high plains desert climate region. The electric substation is comprised of one 20-MVA 138/34.5 kV transformer serving approximately 1,745 customers from 2 feeders.

The case study feeder serves approximately 891 customers, with the customer base comprised mostly of residential, agriculture and irrigation loads. There are no feeders adjacent to the case study feeder. The case study feeder already contains three stages of voltage regulation, a limit on the local utility operation guidelines. There is no projected load growth on the feeder in the near future.

The configuration of the case study feeder includes a 32-km single-phase conductor branch. Approximately 320 customers are served along the single-phase branch, with thirteen customers at the end-of-feeder (from now on referred to as "the line section") experiencing voltage as low as $111.8 \mathrm{~V}$ (on a $120 \mathrm{~V}$ base) during the summer peak. Low voltage is considered to be $114.0 \mathrm{~V}(0.95 \mathrm{pu})$ on a $120 \mathrm{~V}$ base.

The problem was how to maintain the ANSI Standard C84.1 acceptable voltage range for the thirteen customers on the line section experiencing low voltage in a cost-effective manner. 


\subsection{Traditional low voltage mitigation}

The case study feeder experiences low voltage at the end of a long single-phase branch during the summer. The section of the feeder experiencing low voltage was relatively small and has a low growth rate. Several options to mitigate the low voltage issues were evaluated using traditional solutions including:

- Balancing of the loads on the primary feeder

- Transferring loads to adjacent feeders

- Installing a voltage regulator

- Installing shunt capacitors

- Increasing feeder conductor size

- Installing another phase of conductor

There is a $0.82 \mathrm{~km}$ line section constructed with \#6 3SS steel conductor, making it a high impedance circuit requiring active and reactive power support to mitigate low voltage.

The only viable traditional option to mitigate the low voltage was reconductoring approximately $4.2 \mathrm{~km}$ of the feeder. Fig. 7.1 shows the geographic location of the feeder section starting from the second voltage regulator, which is the third zone of voltage regulation. The feeder section is colored by voltage in $\mathrm{kV}$. It shows high voltage at the regulator terminals and a decreasing voltage as the distance from the regulator increases.

\subsection{RSVC Option to Mitigate Low Voltage}

An alternative to reconductoring the line section of the feeder is to deploy multiple RSVCs in the area experiencing low voltage. The RSVCs were modelled as generators in OpenDSS 

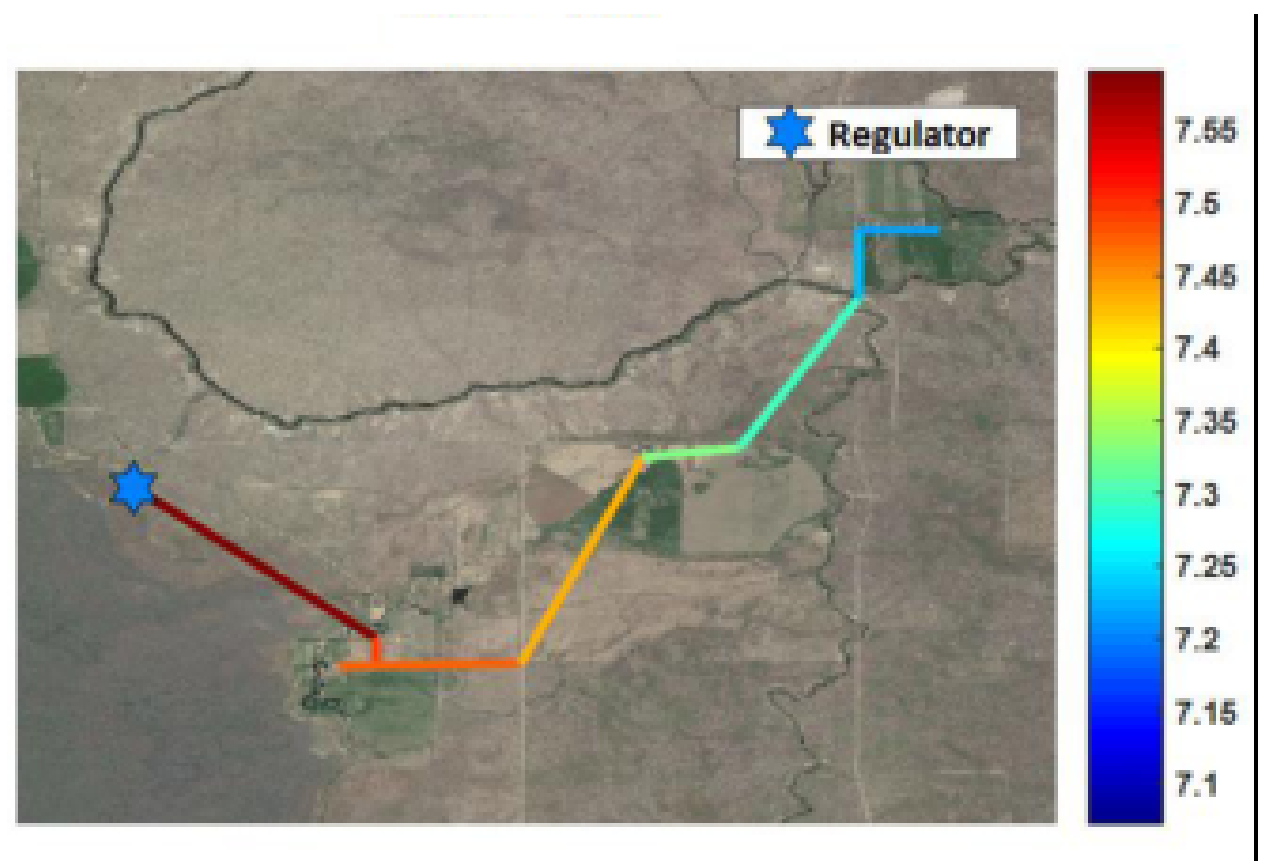

Figure 7.1: Feeder Topology

with the capacitive and reactive power limits set equal to the prototype developed at BSU. The nameplate capacity of a single-phase RSVC was set to $10 \mathrm{kVAR}$ capacitive $\left(Q_{C}\right)$ and $15 \mathrm{kVAR}$ inductive $\left(Q_{L}\right)$. There are two service transformers with $480 \mathrm{~V}$ secondary voltage. When the RSVC is connected on the low side of a transformer with $480 \mathrm{~V}$ in the secondary side, the RSVC was modelled with approximately twice the capacity as the prototype, i.e., $20 \mathrm{kVAR}$ in the capacitive mode and $30 \mathrm{kVAR}$ in the inductive mode.

\subsubsection{Feeder Modeling in OpenDSS}

The section of the feeder experiencing low voltage was modeled in detail using OpenDSS to be able to perform a time-series analysis.

Figure 7.2 shows a simplified single-line diagram of the distribution feeder section under consideration. A voltage meter was installed upstream of the voltage regulator to 
obtain the input voltage at the regulator and a current meter was installed at the load side of the voltage regulator to measure the current flowing downstream. A second voltage meter was installed at the end of the single-phase branch for validating the feeder model developed for simulation.

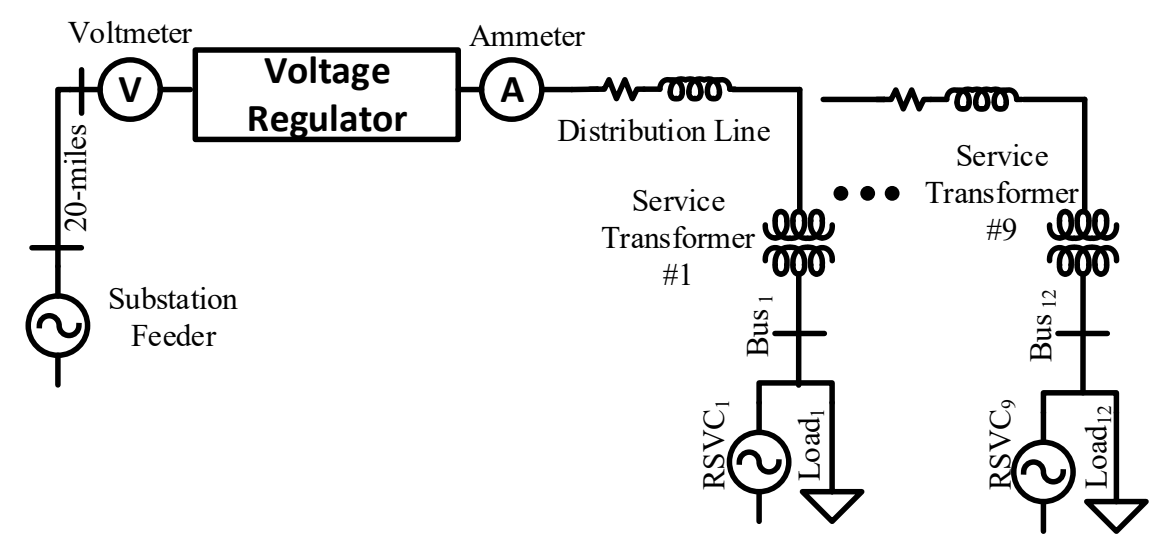

Figure 7.2: Simplified Distribution Feeder topology

The feeder model developed in OpenDSS includes the distribution lines conductors, the service transformers and the service line conductors from the service transformer to the meter. The hourly load data for each customer was obtained using the energy usage data in one-hour intervals from the electric utility billing department. In order to account for the load variations during each hour, the load allocation was fine tuned after every five minutes using the current sensor readings and the voltages obtained from AMI meters. The model was verified by comparing the voltages recorded at the customers using AMI meters and the voltages obtained from the OpenDSS feeder model.

A time-series analysis was performed during a 31-day period, the analysis focuses on the month of July in 2016. During that period, three customers experienced a voltage higher than that specified by ANSI C84.1 standard and two customers experienced lower voltage than the specified by ANSIC84.1. In total, there were a total of 57 minimum voltage violations, nine of them were lower than $113 \mathrm{~V}$. 


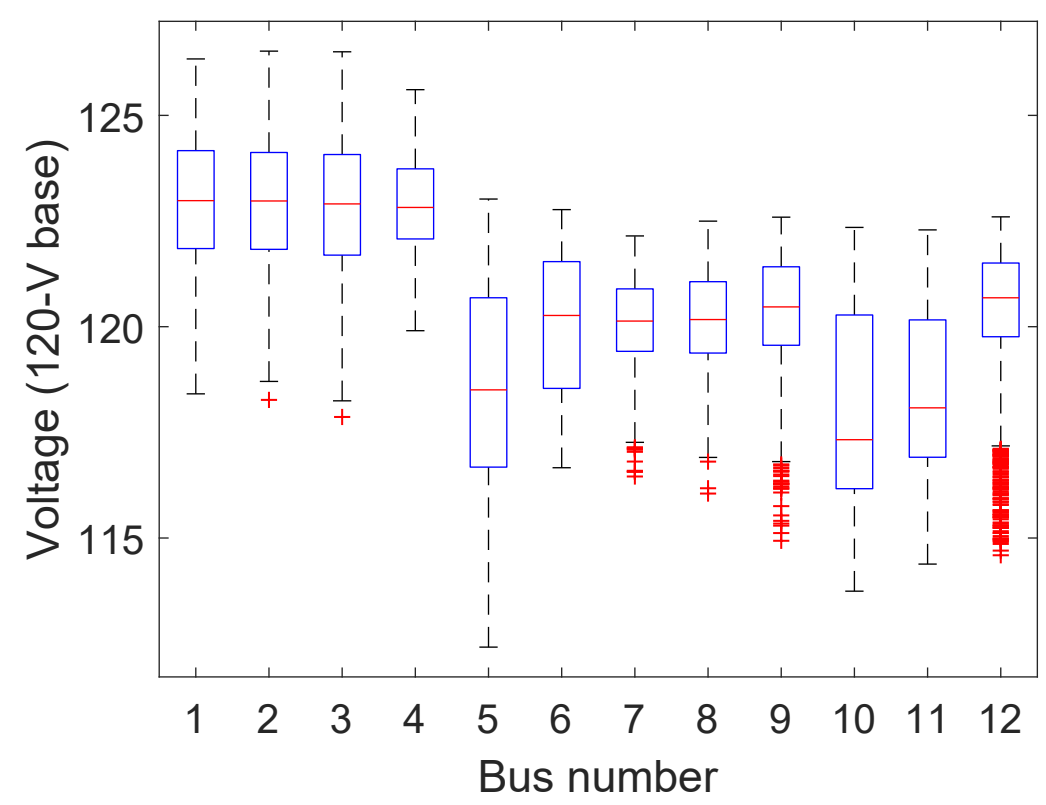

Figure 7.3: Voltage at every customer meter without RSVCs deployed.

Figure 7.3 shows the voltage at each one of the meters located downstream of the regulator using box plots. In each box, the central line indicates the median data value, and the bottom and top edges of the box indicate the $25^{\text {th }}$ and $75^{\text {th }}$ percentiles, respectively. The whiskers extend to the maximum and minimum data points not considered outliers for each box plot. The outliers in the data are plotted individually using the '+' symbol. The data shows that each customer experienced a wide range of voltage swing several times during the month of July. Table 7.1 shows the maximum, minimum and average voltages for every customer.

\subsubsection{Mitigation of Voltage Violations using RSVCs}

The RSVCs were deployed in the area experiencing low voltage. One RSVC was added per service transformer with the voltage reference of the RSVCs set at 1.0 per unit. The same 31-day period was simulated with the RSVCs deployed in the feeder. 
Table 7.1: Voltage swing for each customer without RSVC

\begin{tabular}{|c|c|c|c|}
\hline Bus No. & Minimum Voltage & Maximum Voltage & Average Voltage \\
\hline \hline Bus 1 & 118.41 & 126.33 & 122.90 \\
\hline Bus 2 & 118.27 & 126.52 & 122.87 \\
\hline Bus 3 & 117.86 & 126.50 & 122.78 \\
\hline Bus 4 & 119.91 & 125.61 & 122.83 \\
\hline Bus 5 & 112.42 & 123.02 & 118.46 \\
\hline Bus 6 & 116.66 & 122.77 & 120.02 \\
\hline Bus 7 & 116.46 & 122.15 & 120.09 \\
\hline Bus 8 & 116.05 & 122.50 & 120.10 \\
\hline Bus 9 & 114.93 & 122.59 & 120.23 \\
\hline Bus 10 & 113.74 & 122.35 & 118.00 \\
\hline Bus 11 & 114.38 & 122.29 & 118.43 \\
\hline Bus 12 & 114.59 & 122.60 & 120.13 \\
\hline
\end{tabular}

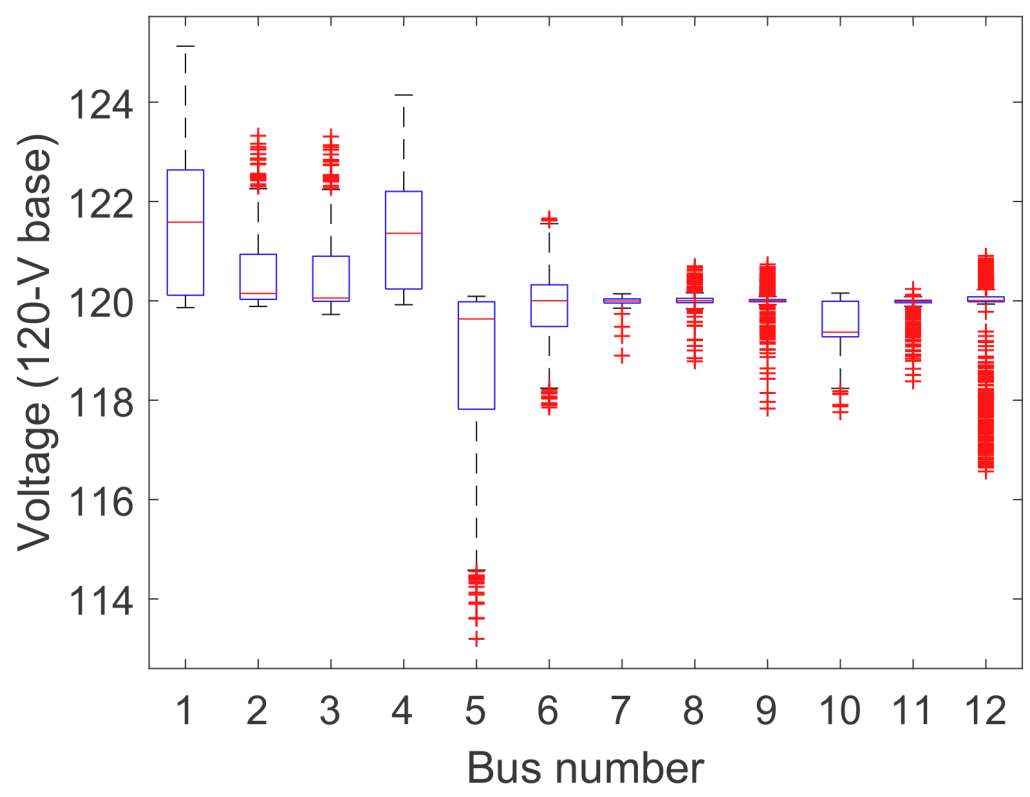

Figure 7.4: Voltage at every customer meter with RSVC deployed

The results show that voltages were improved at every location of the feeder as shown in Fig 7.4. The figure shows the box plot results after adding an RSVC at each bus in the affected section of the distribution feeder. Deploying the RSVCs in the feeder section with 
low voltage reduced the instances of a low voltage occurrences to only six, none of which were below $113 \mathrm{~V}$. The deployment of RSVCs eliminated all high voltage instances. The RSVCs also helped in reducing the voltage swing at each bus in the feeder, thus maintaining a more constant voltage through a month-long simulation.

Table 7.2 shows the results of deploying the RSVC in the feeder. The results show that no customers experienced a voltage higher than $126 \mathrm{~V}$ and only one customer experienced a voltage below $114 \mathrm{~V}$.

Table 7.2: Voltage swing for each customer with RSVC

\begin{tabular}{|c|c|c|c|}
\hline Bus No. & Minimum Voltage & Maximum Voltage & Average Voltage \\
\hline \hline Bus 1 & 119.86 & 125.13 & 121.56 \\
\hline Bus 2 & 119.89 & 123.32 & 120.53 \\
\hline Bus 3 & 119.73 & 123.31 & 120.46 \\
\hline Bus 4 & 119.92 & 123.31 & 121.35 \\
\hline Bus 5 & 113.20 & 120.09 & 118.70 \\
\hline Bus 6 & 117.85 & 121.66 & 119.90 \\
\hline Bus 7 & 118.90 & 120.14 & 120.00 \\
\hline Bus 8 & 118.78 & 120.70 & 120.01 \\
\hline Bus 9 & 117.83 & 120.73 & 119.99 \\
\hline Bus 10 & 117.76 & 120.16 & 119.52 \\
\hline Bus 11 & 118.38 & 120.24 & 119.94 \\
\hline Bus 12 & 116.57 & 120.71 & 119.71 \\
\hline
\end{tabular}

The reactive power output of the RSVCs at each bus is shown in Figure 7.5. Each point in the figure shows the net reactive power provided by the RSVC for a five-minute interval at a specific service transformer during the entire month of July in 2016. The result shows that RSVCs can transition from an inductive operation mode to a capacitive operating mode thus providing a better voltage regulation resulting in a flatter voltage profile than the use of capacitors alone. 


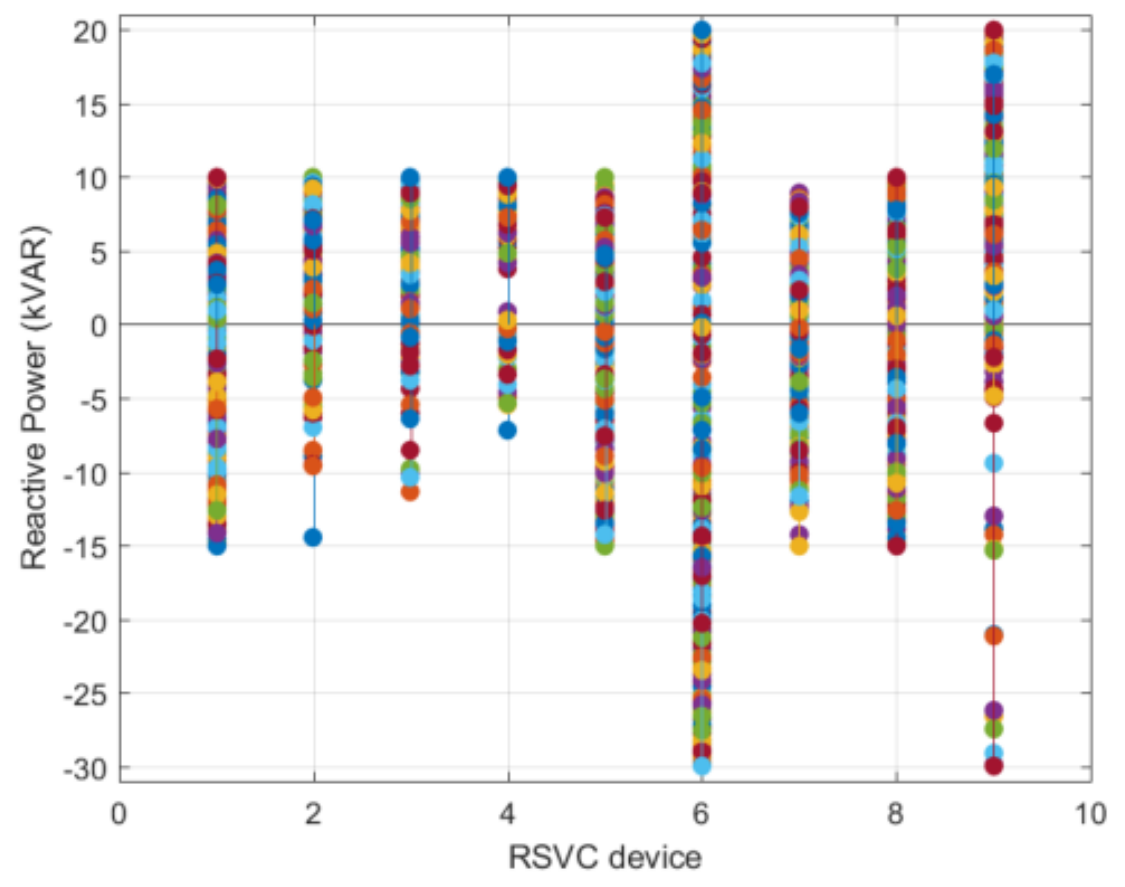

Figure 7.5: RSVC Output

The analysis performed in this case study indicates that distribution voltage violations outside the ANSI C84.1 Range A can be mitigated by deploying RSVCs in the area of concern. The model of the feeder section under investigation was developed in detail in OpenDSS and field verified for accuracy purposes. The simulation results show that it is possible to mitigate low- as well as high-voltage issues in a rural distribution feeder by using RSVCs without upgrading the feeder. Thus, the use of RSVCs could be a more economical solution to resolve voltage issues in distribution feeders. It was also observed that the voltage swing at each RSVC installation was greatly reduced, creating a flatter voltage profile and increasing the flexibility to operate the feeder at a higher or lower voltage level at the feeder head. 


\subsection{Voltage Mitigation Using Solar Photovoltaic}

Given that the RSVCs are not commercially available yet, the time-series simulation and the model developed for the case study were used to determine if adding a solar PV system would be able to mitigate the low voltage. The PV system would have to be more economical than reconductoring the feeder section and be able to mitigate the low and high voltage experienced by the customers in the feeder section.

\subsubsection{Modeling and optimizing the size of the solar PV system}

A solar PV system was modeled using National Renewable Energy Laboratory's (NREL) System Advisory Model (SAM) software. SAM was used to develop the PV system model rather than using the PV model included in OpenDSS. SAM is capable of modeling different PV array orientations and different array tilts, allowing modeling of PV systems with multiple orientations by varying these two parameters. The PV model included in OpenDSS PV currently maximizes system production and does not provide the option to change the azimuth or the tilt of the PV system. The focus of adding the PV system to the feeder is to mitigate low voltage issues rather than to maximize PV production over the year, allowing for different combinations of azimuth and tilt to maximize power production during times of low voltage rather than optimizing energy production over the entire year.

The PV system model required 2016 irradiance data to accurately simulate the output of the PV system corresponding to the 2016 load data. The solar resource data for Summer 2016 was obtained from an irradiance sensor located on a transmission line structure of a line close to the site. The irradiance data included Global Horizontal Irradiance (GHI) sampled every second. The irradiance data was averaged over a one-hour period to match the load data sampling rate; the data gathering method for solar irradiance is discussed in 
[43].

The hourly output of the PV system model created in SAM was fed to the OpenDSS line section model. An iterative process was performed to find the optimal tilt and azimuth angles of the PV system that would mitigate the low voltage. The iterative process resulted in an optimal tilt of 35 degrees and an azimuth angle of 180 degrees (due south).

The goal of the simulation was to mitigate low voltage in a cost-effective way. Thus, the size of the PV array needed to be carefully determined to avoid unnecessary expenditures. The size of the PV array was calculated by solving the power flow for the line section model. The power flow was solved for each hour over the summer, using the OpenDSS time-series simulation. The results for each hour were analyzed to identify the time of the day that the minimum voltage occurred. If the lowest voltage occurred during the sunlight hours, the size of the PV system was increased by $1 \mathrm{~kW}$, and the process was repeated. When the minimum voltage occurred during the non-sunlight hours or when no customer experienced low voltage, the process was stopped. Even though low voltage issues may still exist when the process was stopped, increasing the PV system size would not help to improve the voltage. The process is shown in Fig. 7.6. The process resulted in a solar PV system rated at $18 \mathrm{~kW}$.

\subsubsection{Modeling results}

The simulation results with the PV system connected to the feeder are shown in Table 7.3. The results shows that a few instances of low voltage still could occurred with the addition of the PV system during the late evening hours when the output of the PV system is zero. Additional simulation results indicated that the low voltage condition could be mitigated by adding secondary side capacitors at two different service points. 


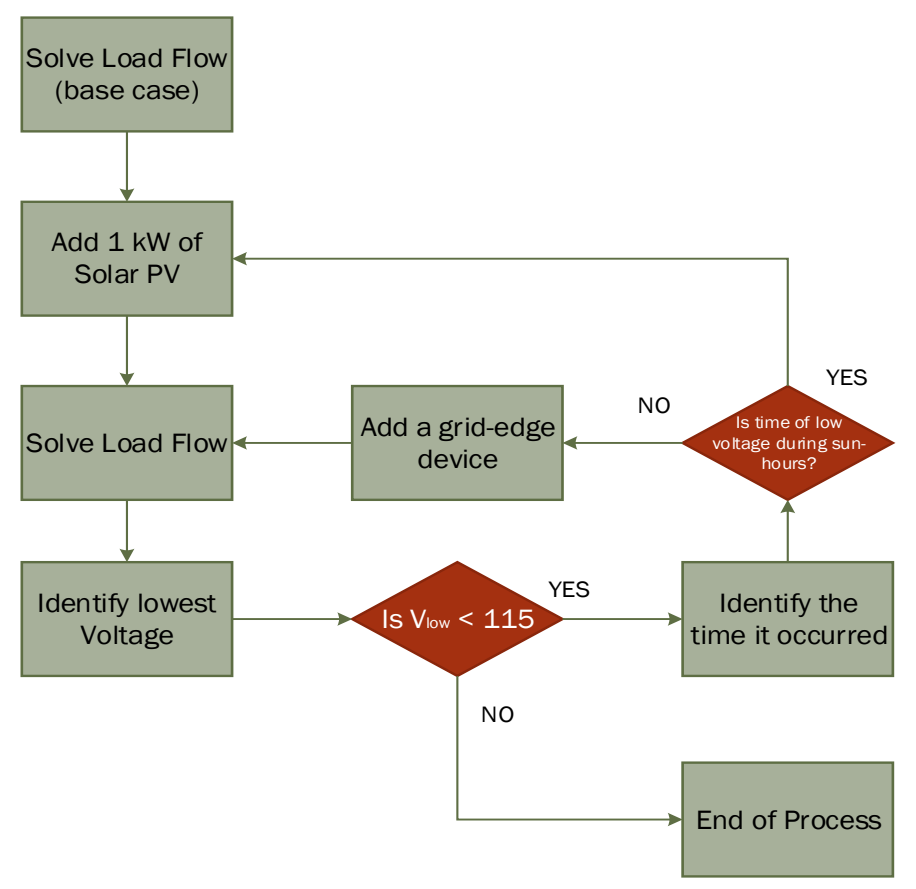

Figure 7.6: PV Sizing Algorithm Flow Chart

Simulation modeling results show improvement in the voltage on the affected line section to be within a range of $0.45 \mathrm{~V}$ to $1.97 \mathrm{~V}$ (on a $120 \mathrm{~V}$ base). Table 7.3 shows the simulated voltage on six service points with and without PV included in the model. Based on the improvement in voltage, the recommended solution was to install the $18 \mathrm{~kW}$ solar PV system, then later re-evaluate the need for a secondary side capacitor.

The feasibility of the proposed solution to install an $18 \mathrm{~kW}$ solar PV system was reviewed and accepted by the Company. The construction began in the Fall of 2016.

\subsubsection{Project Implementation and Results}

The Solar End-of-Feeder Project was constructed and commissioned during the Fall of 2016 at a total cost of $\$ 114,000$. Because of the lack of load growth in the area, this project deferred the need for line section reconductoring, with an estimated cost of $\$ 350,000$, for 
Table 7.3: Low Voltage Results

\begin{tabular}{|l|l|l|l|l|}
\hline \multicolumn{5}{|c|}{ Low Voltage Instances } \\
\hline Transformer & \multicolumn{2}{|c|}{ Occurrences } & \multicolumn{2}{c|}{ Minimum Voltage } \\
& No PV & PV & No PV & PV \\
\hline 1 & 12 & 0 & 113.6 & 114.05 \\
\hline 2 & 1 & 1 & 112.53 & 113.79 \\
\hline 3 & 24 & 2 & 112.6 & 113.86 \\
\hline 4 & 12 & 0 & 112.54 & 114.51 \\
\hline 5 & 5 & 1 & 113.07 & 113.63 \\
\hline 6 & 3 & 0 & 113.38 & 113.83 \\
\hline Total & 57 & 4 & & \\
\hline
\end{tabular}

25 years. The project has been in operation since October 2016. A photograph of the 18-kW solar PV system can be seen in Fig. 7.7.

At the time of commissioning the project, the solar PV system inverters were limited to operate only at unity power factor. The project operated in this condition throughout the Summer of 2017. During the Spring of 2018, a firmware update for the inverters became available, which allowed the inverters to perform advanced functions and operate at a power factor other than unity.

The firmware upgrade was completed during the first quarter of 2018. The same OpenDSS model used to determine the feasibility of the project was used to determine the best advanced function for the inverter operation. The simulation modeling showed that operating the solar PV system at a fixed power factor of 0.95 leading would provide better results than operating the system at unity power factor. The project operated at a 0.95 leading power factor during the Summer of 2018.

Data from a Smart Grid Monitor (SGM) which captures the voltage, was collected to compare the voltage before the project was installed (2016), with the project operating at unity power factor (2017), and with the project operating at 0.95 leading power factor (2018). A voltage-duration-curve of the voltage for the same period of time for all three 


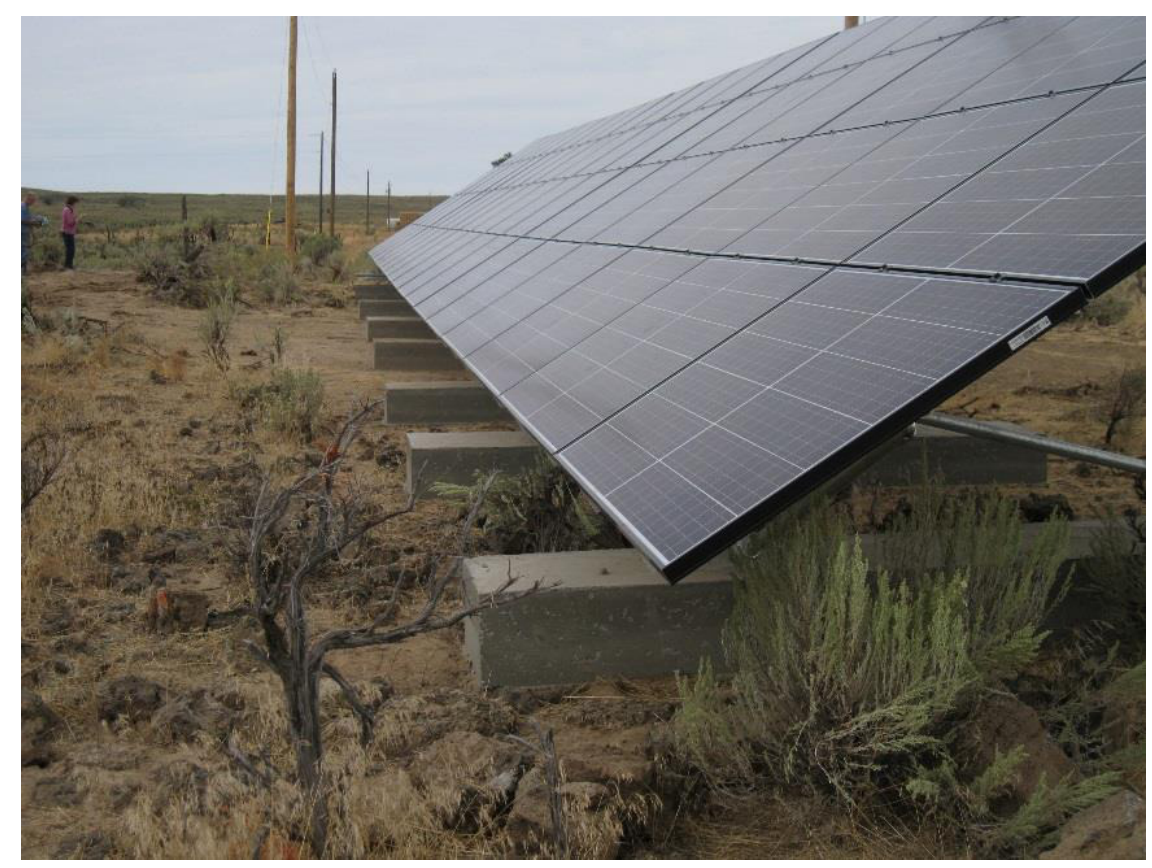

Figure 7.7: PV Array Installation

years is shown in Fig. 7.8. The data from Fig. 7.8 is a 1 minute average voltage measurements obtained from the SGM located near the solar site. The average voltage in 2017 was greater than the average voltage in 2018. However, 2018 experienced fewer low voltage measurements after the inverters were configured to operate at 0.95 leading power factor.

The project has operated successfully through the first two years of operation by effectively mitigating low voltage. Table 7.4 shows voltage measurements and analysis of the affected line section in Summer 2016 (pre-project) with 436 instances of low voltage, 2017 with 33 instances of low voltage, and 2018 with 4 instances of low voltage. 


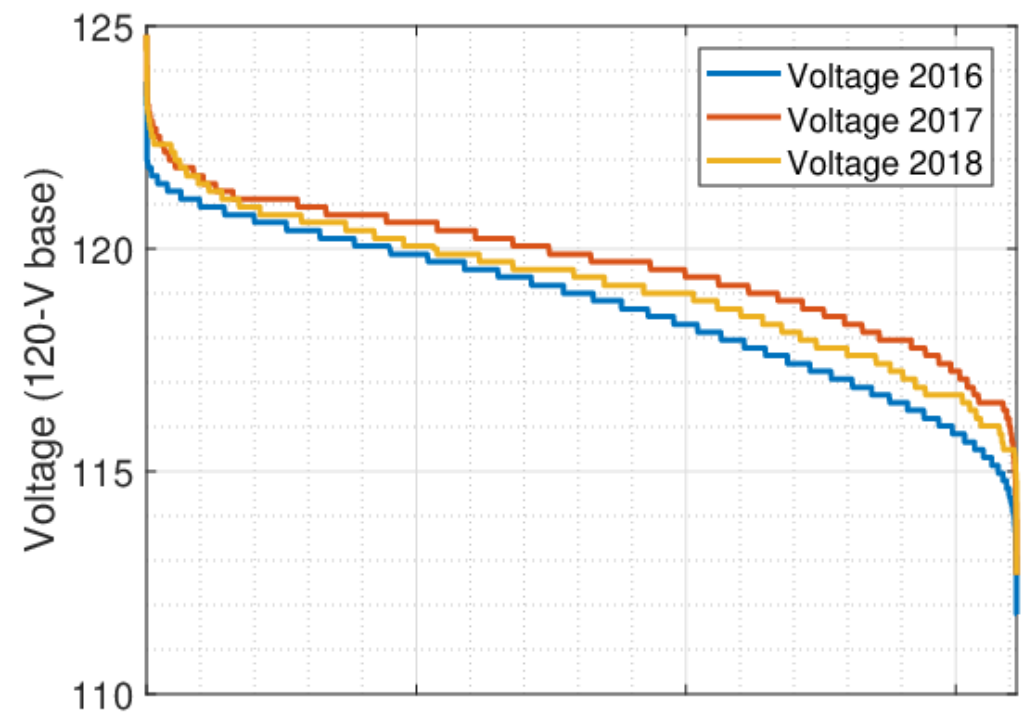

Figure 7.8: Voltage duration curves for Summer 2016, 2017, and 2018

Table 7.4: Implementation Results

\begin{tabular}{|l|l|l|l|}
\hline & 2016 & 2017 & 2018 \\
\hline Low Voltage Count & 436 & 33 & 4 \\
\hline Pct Low Voltage & 0.270 & 0.020 & 0.002 \\
\hline Minimum Low Voltage & 111.80 & 112.68 & 112.68 \\
\hline Average Voltage & 118.71 & 119.67 & 119.20 \\
\hline
\end{tabular}

Fig. 7.9 shows the number of low voltage reads sorted by clock hour. The results show that the low voltage reads prior to the installation of the project occurred primarily during the evening hours. 


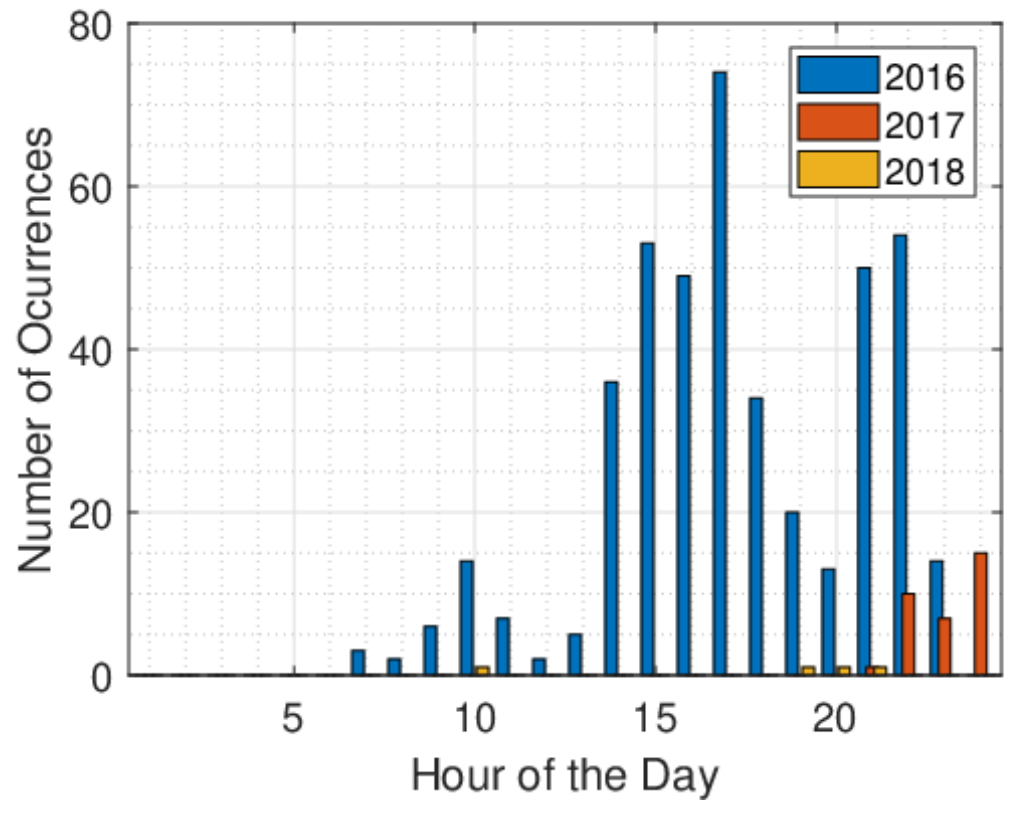

Figure 7.9: Low-voltage occurrences plotted by time of day 


\section{CHAPTER 8}

\section{CONCLUSIONS AND FUTURE WORK}

\subsection{Conclusions}

The work presented in this dissertation shows the design, simulation and implementation of a new device able to mitigate high and low voltage in a distribution feeder. The new device, the RSVC, was designed as a single-phase device operating at 240 Volts. The proposed RSVC utilizes a patented PWM switching technique that allows the RSVC to operate in the $\mathrm{kHz}$ range, eliminating the need for a filter.

The work presented here also shows how the use of LSFs are effective in identifying the buses that require reactive compensation, reducing the number of buses or nodes that need to be considered to host an RSVC, reducing the simulation time. The results show that LSFs have minimal variation with the addition of PV in the feeder, eliminating the need to re-calculate the LSF when PV is added or removed from the feeder.

A publicly available feeder was used as the test feeder for the work presented in the dissertation. The feeder was picked because the feeder has the service transformers already modeled, something not common in the industry. The feeder was already modeled in OpenDSS, an open source distribution simulator that is able to perform QSTS. The feeder also has a high penetration of DG, causing high and low voltage in the feeder.

A static test was performed to verify that high and low voltage were present in the feeder. The voltage test verified that some customers in the feeder experience high and low 
voltage due to the PV when the PV output changes rapidly from full output to zero output or vice-versa. The deployment of the RSVCs, guided by the use of LSF, proved to be an effective mitigation option of the voltage issues in the feeder.

A time-series analysis was also presented in this dissertation. The feeder was first solved without any RSVC connected. The analysis included the the minimum and maximum voltage on the feeder for each iteration, the voltage variability in the feeder, and the number of operations from the voltage regulating devices. The second part of the analysis included deploying 40 RSVCs in the feeder, utilizing the LSFs as a guide to determine which nodes should host an RSVC. The results show how the deployment of RSVCs are effective at increasing the minimum voltage experienced in the feeder during each iteration, reducing the maximum voltage during each iteration and reducing the range for both, minimum and maximum voltages. The analysis also shows that the deployment of the RSVCs in the feeder were able to reduce by half the maximum variability experienced in the feeder. The number of operations from the voltage regulating devices was significantly reduced with the incorporation of the RSVCs in the feeder.

\subsection{Future Work}

A second prototype of the RSVC is currently under development. The second prototype will use an emitter connected Insulated-Gate Bipolar Transistor (IGBT) module manufactured by Semikron, instead of the individually driven Metal-Oxide-Silicon Field-Effect Transistor (MOSFET) used in the first prototype.

The control system is also being updated in the RSVC to be able to implement a minimum power tracker algorithm. The current prototype is able to maintain a reference voltage that can be adjusted. However, the minimum power tracker will change the voltage 
reference depending on the type of load for which the RSVC is providing support. The voltage reference will be adjusted so the power consumption for any given load will be minimum while the voltage is still maintained within the allowable range. 


\section{REFERENCES}

[1] "Photovoltaic Power Systems Programme, Trends in Photovoltaic Applications Survey Report of Selected IEA Countries between 1992 and 2015, International Energy Agency, 2016, IEA-PVPS T1-30:2016,” New York NY, Tech. Rep., 1985.

[2] M. J. Reno and R. J. Broderick, "Predetermined Time-Step Solver for Rapid QuasiStatic Time Series (QSTS) of distribution systems," in 2017 IEEE Power Energy Society Innovative Smart Grid Technologies Conference (ISGT), April 2017, pp. 1-5.

[3] Electric Power Research Institute. Distributed PV Monitoring and Feeder Analysis. Accessed: 2019-09-04. [Online]. Available: https://dpv.epri.com/feeder_j.html

[4] T.-H. Chen, L.-S. Chiang, and N.-C. Yang, "Examination of Major Factors Affecting Voltage Variation on Distribution Feeders," Energy and Buildings, vol. 55, pp. 494 - 499, 2012, cool Roofs, Cool Pavements, Cool Cities, and Cool World. [Online]. Available: //www.sciencedirect.com/science/article/pii/S0378778812004252

[5] American National Standard Institute. American National Standard for Electric Power Systems and Equipment-Voltage Ratings $(60 \mathrm{~Hz})$. Accessed: 2019-09-04. [Online]. Available: https://www.nema.org/Standards/Pages/ American-National-Standard-for-Electric-Power-Systems-and-Equipment-Voltage-Ratings. aspx

[6] National Electrical Manufacturers Association. American National Standard for Electric Power Systems and Equipment-Voltage Ratings (60 Hz). Accessed: 2019-09-14. [Online]. Available: https:/www.nema.org/Standards/Pages/ American-National-Standard-for-Electric-Power-Systems-and-Equipment-Voltage-Ratings. aspx

[7] M. H. Bollen and I. Gu, Origin of Power Quality Variations. IEEE, 2006. [Online]. Available: https://ieeexplore.ieee.org/document/5224884

[8] H. E. Lokay and D. N. Reps, "Distribution System Primary-Feeder Voltage Control I - A New Approach Using the Digital Computer," Transactions of the American Institute of Electrical Engineers. Part III: Power Apparatus and Systems, vol. 77, no. 3, pp. 845-855, April 1958. 
[9] D. F. Teshome et al., "A Reactive Power Control Scheme for DER-caused Voltage Rise Mitigation in Secondary Systems," IEEE Transactions on Sustainable Energy, pp. 1-12, 2018.

[10] M. H. J. Bollen and F. Hassan, IEEE Press Series on Power Engineering. IEEE, 2011. [Online]. Available: https://ieeexplore.ieee.org/document/6047618

[11] R. A. Shayani and M. A. G. de Oliveira, "Photovoltaic Generation Penetration Limits in Radial Distribution Systems," IEEE Transactions on Power Systems, vol. 26, no. 3, pp. 1625-1631, Aug 2011.

[12] O. Leitermann, V. Martinelli, and J. Simonelli, "Estimating LV Secondary Voltage Drop Using AMI Data for Improved Distribution Management," in 2016 IEEE/PES Transmission and Distribution Conference and Exposition (T D), May 2016, pp. 1-5.

[13] S. N. Salih and P. Chen, "On Coordinated Control of OLTC and Reactive Power Compensation for Voltage Regulation in Distribution Systems With Wind Power," IEEE Transactions on Power Systems, vol. 31, no. 5, pp. 4026-4035, Sept 2016.

[14] C. Long and L. Ochoa, "Voltage Control of PV-Rich LV networks: OLTC-fitted Transformer and Capacitor Banks," in 2016 IEEE Power and Energy Society General Meeting (PESGM), July 2016, pp. 4016-4025.

[15] R. C. Dugan and T. E. McDermott, "Operating Conflicts for Distributed Generation on Distribution systems," in 2001 Rural Electric Power Conference. Papers Presented at the 45th Annual Conference (Cat. No.01CH37214), April 2001, pp. A3/1-A3/6.

[16] I. A. Pires, B. de Jesus Cardoso Filho, and J. C. de Oliveira, "A Series Voltage Regulator Based on Quasi-Sinusoidal Waveform to Achieve Smart-Grid Requirements," in 2010 IEEE Industry Applications Society Annual Meeting, Oct 2010, pp. 1-7.

[17] A. Garces and A. Trejos, "A Voltage Regulator Based on Matrix Converter for Smart Grid Applications," in 2011 IEEE PES CONFERENCE ON INNOVATIVE SMART GRID TECHNOLOGIES LATIN AMERICA (ISGT LA), Oct 2011, pp. 1-6.

[18] D. Ranamuka, A. P. Agalgaonkar, and K. M. Muttaqi, "Online Voltage Control in Distribution Systems With Multiple Voltage Regulating Devices," IEEE Transactions on Sustainable Energy, vol. 5, no. 2, pp. 617-628, April 2014.

[19] K. M. Muttaqi et al., "A Coordinated Voltage Control Approach for Coordination of OLTC, Voltage Regulator, and DG to Regulate Voltage in a Distribution Feeder," IEEE Transactions on Industry Applications, vol. 51, no. 2, pp. 1239-1248, March 2015. 
[20] M. N. M. Nasir et al., "A Distribution Network Reconfiguration based on PSO: Considering DGs sizing and allocation evaluation for voltage profile improvement," in 2014 IEEE Student Conference on Research and Development, Dec 2014, pp. 1-6.

[21] T. H. Sikiru et al., "Voltage profile improvement based on network structural characteristics," in 2012 Sixth IEEE/PES Transmission and Distribution: Latin America Conference and Exposition (T D-LA), Sep. 2012, pp. 1-5.

[22] Iyer, Ray, and Ramakumar, "Assessment of Distributed Generation Based on Voltage Profile Improvement and Line Loss Reduction," in 2005/2006 IEEE/PES Transmission and Distribution Conference and Exhibition, May 2006, pp. 1171-1176.

[23] J. Dixon et al., "Reactive Power Compensation Technologies: State-of-the-Art Review," Proceedings of the IEEE, vol. 93, no. 12, pp. 2144-2164, Dec 2005.

[24] A. Prasai, J. Sastry, and D. M. Divan, "Dynamic Capacitor (D-CAP): An Integrated Approach to Reactive and Harmonic Compensation," IEEE Transactions on Industry Applications, vol. 46, no. 6, pp. 2518-2525, Nov 2010.

[25] Y. Ren and Z. Piao, "Theoretical Research and Simulation of Series Compensation Technology of Distribution Line," in Proceedings of 2011 International Conference on Electronic Mechanical Engineering and Information Technology, vol. 4, Aug 2011, pp. 2094-2097.

[26] Ankita and P. Prakash, "Multi Sensitivity Factors and FPA for Loss Reduction and Voltage Profile Improvement by Optimal Placement and Sizing of Capacitor in Mesh Network," in 2018 2nd International Conference on Power, Energy and Environment: Towards Smart Technology (ICEPE), June 2018, pp. 1-6.

[27] B. M. Dehkordi et al., "Optimal Capacitor Placement and sizing in TABRIZ Distribution System Using Loss Sensitivity Factors and Particle Swarm Optimization (PSO)," in 2012 Proceedings of 17th Conference on Electrical Power Distribution, May 2012, pp. 1-6.

[28] K. Prakash and M. Sydulu, "Particle Swarm Optimization Based Capacitor Placement on Radial Distribution Systems," in 2007 IEEE Power Engineering Society General Meeting, June 2007, pp. 1-5.

[29] J. Sardi, N. Mithulananthan, and D. Q. Hung, "A loss sensitivity factor method for locating ES in a distribution system with PV units," in 2015 IEEE PES Asia-Pacific Power and Energy Engineering Conference (APPEEC), Nov 2015, pp. 1-5.

[30] F. Bai, R. Yan, and T. K. Saha, "Impact of Power Fluctuations on Voltage Variations for Remote Distribution Networks with High PV Penetrations," in 2018 IEEE Power Energy Society General Meeting (PESGM), Aug 2018, pp. 1-5. 
[31] D. Das, D. Kothari, and A. Kalam, "Simple and Efficient Method for Load Flow Solution of Radial Distribution Networks," International Journal of Electrical Power \& Energy Systems, vol. 17, no. 5, pp. 335 - 346, 1995. [Online]. Available: http://www.sciencedirect.com/science/article/pii/0142061595000500

[32] Electric Power Research Institute. Load Shape Library. Accessed: 2019-09-14. [Online]. Available: http://loadshape.epri.com/

[33] Engo Varentec. Varentec. Accessed: 2019-08-08. [Online]. Available: http: //varentec.com/products/engo-v10/

[34] Gridco Systems. SVC-20 Gridco Systems. Accessed: 2019-08-08. [Online]. Available: https://d3pcsg2wjq9izr.cloudfront.net/files/93836/download/710171/6.pdf

[35] T. E. Grebe, "Application of Distribution System Capacitor Banks and their Impact on Power Quality," IEEE Transactions on Industry Applications, vol. 32, no. 3, pp. 714-719, May 1996.

[36] R. A. Adams et al., "Solving Customer Power Quality Problems Due to Voltage Magnification," IEEE Transactions on Power Delivery, vol. 13, no. 4, pp. 1515-1520, Oct 1998.

[37] B. W. Kennedy and R. H. Fletcher, "Conservation Voltage Reduction (CVR) at Snohomish County PUD," IEEE Transactions on Power Systems, vol. 6, no. 3, pp. 986-998, Aug 1991.

[38] J. C. Erickson and S. R. Gilligan, "The Effects of Voltage Reduction on Distribution Circuit Loads," IEEE Transactions on Power Apparatus and Systems, vol. PAS-101, no. 7, pp. 2014-2018, July 1982.

[39] V. J. Warnock and T. L. Kirkpatrick, "Impact of Voltage Reduction on Energy and Demand: Phase II," IEEE Transactions on Power Systems, vol. 1, no. 2, pp. 92-95, May 1986.

[40] "IEEE Standard for Interconnection and Interoperability of Distributed Energy Resources with Associated Electric Power Systems Interfaces," IEEE Std 1547-2018 (Revision of IEEE Std 1547-2003), pp. 1-138, April 2018.

[41] C. Farhana et al., "Impact Study of Practical Harmonic Data using Time Series Simulation," 06 2012, pp. 618-623.

[42] "IEEE Guide for Identifying and Improving Voltage Quality in Power Systems," IEEE Std 1250-2011 (Revision of IEEE Std 1250-1995), pp. 1-70, March 2011. 
[43] P. Anderson, B. Efaw, and E. McKinney, "A method for determining the relationship between solar irradiance and distribution feeder peak loading," in 2016 IEEE/PES Transmission and Distribution Conference and Exposition (T\&D), May 2016, pp. 1-5. 